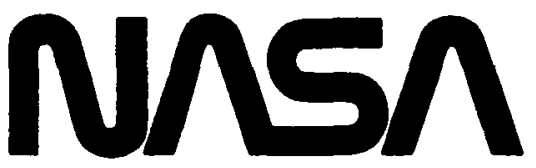

National Aeronautics and

Space Administration

\title{
THERMAL BARRIER COATING LIFE PREDICTION MODEL
}

\section{SECOND ANNUAL REPORT APRIL 1986}

\author{
By \\ R.V. Hillery \\ B.H. Pilsner \\ T.S. Cook \\ K.S. Kim \\ General Electric Company \\ Aircraft Engine Business Group \\ Cincinnati, Ohio 45215 \\ (NASA-CB-179504) THERMAL BAREIER COATING \\ N87-13539 \\ IIFE FREDICTICN MCDEL Annual BEFOrt \\ (General Electric Co.) $129 \mathrm{~F}$ CSCL 11B
G 3/27
Unclas
43607

\section{Prepared for} \\ National Aeronautics and Space Administration
}


The Second Annual Report, covering the period April 1985 to March 1986, was prepared by the Engineering Materials Technology Laboratories (EMTL) of General Electric's Aircraft Engine Business Group, Cincinnati, Ohio 45215, under NASA Contract NAS3-23943. R.V. Hillery of General Electric is the Program Manager and B. H. Pilsner is the Principal Investigator. J.A. Nesbitt is the Project Manager for NASA (Lewis Research Center). 
SUMMARY

INTRODUCTION 2

TASK I FAILURE MECHANISM DETERMINATION 5

Experimental Procedures 6

$\begin{array}{lr}\text { Specimen Preparation } & 6\end{array}$

$\begin{array}{ll}\text { Thermal Cycle Testing } & 10\end{array}$

Bond Coat Oxidation Effect Experiments $\quad 15$

Results - Bond Coat Oxidation Effect Experiments 21

Bond Coat Creep Effect Experiment 37

Results - Bond Coat Oxidation Effect Experiment 41

As-sprayed Microstructure $\quad 41$

$\begin{array}{ll}\text { Pre-Exposure } & 41\end{array}$

Thermal Cycle Testing $\quad 47$

Test Results $\quad 47$

Specimen Appearance $\quad 50$

Microstructure 54

Bond Coat Failure Criteria Experiment $\quad 58$

Key Property Determinations $\quad 60$

$\begin{array}{ll}\text { Bond Coat Properties } & 60\end{array}$

Tensile Strength $\quad 60$

Poisson's Ratio 63

Dynamic Elastic Modulus 63

Coefficient of Thermal Expansion 63 
Table of Contents, (continued)

Page

Top Coat Properties 63

Dynamic Elastic Modulus, Dynamic Shear Modulus, and Poisson's Ratio $\quad 64$

Coefficient of Thermal Expansion $\quad 75$

$\begin{array}{ll}\text { Bend Strength } & 75\end{array}$

TASK II MAJOR MODE LIFE PREDICTION MODELS 77

CYANIDE Finite Element Program $\quad 77$

TBC Analytical Modeling Program $\quad 85$

Results - TBC Analytical Modeling Program 89

$\begin{array}{ll}\text { Thermomechanical Experiments } & 102\end{array}$

$\begin{array}{ll}\text { Results - Thermomechanical Experiments } & 106\end{array}$

CONCLUSIUNS

APPENDIX I, POWDER CHARACTERISTICS 112

$\begin{array}{ll}\text { APPENDIX II, BOND COAT MICRUSTRUCTURE } & 114\end{array}$

APPENDIX III, MATERIAL PROPERTIES USED IN CYANIDE PROGRAM 117

$\begin{array}{lr}\text { REFERENCES } & 119\end{array}$ 


\section{LIST OF FIGURES}

Figure

Page

1 Tubular thermal barrier coating specimen 8

2 Button thermal barrier coating specimen 9

3 Tapered top coat edge developed by shadow masking 11

4 Baseline TBC as-sprayed microstructure (Rene' 80,

5 Rapid temperature thermal cycle furnace 14

6 Inconel 718 canister utilized for thermal cycle testing 18

$7 \quad$ Test results for thermal cycle testing in air for bond 22 coat oxidation specimens (values plotted for each individual specimen) in the $1093^{\circ} \mathrm{C}$ test

8 0xide scale thickness at the bond coat/top coat interface after thermal cycle testing in the $1093^{\circ} \mathrm{C}$ test (bond coat oxidation effect experiment \#1)

9 Thermal cycle results for specimens thermal cycle tested at $1093^{\circ} \mathrm{C}$ in sealed and unsealed canisters (bond coat oxidation effect experiment \#2)

10 Microstructure of specimens (Rene' $80 / \mathrm{NiCrAIY}_{2} \mathrm{ZrO}_{2}-\mathrm{Y}_{2} \mathrm{O}_{3}$ ) after thermal cycle testing in a sealed canister containing argon in the $1093^{\circ} \mathrm{C}$ test

11 Microstructure of specimens (no prior pre-exposure) at failure after thermal cycle testing in an unsealed canister (94 cycles) in the $1093^{\circ} \mathrm{C}$ test

12 Electron microprobe mapping of specimen (no pre-exposure) thermally cycled in an unsealed canister in the $1093^{\circ} \mathrm{C}$ test

13 Thermal cycle results for specimens thermal cycle tested at $1093^{\circ} \mathrm{C}$ that received special pre-exposures (bond coat oxidation effect experiment \#3).

14 Microstructure of as-sprayed TBC with aluminide coated bond coat (Rene' $80 / \mathrm{NiCrATY} /$ Aluminide/ $/ \mathrm{ZrO}_{2}-\mathrm{Y}_{2} \mathrm{O}_{3}$ )

15 Microstructure of four as-sprayed bond coat creep effect TBC systems (Rene' $80 /$ Bond Coat/Aluminide/ $/ \mathrm{rO}_{2}-\mathrm{Y}_{2} \mathrm{O}_{3}$ ) 
List of Figures, (continued)

Figure

Page

16 Micröstucture of four bond coat creep effect TBC systems (Rene' 80 /Bond Coat/Aluminide/ $\mathrm{ZrO}_{2}-\mathrm{Y}_{2} \mathrm{O}_{3}$ ) after

100 hour pre-exposure in air at $1093^{\circ} \mathrm{C}$

17 Microstructure of four bond coat creep effect TBC systems (Rene' $80 /$ Bond Coat/Aluminide/ $/ \mathrm{CO}_{2}-\mathrm{Y}_{2} \mathrm{O}_{3}$ ) after

100 hour pre-exposure in argon at $1093^{\circ} \mathrm{C}$

18 Test results for thermal cycle testing in air at $1093^{\circ} \mathrm{C}$ for bond coat creep effect specimens (values plotted for each specimen, duplicate testing), no prior pre-exposure

19 Test results for thermal cycle testing in air at $1093^{\circ} \mathrm{C}$ for bond coat creep effect specimens (values plotted for each specimen, duplicate testing) after prior air or argon pre-exposure at $1093^{\circ} \mathrm{C}$

20 Effect of heat treatment of bond coat \#4 on thermal cycle life of TBC (Rene' $80 /$ Bond Coat \#4/Aluminide/ $/ \mathrm{rO}_{2}-\mathrm{Y}_{2} \mathrm{O}_{3}$ ) in $1135^{\circ} \mathrm{C}$ test

21 Failed TBC specimen after thermal cycle testing in air at $1093^{\circ} \mathrm{C}$ for TBC systems $\# 1$ and $\# 2$ (bond coat creep effect experiment)

22 Failed TBC specimens after thermal cycle testing in air at $1093^{\circ} \mathrm{C}$ for TBC systems $\# 3$ and $\# 4$ (bond coat creep effect experiment)

23 Microstructure after failure of bond coat creep effect specimens (no prior pre-exposure) after thermal cycling in the $1093^{\circ} \mathrm{C}$ test

24 Microstructure after failure of bond coat creep effect specimens ( 100 hour pre-exposure in air at $1093^{\circ} \mathrm{C}$ ) after thermal cycling in the $1093^{\circ} \mathrm{C}$ test

25 Microstructure after failure of bond coat creep effect specimens ( 100 hour pre-exposure in argon at $1093^{\circ} \mathrm{C}$ ) after thermal cycling in the $1093^{\circ} \mathrm{C}$ test

26 Bond coat specimen configurations (all dimensions in centimeters)

27 Dynamic elastic modulus results for the $\mathrm{Ni}-22 \mathrm{C}-10 \mathrm{Al}-0.3 \mathrm{Y}$ bond coat material

28 Thermal expansion results for the $\mathrm{Ni}-22 \mathrm{Cr}-10 \mathrm{Al}-0.3 \mathrm{Y}$ bond coat material 
List of Figures, (continued)

$\underline{\text { Figure }}$

Page

29 Top coat specimen configurations (all dimensions in 68

30 centimeters modes of vibration

31 Thermal expansion results for the $2 \mathrm{ZO}_{2}-\mathrm{Y}_{2} \mathrm{O}_{3}$ top coat material

Point by point stress-strain curve representation

69

Creep curve representation for constant temperature

76

Creep strain versus time for several stress levels, Rene' 80 material

35 Temperature profile for GE cyclic rig

37 Plot of stress versus distance in the substrate, bond coat, and top coat in the radial direction - CYANIDE Analysis for Task a (no temperature gradient)

Plot of stress versus distance in the substrate, bond coat, and top coat in the radial direction - CYANIDE Analysis for Task b (temperature gradient)

Sketch of furnace system for thermomechanical experiment \#1 test specimens pre-exposure and thermal cycle testing 


\section{LIST OF TABLES}

Table

I Baseline Thermal Barrier Coating System (Weight Percent)

7

II Plasma Spray Parameters

III Experiment \#1 - Pre-Exposure $\left(1093^{\circ} \mathrm{C}\right)$ Times for Bond Coat

Oxidation Effect Specimens (Thermal Cycle Testing in Air)

IV Experiment *2 - Thermal Cycle Testing in Argon and Various

Pre-Exposure Temperatures

$V \quad$ Experiment \#3 - Special Pre-Exposures at $1093^{\circ} \mathrm{C}\left(2000^{\circ} \mathrm{F}\right)$

VI Top Coat X-ray Diffraction Results

VII Bond Coat Creep Effect TBC Systems

VIII Pre-Exposure $\left(1093^{\circ} \mathrm{C}\right)$ Times for Bond Coat Creep Effect

Specimens (Thermal Cycle Testing in Air)

IX Oxide Scale Thickness at Bond Coat/Top Coat Interface After 100 Hour Air Pre-Exposure $\left(1093^{\circ} \mathrm{C}\right)$ for Bond Coat Creep Effect Specimens

$x \quad$ Evaluation of TBC Integrity vs. Thermal Cycles

XI LPPS Ni-22Cr-10Al-0.3Y Bond Coat Tensile Properties 
List of Tables, (continued)

Table

Page

XIII Values for Room Temperature Measurement of Elastic Moduius and Shear Modulus of APS $\mathrm{ZrO}_{2}-8 \mathrm{~S}_{2} \mathrm{O}_{3}$ (Cotton Thread)

XIV Mechanical Testing of Plasma-Sprayed Zirconia Bars

XV Elevated Temperature Determination of Elastic Modulus,

Shear Modulus, and Poisson's Ratio of APS $\mathrm{ZrO}_{2}-8 \mathrm{Y}_{2} \mathrm{O}_{3}$

XVI Powder Manufacturers

XVII Powder True Density

XVIII Powder Sieve Analys is

XIX Powder Microtrac Analysis

XX Elastic Modulus of TBC Components

XXI Poisson's Ratio of TBC Components 


\section{SUMMARY}

This is the second annual report of the first 3-year phase of a 2 phase, 5-year program. The objectives of the first phase are to determine the predominant modes of degradation of a plasma sprayed thermal barrier coating system and to develop and verify life prediction models accounting for these degradation modes. The primary $T B C$ system consists of an air plasma sprayed ZrO- $\mathrm{Y}_{2} \mathrm{O}_{3}$ top coat, a low pressure plasma sprayed $\mathrm{NiCrAlY}$ bond coat, and a Rene' 80 substrate.

The first task (Task I) was to evaluate TBC failure mechanisms. Both bond coat oxidation and bond coat creep have been identified as contributors to TBC failure. Key property determinations have also been made for the bond coat and the top coat, including tensile strength, Poisson's ratio, dynamic modulus, and coefficient of thermal expansion.

The second task (Task II) is to develop TBC life prediction models for the predominant failure modes. These models will be developed based on the results of thermomechanical experiments and finite element analysis. The thermomechanical experiments have been defined and testing initiated. Finite element models have also been developed to handle TBCs and are being utilized to evaluate different $T B C$ failure regimes. 


\section{INTRODUCTION}

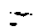

The objectives of this program are to determine the predominant modes of degradation of a plasma sprayed thermal barrier coating system and to develop and verify life prediction models accounting for these degradation modes. The program is divided into two phases, each consisting of several tasks. The Government will have the option to exercise Phase II after the first phase has been successfully completed.

The work in Phase I is aimed at identifying the relative importance of the various failure modes for a thermal barrier coating system and developing and verifying a life prediction model(s) for the predominant mode. These objectives will be accomplished in a 36-month effort consisting of three technical tasks plus a reporting task. Task I will identify, through the design and performance of a series of experiments, the relative importance of the various failure modes for a baseline thermal barrier coating system. Preliminary models will then be tested and modified based on confirmation tests. This TBC system consists of a low pressure plasma sprayed (LPPS) $\mathrm{Ni}-22 \mathrm{Cr}-10 \mathrm{~A} 1-0.3 Y$ bond coat $(0.13 \pm 0.025 \mathrm{~mm}$ thick) and a plasma sprayed $\mathrm{ZrO}_{2}-8 \% \mathrm{Y}_{2} \mathrm{O}_{3}$ top coat $(0.25 \pm 0.050 \mathrm{~mm}$ thick $)$ on conventionally-cast Rene' 80 alloy substrate. Task I also includes determination of key properties of the coating materials such as tensile strength, Poisson's ratio, dynamic modulus, and coefficient of thermal expansion. 
In Task II, - life prediction models for the predominant failure modes will be developed. This will be accomplished by designing a suitable set of experiments and concomitant analyses, thus creating a life prediction model by means of a combined analytical and experimental program.

These models will be verified in Task III through a series of selected tests and analyses. The results obtained from this task should provide a better understanding of the behavior of TBC systems and the suitability of the developed models. This understanding will be used to formulate recormendations for further research required to arrive at a fully satisfactory engine life prediction methodology.

The work in Phase II will develop design-capable, causal, life prediction models for thermomechanical and thermochemical failure modes, and for the exceptional conditions of foreign object damage and erosion. This will be accomplished in a 24-month effort consisting of five technical tasks plus a reporting task. In Task $V$, thermomechanical life models will be developed. This involves the development of fracture mechanics and continuum mechanics based, and possibly other life prediction models. In Task VI, thermochemical failure models will be developed, including oxidation and hot corrosion failure models. - In Task VII, models for erosion and foreign object damage will be developed. The integration of appropriate combinations of models into 
a comprehensive life prediction model will be accomplished in Task VIII. In the final technical task, Task IX, the integrated model developed in Task VIII will be exercised through a combination of critical tests and analyses to determine its applicability and accuracy.

This report describes the work performed during the period April 1985 to March 1986 on Tasks I and II of the first phase. 


\section{TASK I FAILURE MECHANISM DETERMINATION}

One of the potential failure mechanisms being investigated in Task $I$ is bond coat oxidation. Many studies (1-4) indicate that bond coat oxidation may be a major failure mechanism. Pre-exposures in air and argon were utilized to try to isolate the effect of bond coat oxidation on ceramic layer spalling.

Another failure mechanism investigated was bond coat creep. GE evidence has indicated that the thermal cycle life of TBC systems can be extended by using strong bond coat alloys (5). It is believed that creep of the bond coat at elevated temperatures leads to a shift in the stress free temperatures and larger compressive stresses develop in the zirconia layer on return to room temperature, thus causing a greater propensity for spalling.

Task I also includes determination of key properties of the coating materials such as tensile strength, Poisson's ratio, dynamic modulus, and coefficient of thermal expansion. 


\section{Experimental Procedures}

\section{Specimen Preparation}

The baseline system in this effort consists of a low pressure plasma sprayed (LPPS) $\mathrm{Ni}-22 \mathrm{Cr}-10 \mathrm{Al}-0.3 \mathrm{Y}$ (wt. \%) bond coat and an air plasma sprayed (APS) yttria partially stabilized zirconia $\left(\mathrm{ZrO}_{2}-8 \% \mathrm{Y}_{2} \mathrm{O}_{3}\right)$ top coat on conventionally cast Rene' 80 alloy substrate (Table I). Bond coat thickness was $0.13 \pm 0.025 \mathrm{~mm}(0.005 \pm 0.001 \mathrm{inch})$, and zirconia thickness was $0.25 \pm 0.05 \mathrm{~mm}(0.010 \pm 0.002$ inch $)$.

The bond coat and top coat were applied to two types of specimens. The first is a tube specimen (Figure 1) which simulates the curvature of engine components, and the second is a button specimen (Figure 2) which has become a standard test specimen at GE for evaluating TBCs. The specimens were given the standard Rene ' 80 solution heat treatment $\left[1204^{\circ} \mathrm{C}\left(2200^{\circ} \mathrm{F}\right)\right.$ for 2 hours, followed by $1093^{\circ} \mathrm{C}\left(2000^{\circ} \mathrm{F}\right)$ for 4 hours, both in vacuum] and the substrate surface was then grit blasted and vapor honed prior to application of the bond coat. The bond coat was applied on four tube specimens at a time using a planetary holder, and was applied on 35 button specimens at a time using a rotating drum. Both types of specimens were coated in an automated LPPS system. A bond coat powder size of $-230+400$ mesh (see Appendix 1, Powder Characteristics) was used to produce surface roughnesses greater than 400 , win in Ra* (necessary to produce good bond coat/top coat bonding). Next, the bond coated specimens were cleaned in acetone. Tube specimens were also shadow 


\section{TABLE I}

\section{BASELINE THERMAL BARRIER COATING SYSTEM (WEIGHT PERCENT)}

Substrate (Rene ' 80 ): $N i-14 C r-9.5 C 0-5 T i-4 W-4 M O-3 A 1-0.17 C-0.03 Z r-0.015 B$

Bond Coating : Ni-22Cr-10Al-0.3Y (Low Pressure Plasma Spray)

Top Coating : $\mathrm{ZrO}_{2}-8 \mathrm{Y}_{2} \mathrm{O}_{3}$ (Air Plasma Spray) 


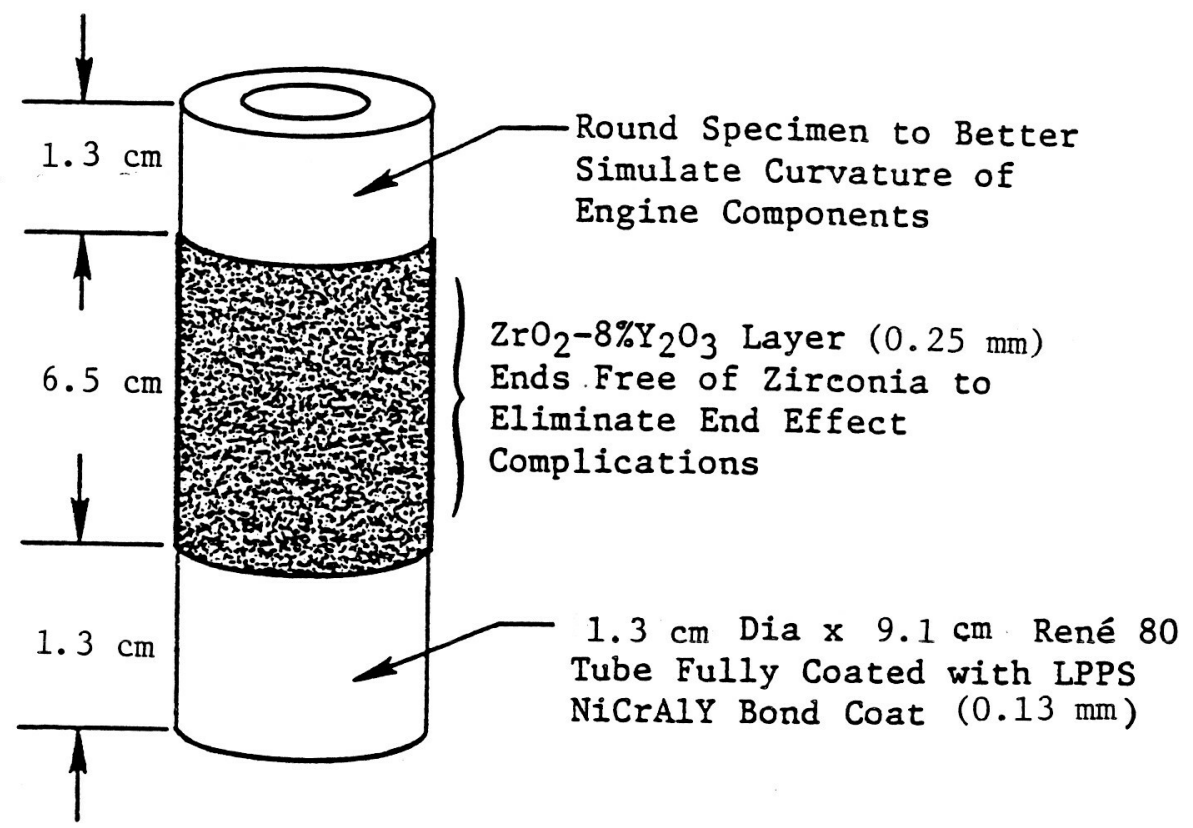

a) Test specimen configuration

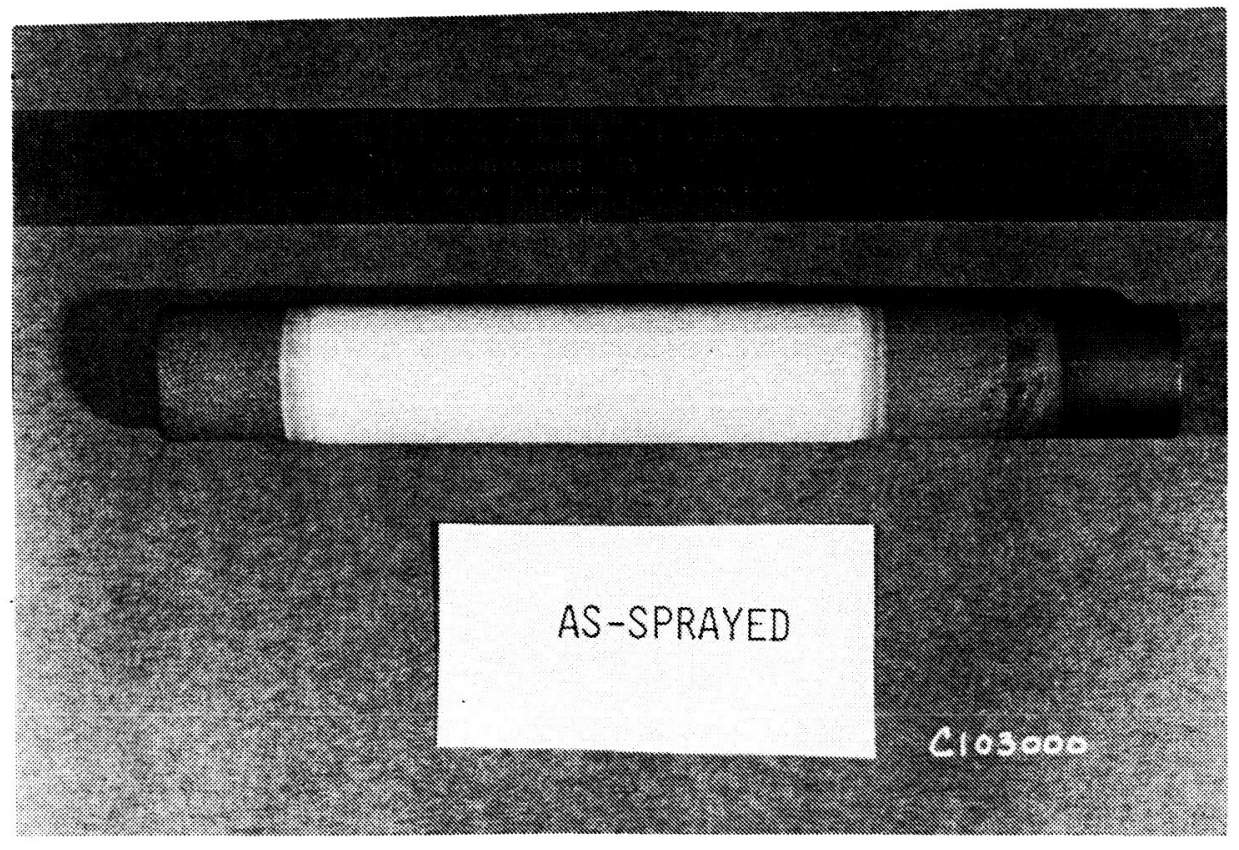

b) As-sprayed specimen

Figure 1 Tubular thermal barrier coating specimen 


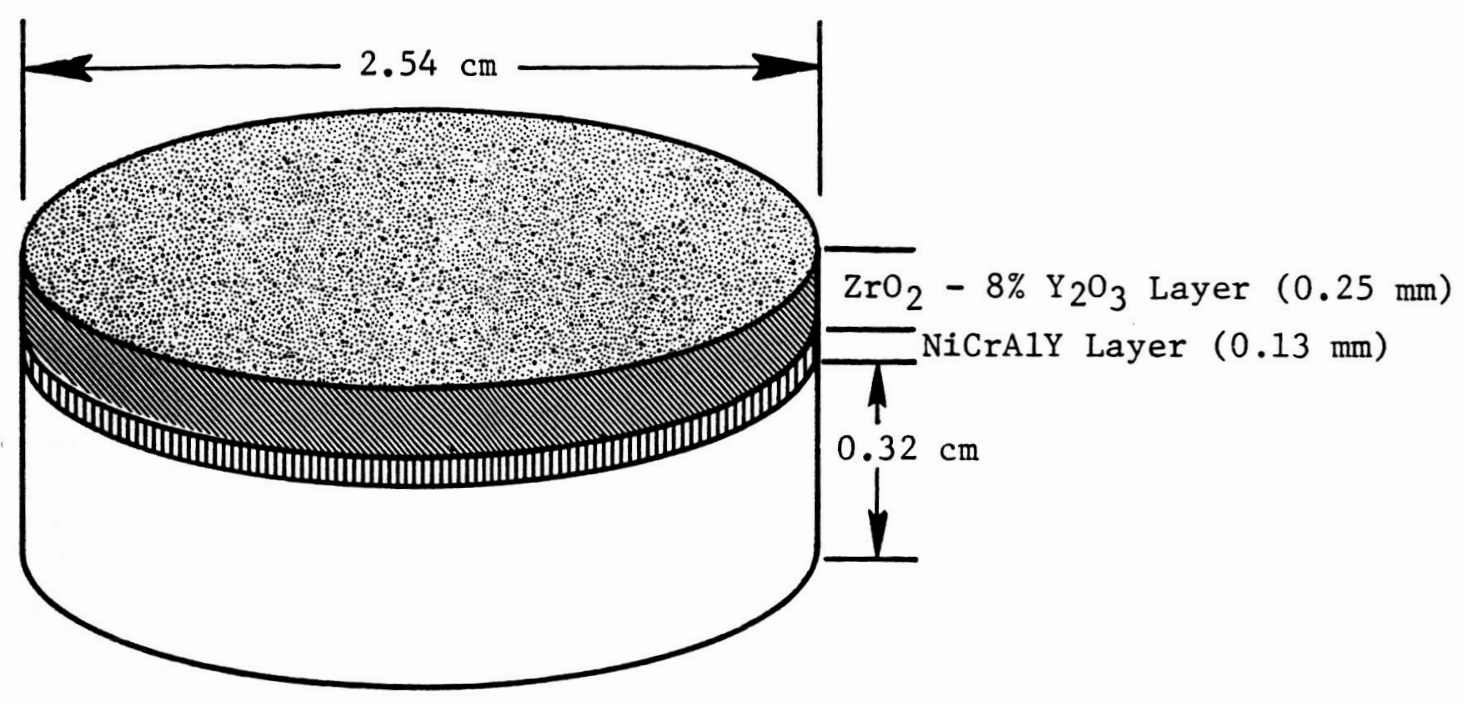

a) Test specimen configuration

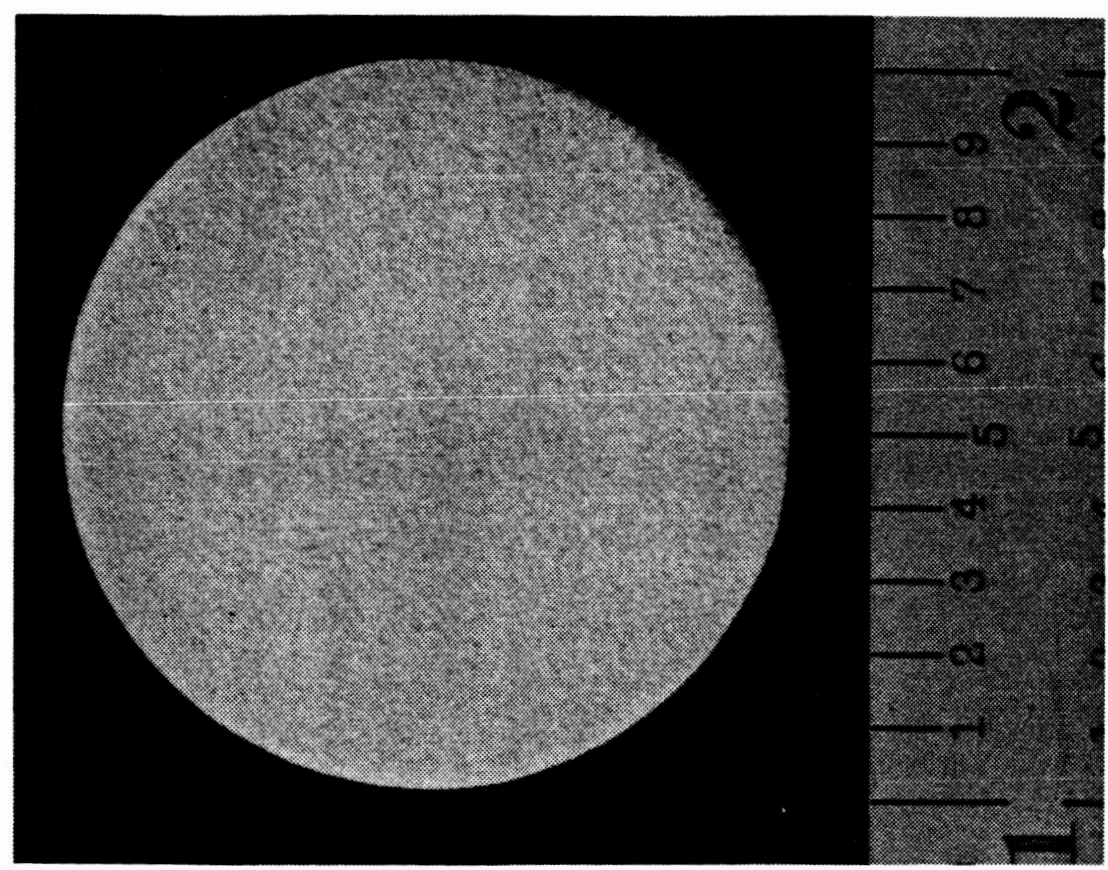

b) As-sprayed specimen

Figure 2 Button thermal barrier coating specimen 
masked prior to the top coat application to produce a tapered edge (Figure 3 ) on the zirconia coating layer to help reduce premature coating spallation during thermal cycle testing. The top coat (see Appendix 1 for Powder Characteristics) was applied to each tube specimen individually using a GE P50 robot and a Metco Computerized Plasma Process Controller Spray System. The robot controls the plasma torch manipulations, while the Metco system controls the spray parameters. The top coat was deposited on up to 100 button specimens simultaneously using a semi-automated Metco APS System. The spray parameters used for both the bond coat and top coat are listed in Table II. The microstructure of the resultant TBC System is shown in Figure 4.

\section{Thermal Cycle Testing}

Thermal cycling of the TBC specimens, to a maximum temperature of $1093^{\circ} \mathrm{C}$ $\left(2000^{\circ} \mathrm{F}\right)$, was accomplished in a programmable, microprocessor controlled, rapid-heating furnace with $\mathrm{MoSi}_{2}$ heating elements (Figure 5). Up to 36 tubular specimens or up to 60 button specimens were cycled simultaneously in the furnace. The thermal cycle was approximately 70 minutes long with approximately 10 minutes heat up, 45 minutes at temperature $\left(1093^{\circ} \mathrm{C}\right)$, and 15 minutes forced-air cooling. Tube specimens were removed from the test after every fifth cycle and visually examined for evidence of cracking and loss of the zirconia layer. Button specimens were examined after every twentieth cycle. Each specimen was removed from test when 10 percent (surface area) of the zirconia layer had spalled. Selected specimens were evaluated metal lographically. 


\section{ORIGINAL PAC: \\ Q. POOR QUALITY}

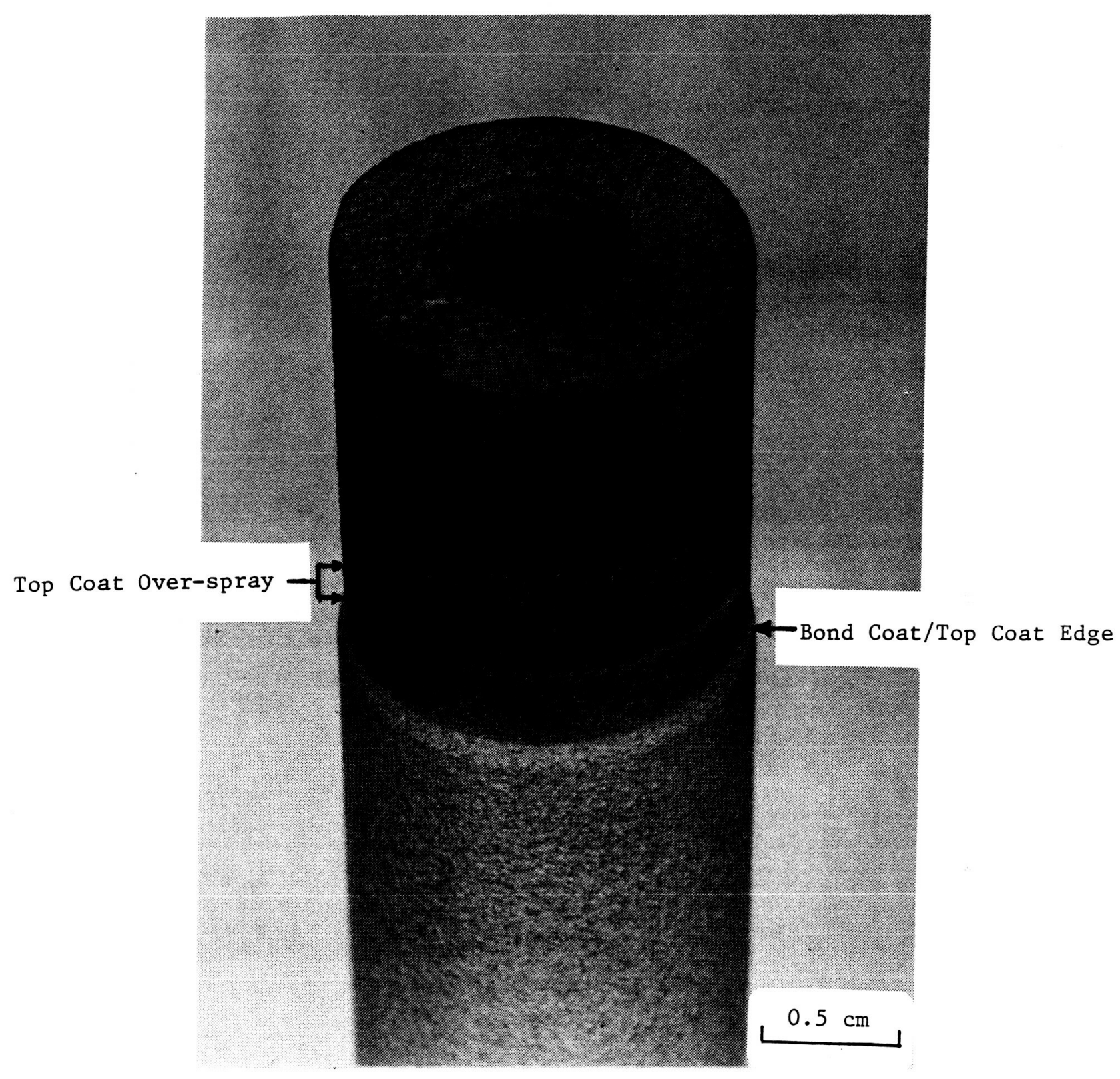

Figure 3 Tapered top coat edge developed by shadow masking 


\section{TABLE II}

\section{PLASMA SPRAY PARAMETERS}

APS

Metco 7MB

$\mathrm{N}_{2} / \mathrm{H}_{2}$

$36 \mathrm{KW}$

6 Lbs./Hr.

$-$

5 In.

90० air impingement, and center of tube cooling.
LPPS

Metco 7MB

$\mathrm{Ar} / \mathrm{H}_{2}$

$50 \mathrm{KW}$

5 Lbs./Hr.

$1800^{\circ} \mathrm{F}$

12 In.

$\mathrm{Al}_{2} \mathrm{O}_{3}$ grit blast

and vaper hone cleaning 


\section{ORIGHAL PRE ie \\ QE POOR QUALITY}

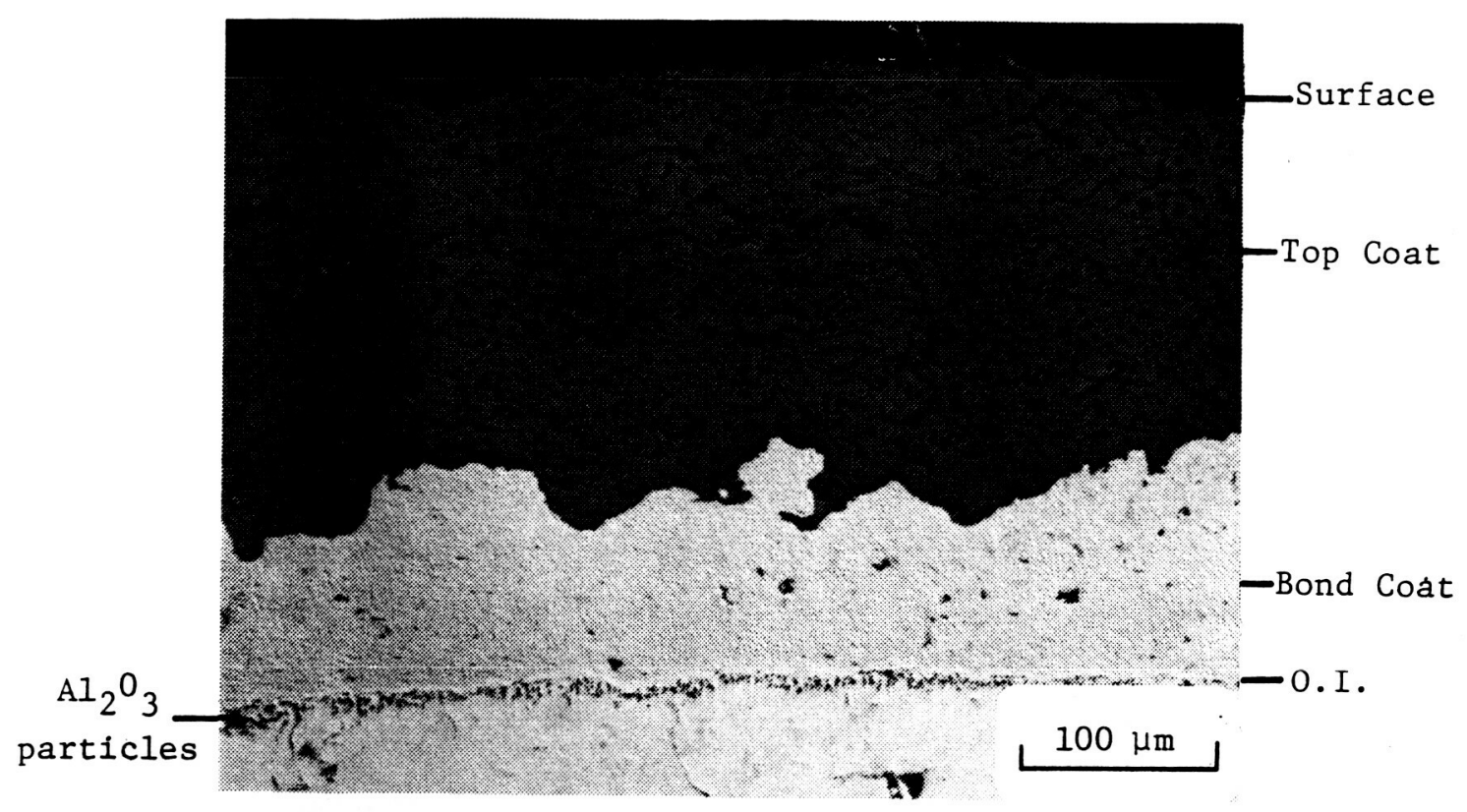

a) As-sprayed microstructure

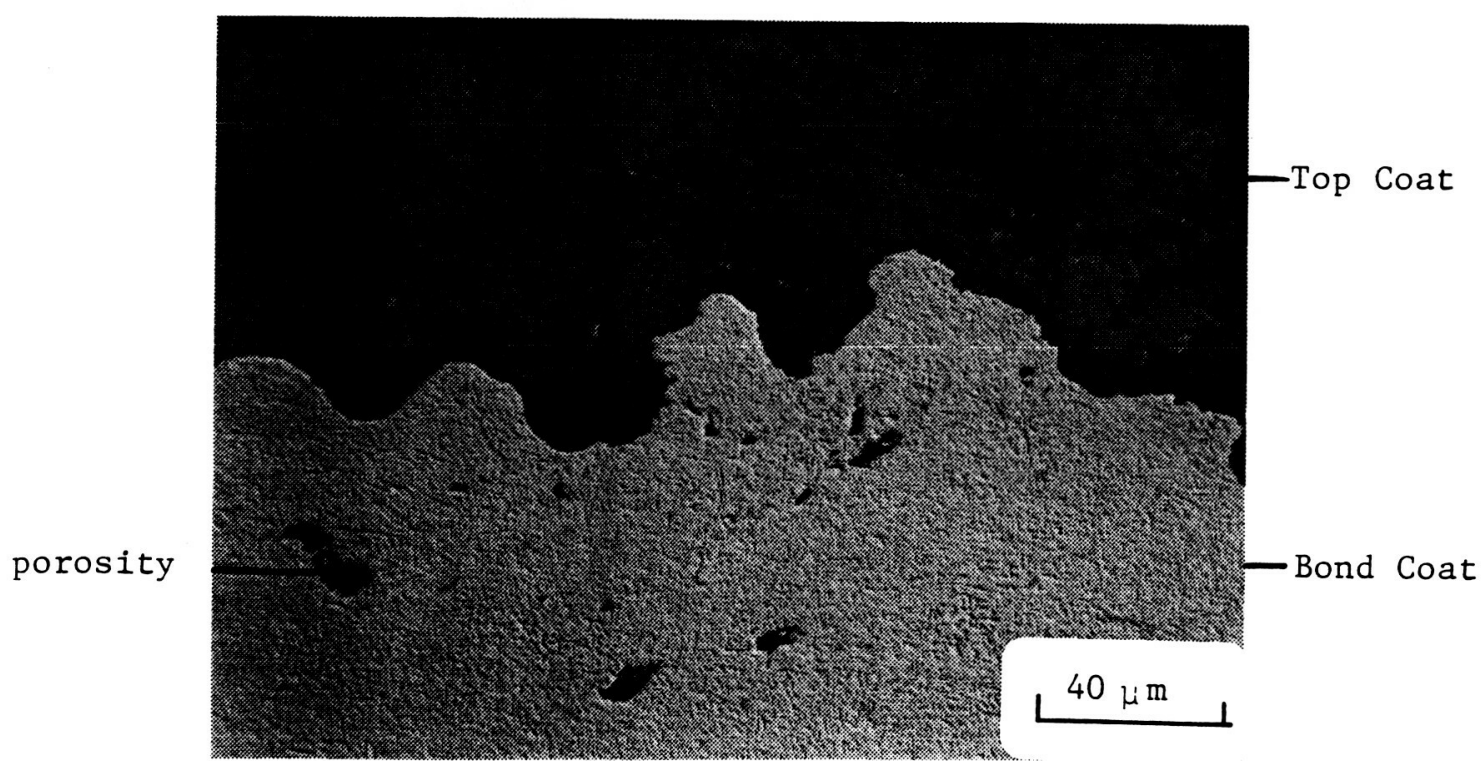

b) Bond coat/top coat interface

Figure 4 Baseline TBC as-sprayed microstructure (Rene '80, NiCrAlY, $\mathrm{ZrO}_{2}{ }^{-\mathrm{Y}_{2}} \mathrm{O}_{3}$ ) 


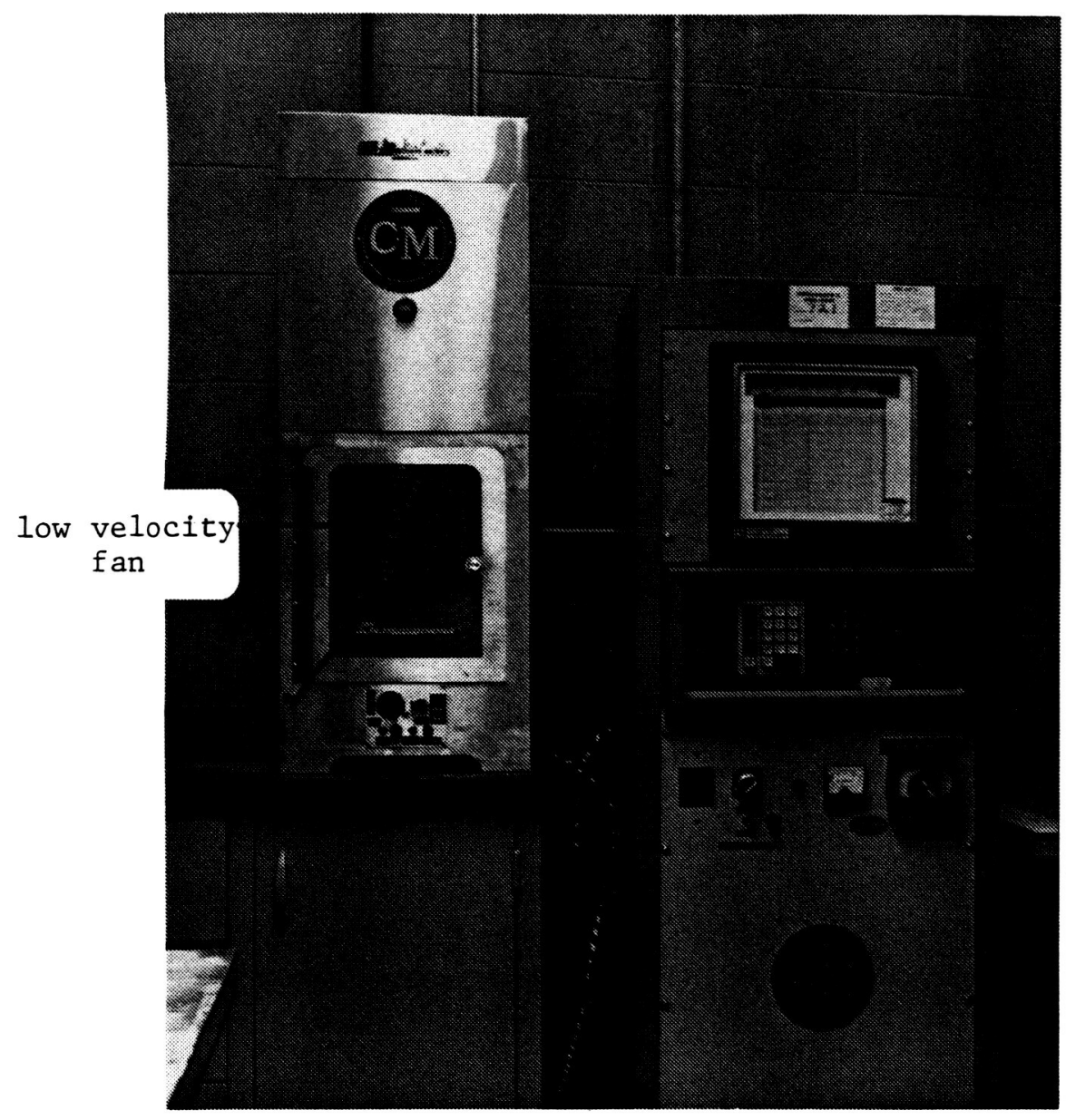

RAPID TEMPERATURE FURNACE

--- 10 minute heat up

--- 45 minute exposure at $1093 \mathrm{C}$

--- 15 minute forced air cool ing

Figure 5 Rapid temperature thermal cycle furnace 


\section{$=\quad$ Bond Coat 0xidation Effect Experiments}

Three experiments were utilized to evaluate the effects of bond coat oxidation on coating failure.

In the first experiment, thermal cycle tests (Table III) were performed in air on specimens that had received isothermal pre-exposures in either oxidizing (static air) or inert (static argon) atmospheres for selected times at $1093^{\circ} \mathrm{C}\left(2000^{\circ} \mathrm{F}\right)$. In this experiment, all pre-exposed specimens should contain "predamage" resulting from the thermally activated processes other than oxidation, but only specimens pre-exposed in air should contain, in addition, the "predamage" due to oxidation (oxide scale growth on the bond coat). Thus, the difference in thermal cycle test lives of the two groups should reflect the effect of bond coat oxidation and allow evaluation of the magnitude of the other thermally-activated phenomena (sintering of the bond coat and zirconia layer, bond coat and ceramic coat creep, and bond coat/substrate interdiffusion). Tube specimens were utilized in this experiment. 


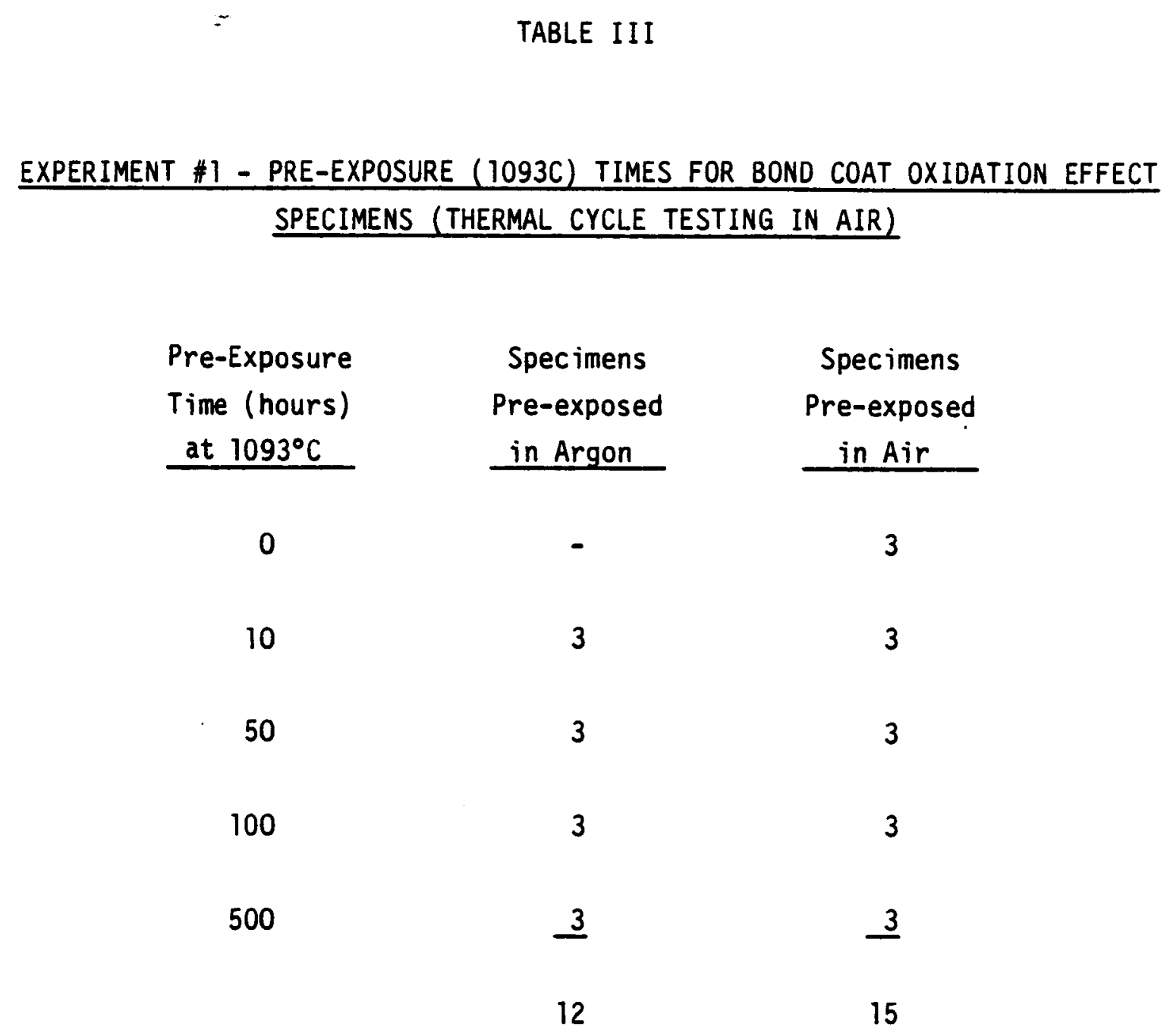




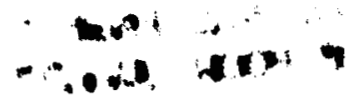

The second experiment was similar to the first except that some of the specimens were also thermally cycled in argon, and the effect of different pre-exposure temperatures was evaluated. Thermal cycling in argon was achieved by sealing specimens in argon filled Inconel 718 canisters (Figure 6) and testing them in the thermal cycle furnace. Argon pressure in the canisters was adjusted to be approximately 1 atmosphere at test temperature $1093^{\circ} \mathrm{C}\left(2000^{\circ} \mathrm{F}\right)$. Some specimens received no pre-exposure (as-sprayed), others received 100 hour isothermal pre-exposures at $1093^{\circ} \mathrm{C}\left(2000^{\circ} \mathrm{F}\right)$ in either static air or static argon (Table IV). Baseline specimens in unsealed canisters that had received no pre-exposure (as sprayed), 100 hour isothermal pre-exposure at $1093^{\circ} \mathrm{C}\left(2000^{\circ} \mathrm{F}\right)$ in either static air or static argon, or 250 hour isothermal pre-exposure at $982^{\circ} \mathrm{C}\left(1800^{\circ} \mathrm{F}\right)$ in either static air or static argon were also included in this experiment (Table IV). These were run to assess the effect of reduced heating and cooling rates (experienced in the canister tests), and to assess the effect of different pre-exposure temperatures. By thermal cycling in argon, the advantage of minimum scale growth during cycling was achieved. Button specimens were utilized in this experiment.

In the third experiment, thermal cycle tests were performed in air on specimens that had received combinations of isothermal pre-exposures in static air and/or static argon before and/or after the top coat application (Table V). This experiment was aimed at understanding how argon pre-exposures reduce the thermal cycle life of TBCs (observed in the first experiment). This will be discussed in detail in the next section. Button specimens were utilized in this experiment. 


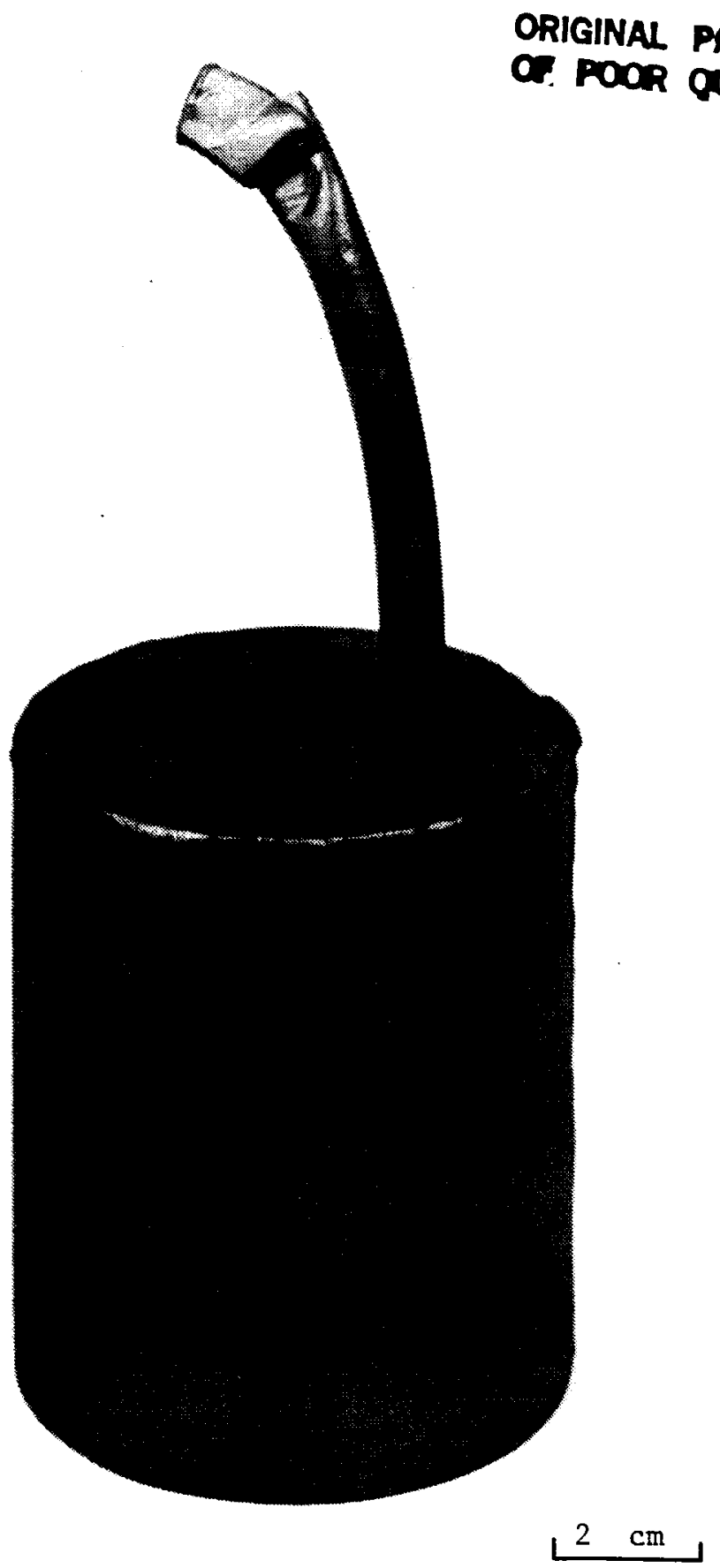

Figure 6 Inconel 718 canister utilized for thermal cycle testing in argon 


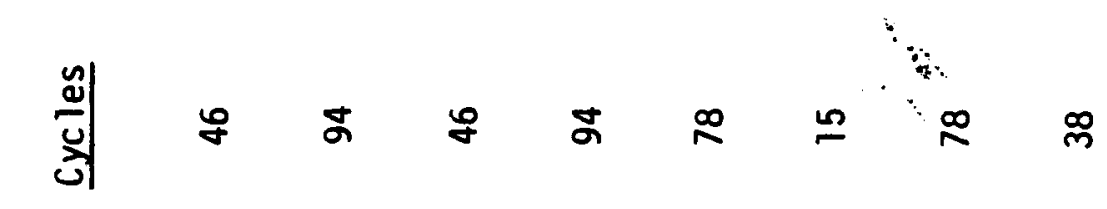

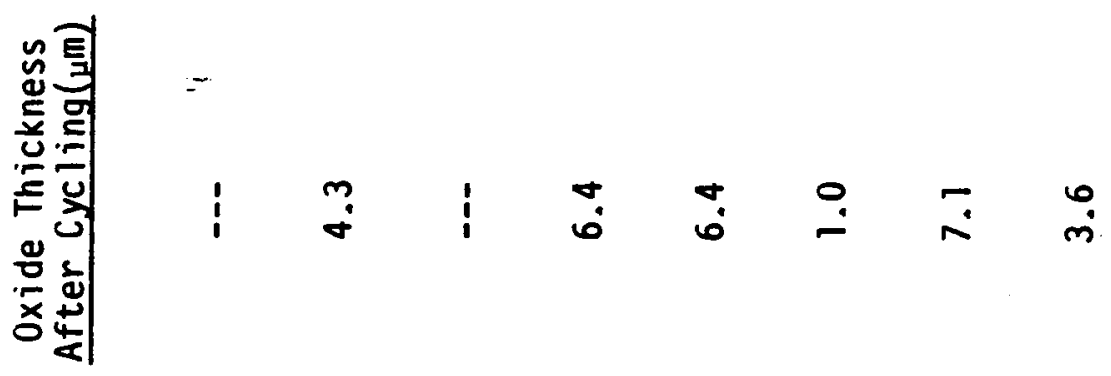

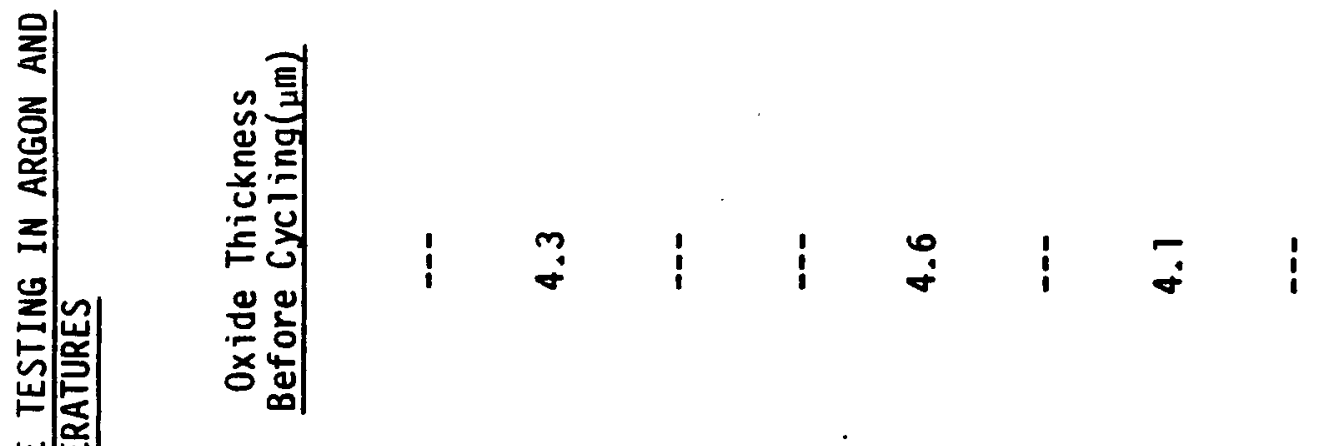

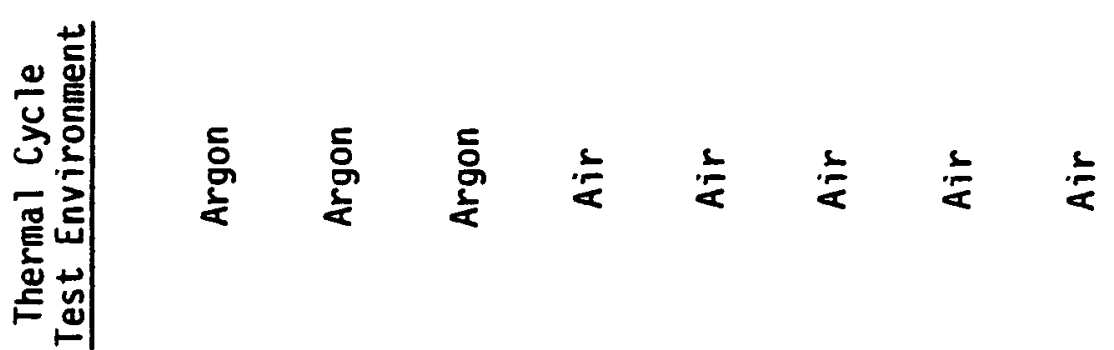

客

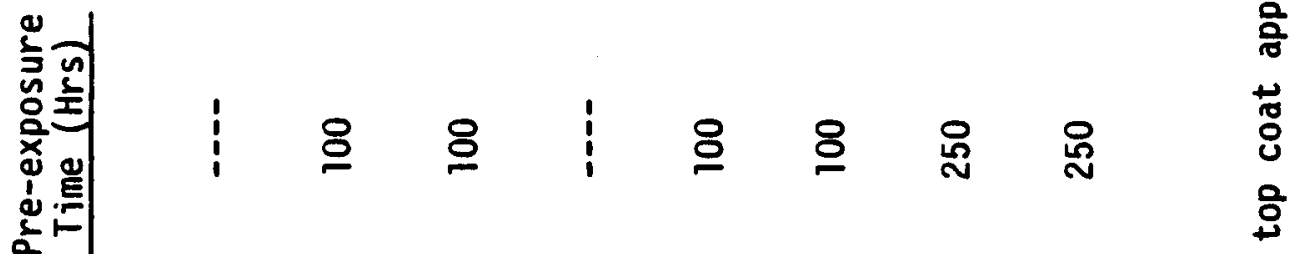

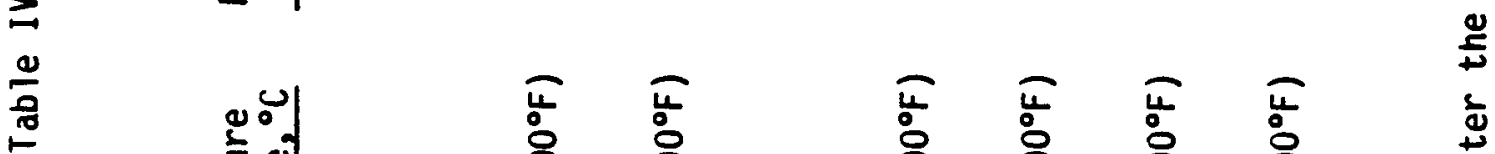

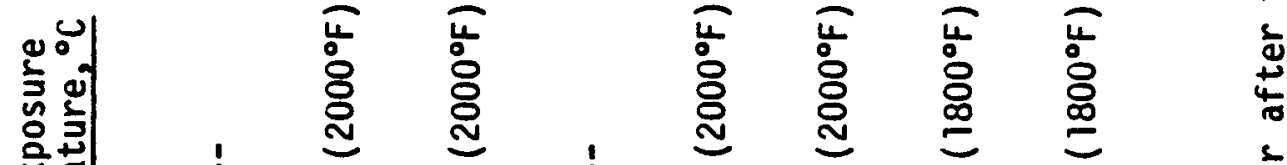

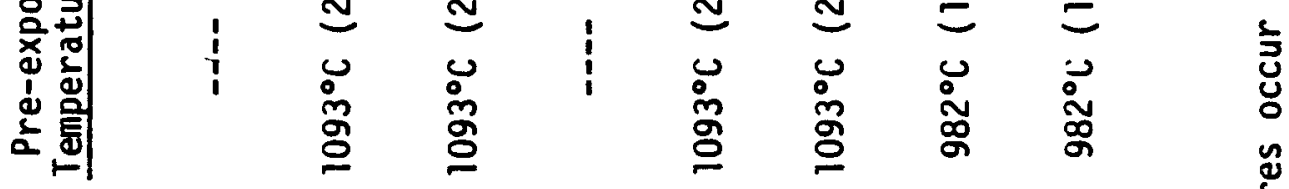

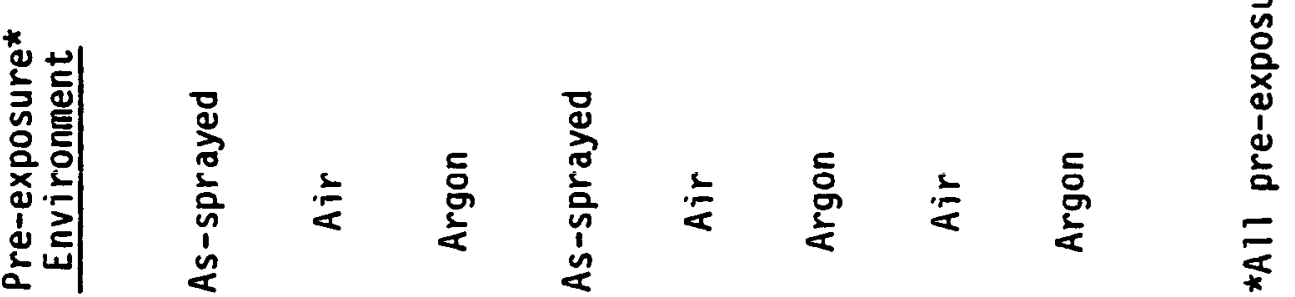




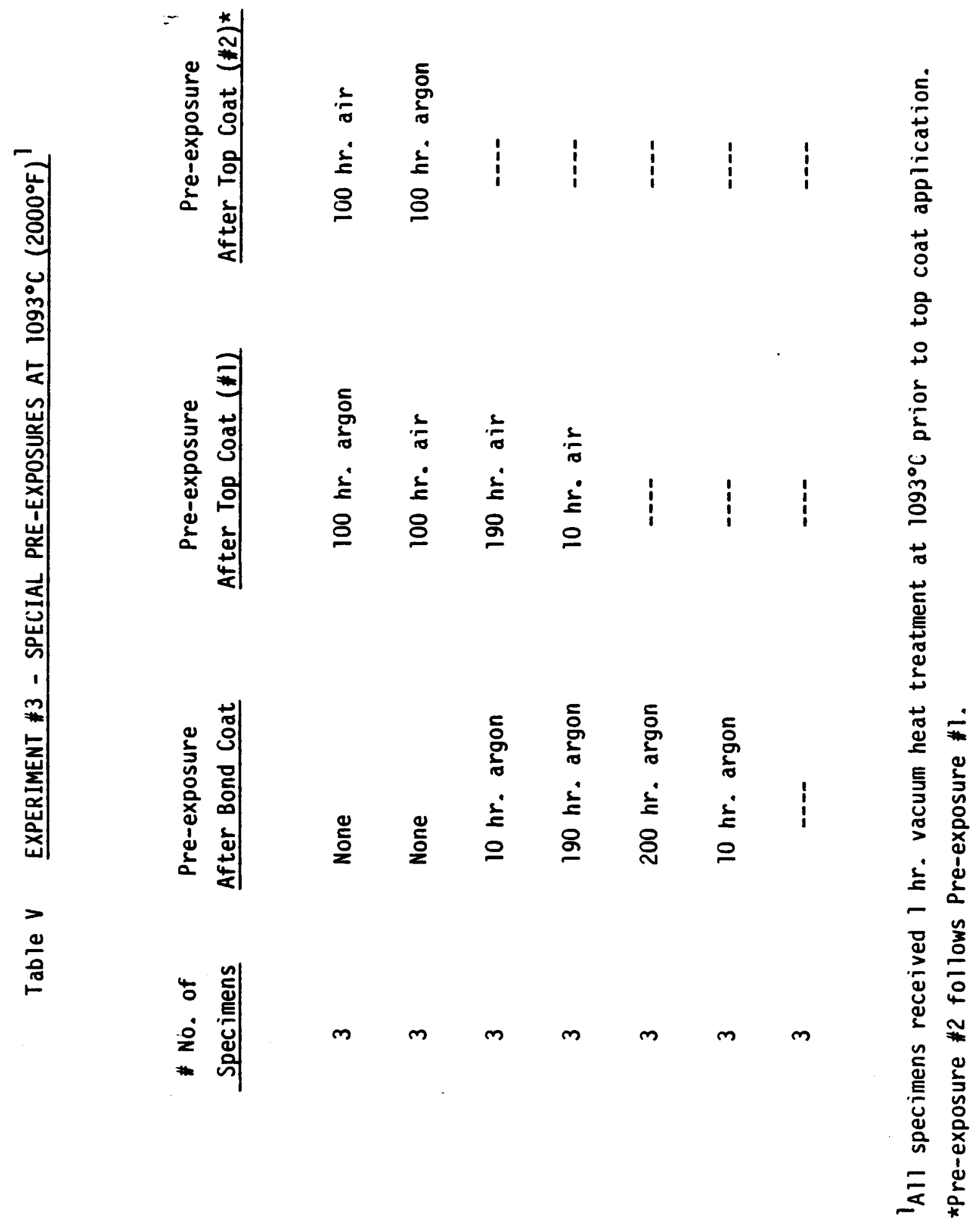




\section{Results - Bond Coat Oxidation Effect Experiments}

As reported previously (6), thermal cycle testing in air of Experiment \#1 specimens (pre-exposures in static air or static argon for 10, 50, 100, and 500 hours) has been completed. Unexpectedly, the specimens pre-exposed in argon failed (failure was defined as when $10 \%$ of the surface area of the ceramic top coat had spalled) with thermal cycle lives less than the specimens pre-exposed in air (Figure 7). Failures in all cases occurred in the ceramic top coat approximately $0.025-0.050 \mathrm{~mm}\left(0.001-0.002^{\prime \prime}\right)$ from the bond coat/top coat interface (this is the normal TBC failure location). Continuous oxide scales of approximately $4 \mu \mathrm{m}$ (excluding the 472 hour pre-exposure specimens) were observed at the bond coat/top coat interface for the as-sprayed and air pre-exposed specimens at failure after thermal cycle testing (Figure 8). This is contrasted with the specimens pre-exposed in argon where oxide scales generally less than $1 \mu \mathrm{m}$ developed and appeared non-continuous by optical microscopy (a detailed examination of pre-exposure microstructure and failed specimen microstructure is presented in the First Annual Report [6]). The observation that, at failure, the bond coat oxide scale thicknesses were essentially identical for the specimens that received no pre-exposure or air pre-exposures is consistent with the work of Miller (7), who noted similar weight gains (oxidation) at failure of specimens with a $\mathrm{CaSiO}_{4} / \mathrm{MCrALY} \mathrm{TBC}$ regardless of test temperature. These results demonstrate the importance of bond coat oxidation to the overall TBC failure mechanism. 


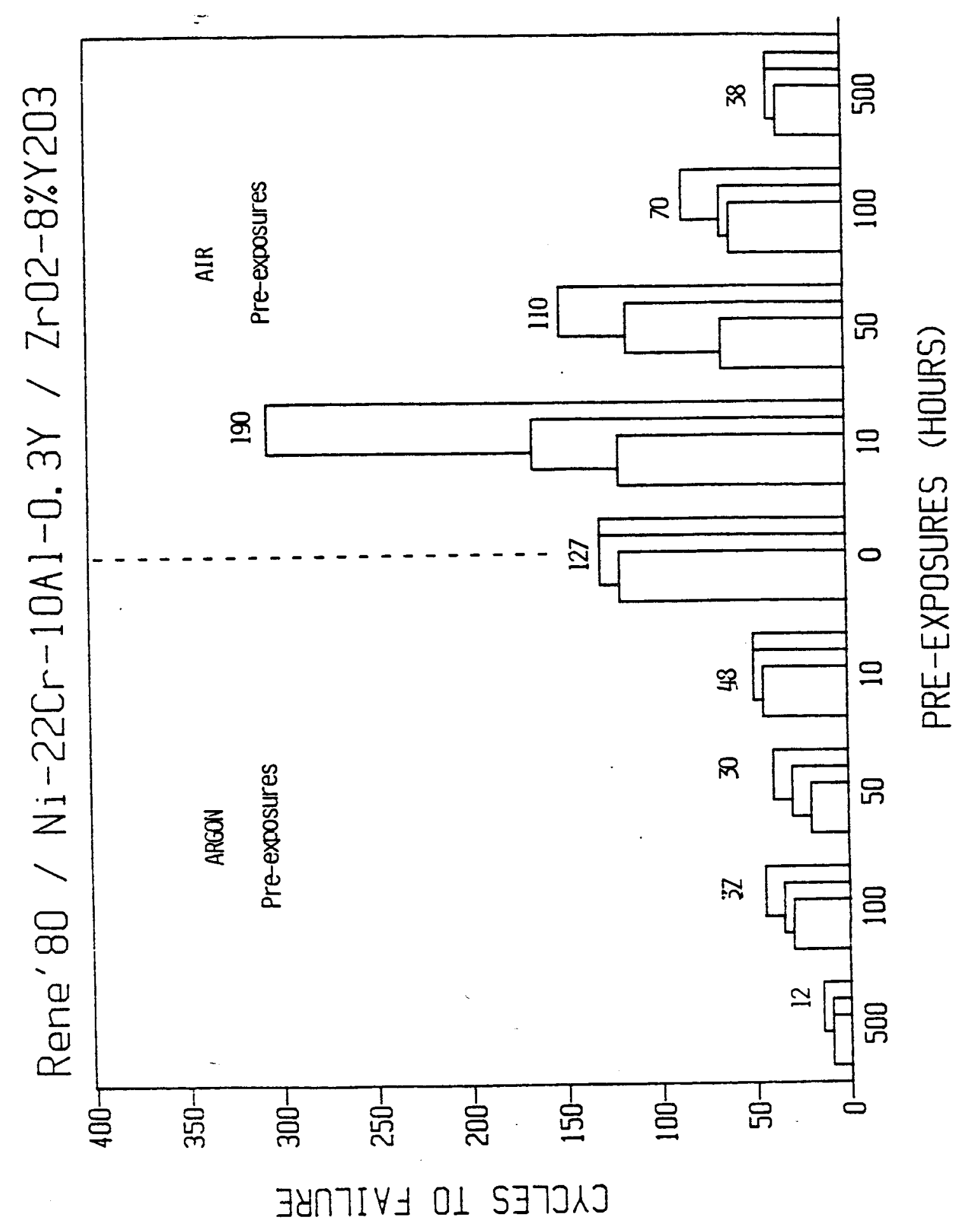

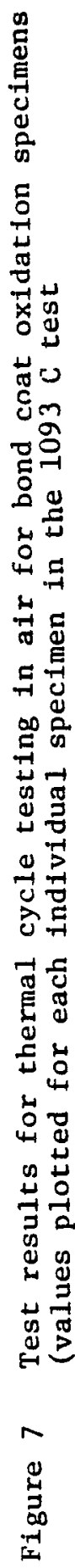




\section{Average Oxide Scale Thickness at Fallure (Microns)}

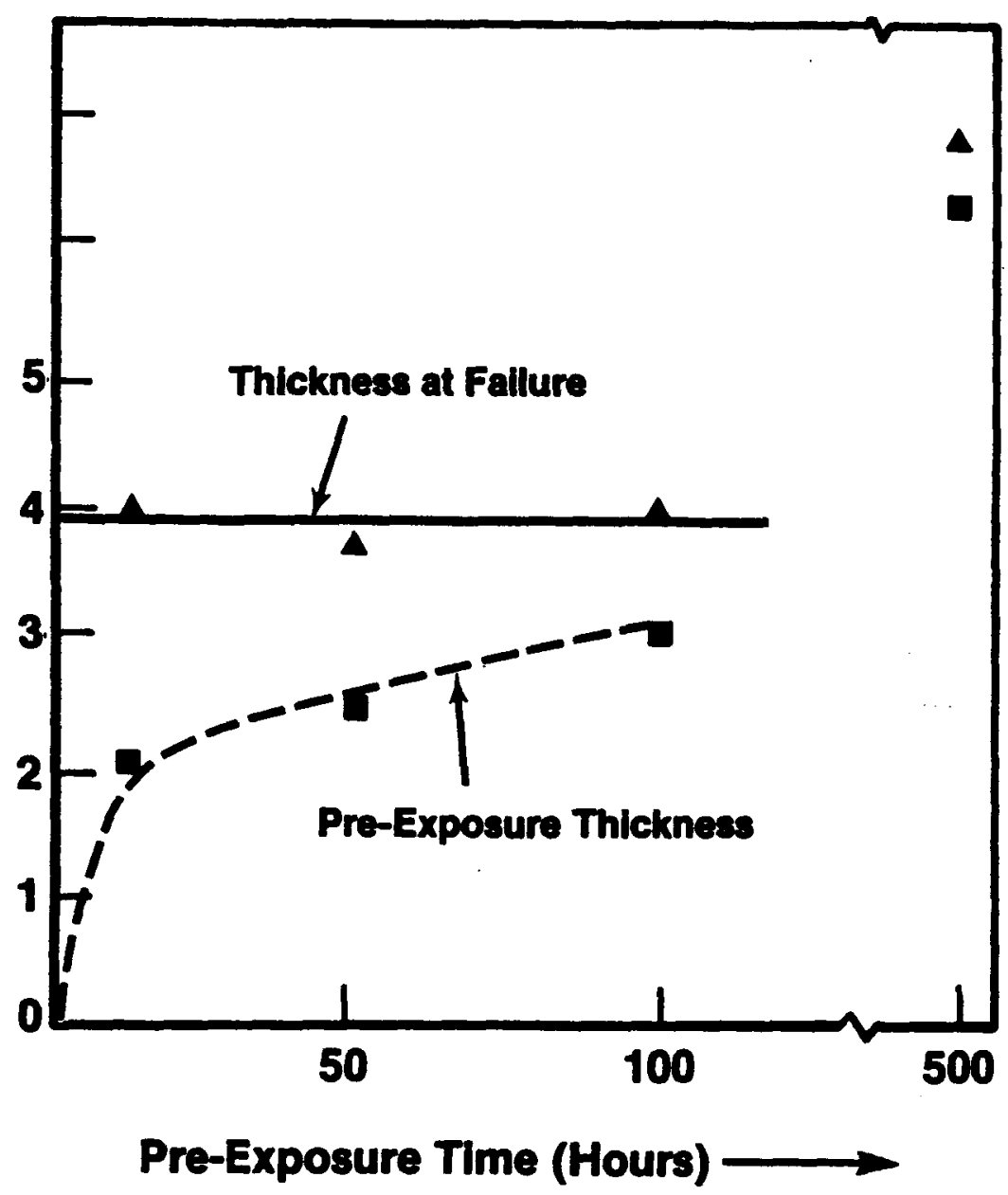

Figure 8 Oxide scale thickness at the bond coat/top coat interface after thermal cycle testing in the $1093^{\circ} \mathrm{C}$ test(bond coat oxidation effect experiment \#1) 
The detrimental effect of argon is believed to be associated with its effect on the oxidation of the bond coat. (Extensive interdiffusion between the bond coat and the substrate was clearly documented in the First Annual Report [6]). An internal investigation (8) was performed to understand how argon may be affecting the thermal cycle life of TBCs. This study indicated that a possible cause of the shortened life was the diffusion of $\mathrm{Cr}, \mathrm{Ta}, \mathrm{W}$, and other substrate elements to the bond coat/top coat interface during the argon pre-exposure prior to significant bond coat oxidation. In most cases, the precipitation of carbides (presumably $M_{23} C_{6}$ carbides) was noted in the bond coat at the bond coat/top coat interface (also noted in other locations in the bond coat). This was observed to a greater degree in specimens that were pre-exposed in argon. Therefore, the decrease in life may be associated with the formation of $\mathrm{Cr}, \mathrm{Ta}, \mathrm{W}$, and other less protective oxides which interfere with the formation of stable, adherent $\mathrm{Al}_{2} \mathrm{O}_{3}$ scales. In the case of specimens pre-exposed in argon, significant oxidation of the bond coat will occur upon thermal cycling. Since significant diffusion occurs during the pre-exposure, a less protective scale may form, which results in a less adherent oxide scale at the bond coat/top coat interface. This reduction in chemical bonding would therefore result in earlier failure of the TBC. The TBC in this case is held on only by mechanical bonding resulting from the high surface roughness of the bond coat. Therefore, cracking which leads to spalling still occurs in the ceramic, but only because the roughness of the bond coat makes the preferred crack initiation locations at the peaks of the bond coat. The cracks initiated at these peaks then 
propagate through the ceramic resulting in failure in the normal TBC location. More investigation of this phenomenon is required, however, the following two experiments also tend to indicate that the detrimental effects can be attributed to how argon exposure is affecting the bond coat.

In the second experiment, thermal cycle testing in argon was performed in a sealed canister, while thermal cycle testing in air was performed in an unsealed canister. To compensate for the slower cooling rate of the specimens enclosed in canisters, the cooling period was increased from 15 minutes to 30 minutes for this thermal cycle test to assure cooling to similar temperatures to those experienced in regular tests.

The test results of thermal cycle in argon experiment again indicate that exposing TBCs in argon can substantially decrease thermal cycle life, and the decrease in life is probably associated with an effect on bond coat oxidation. In this test, the longest thermal cycle life was associated with specimens that received a pre-exposure in air prior to thermal cycling in argon (Figure 9, left side). Their lives were longer than those of the specimens that received no pre-exposure and specimens that had been pre-exposed in argon. The longer life of specimens pre-exposed in air may be associated with the development of a more continuous adherent $\mathrm{Al}_{2} \mathrm{O}_{3}$ scale prior to thermal cycling in argon. Microstructural examination indicated that thermal cycling in argon was highly effective in minimizing bond coat oxidation. For the specimens that received no pre-exposure (Figure 10a) or received pre-exposures in argon, essentially no oxide scale was present at 


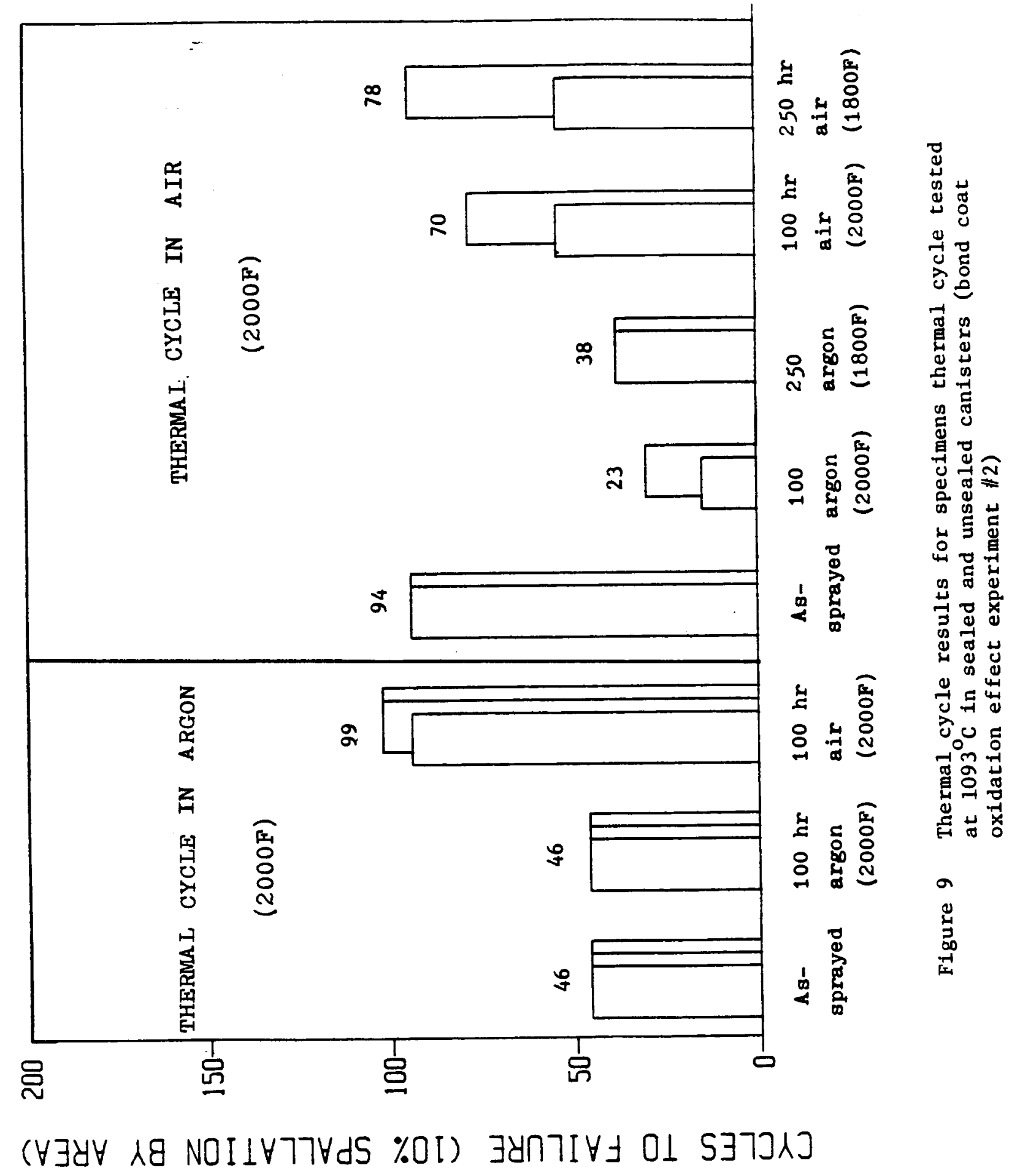




\section{ORIGINAL PAI \\ OF POOR QUALTY}

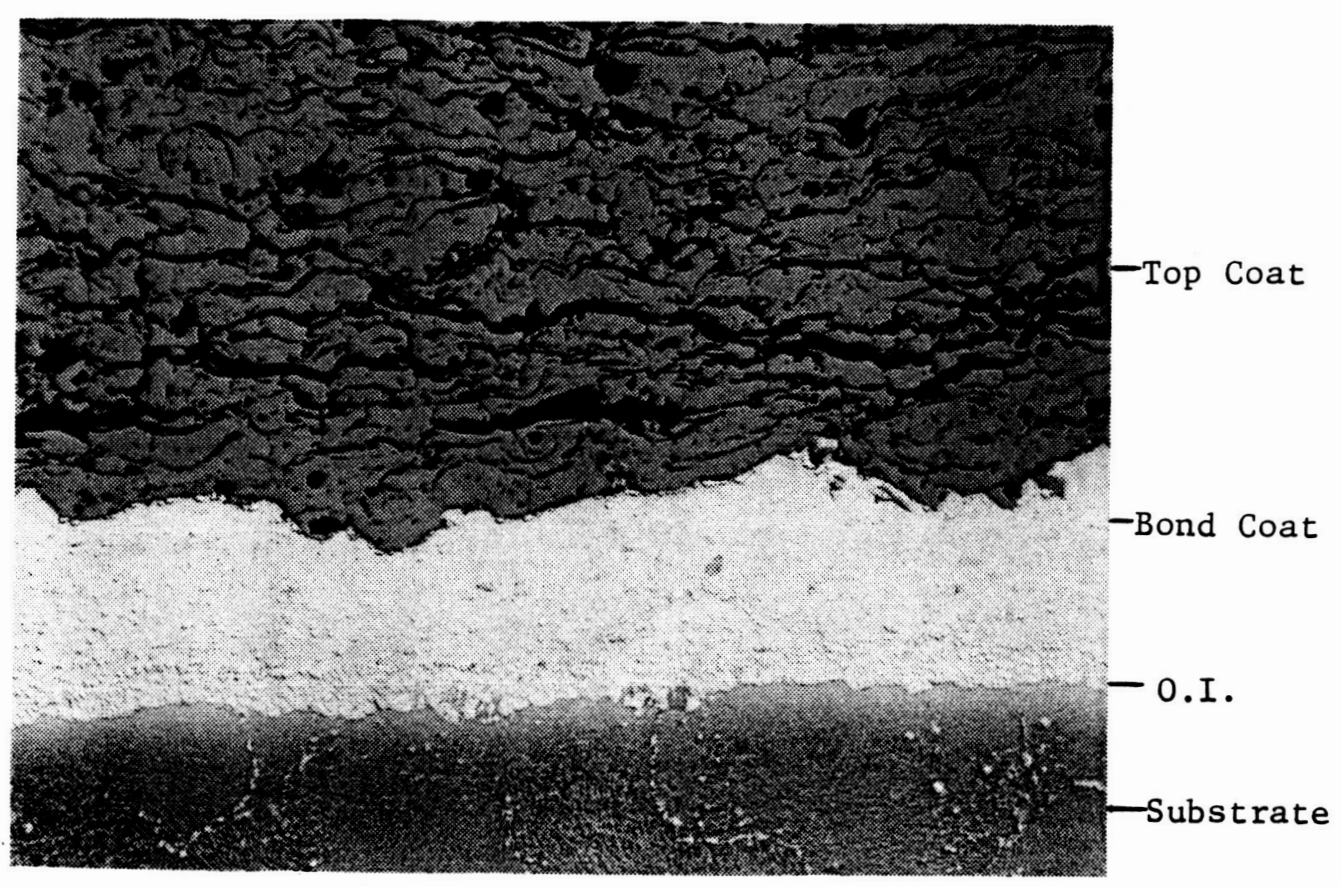

a) No prior pre-exposure

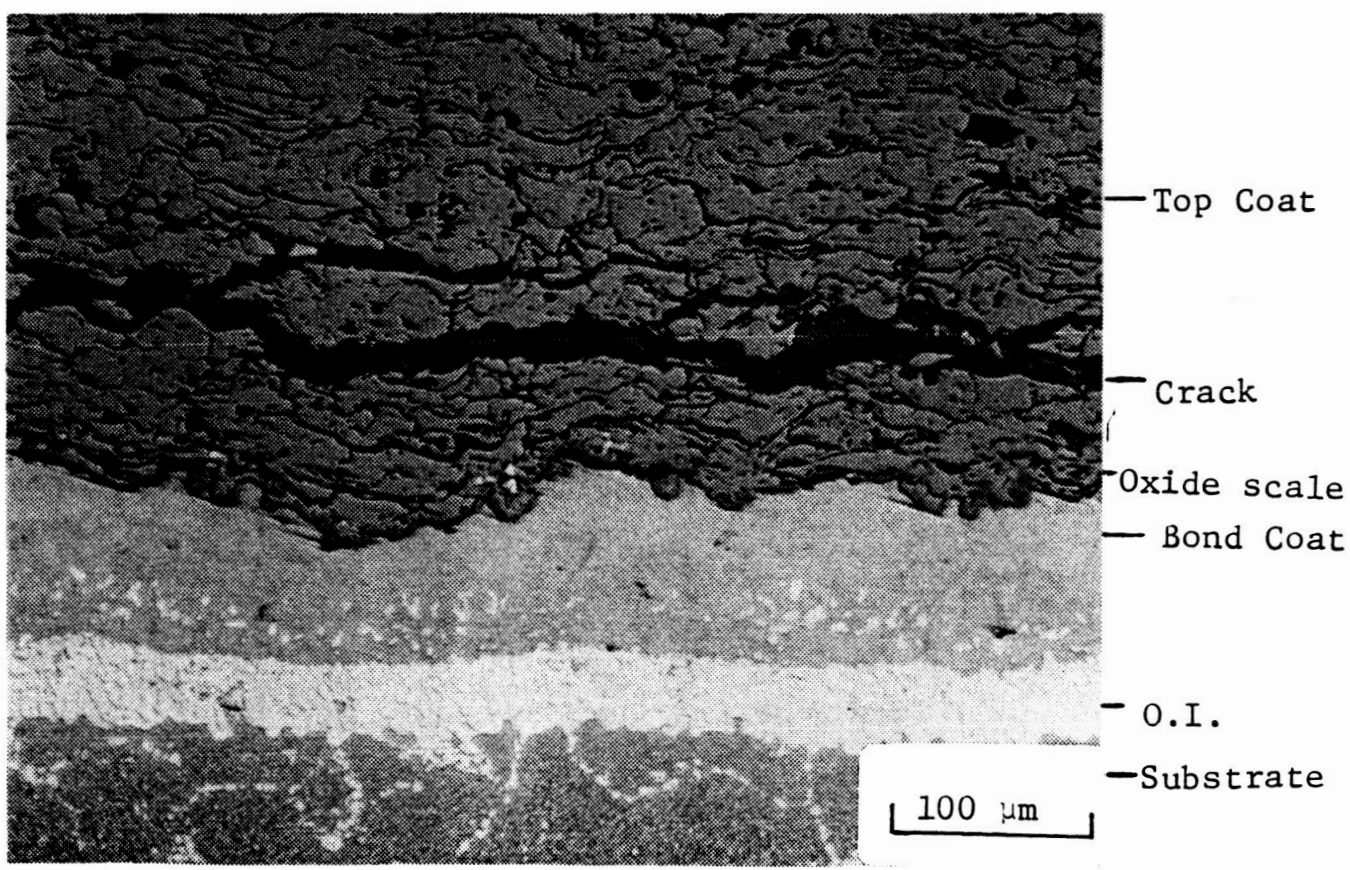

b) 100 hour air pre-exposure at $1093^{\circ} \mathrm{C}$

Figure 10 Microstructure of specimens (Rene' $80 / \mathrm{NiCrAlY} / \mathrm{ZrO}_{2}-\mathrm{Y}_{2} \mathrm{O}_{3}$ ) after thermal cycle testing in a sealed canister containg argon in the $1093^{\circ} \mathrm{C}$ test 
the bond coat/top coat interface (less than $1 \mu \mathrm{m}$ of non-continuous oxide scale), while no measurable increase in oxide scale thickness during thermal cycling was noted for the specimens that had been pre-exposed in air (Table IV and Figure 10b).

The results for the specimens thermal cycled in the unsealed canister indicate that pre-exposures in argon were detrimental for this TBC system regardless of pre-exposure temperature. For both the $982^{\circ} \mathrm{C}\left(1800^{\circ} \mathrm{F}\right)$ and the $1093^{\circ} \mathrm{C}\left(2000^{\circ} \mathrm{F}\right)$ pre-exposures, the specimens pre-exposed in argon failed before the specimens pre-exposed in air.

Another interesting result was the extremely short lives exhibited by the specimens that received no pre-exposure or pre-exposures in air that were thermal cycled in the unsealed (air) canister. Typically, these button specimens with no prior pre-exposure will have thermal cycle lives of approximately 400 cycles when cycled in an alumina holder outside the canister. However, in this test, specimens with no prior pre-exposure failed in less than 100 cycles when cycled in this unsealed canister (Figure 9, right side). Microstructural examination of these specimens indicated that significant frontal oxidation (oxidation of bond coat at bond coat/top coat interface) of the bond coat had occurred for these specimens (Figure 11). Electron microprobe mapping of these oxide scales (Figure 12) revealed that they contained high levels of $\mathrm{Cr}$ and $\mathrm{Ni}$. These high levels of $\mathrm{Cr}$ and $\mathrm{Ni}$ indicate that less protective oxide scales with higher growth kinetics had formed on the bond coats of these specimens cycled in the unsealed canister. General Electric baseline specimens ( Hast-X/NiCrAlY $/ \mathrm{ZrO}_{2}-8 \mathrm{YY}_{2} \mathrm{O}_{3}$ ), which are included in all GE thermal cycle tests, also failed early in this test. 


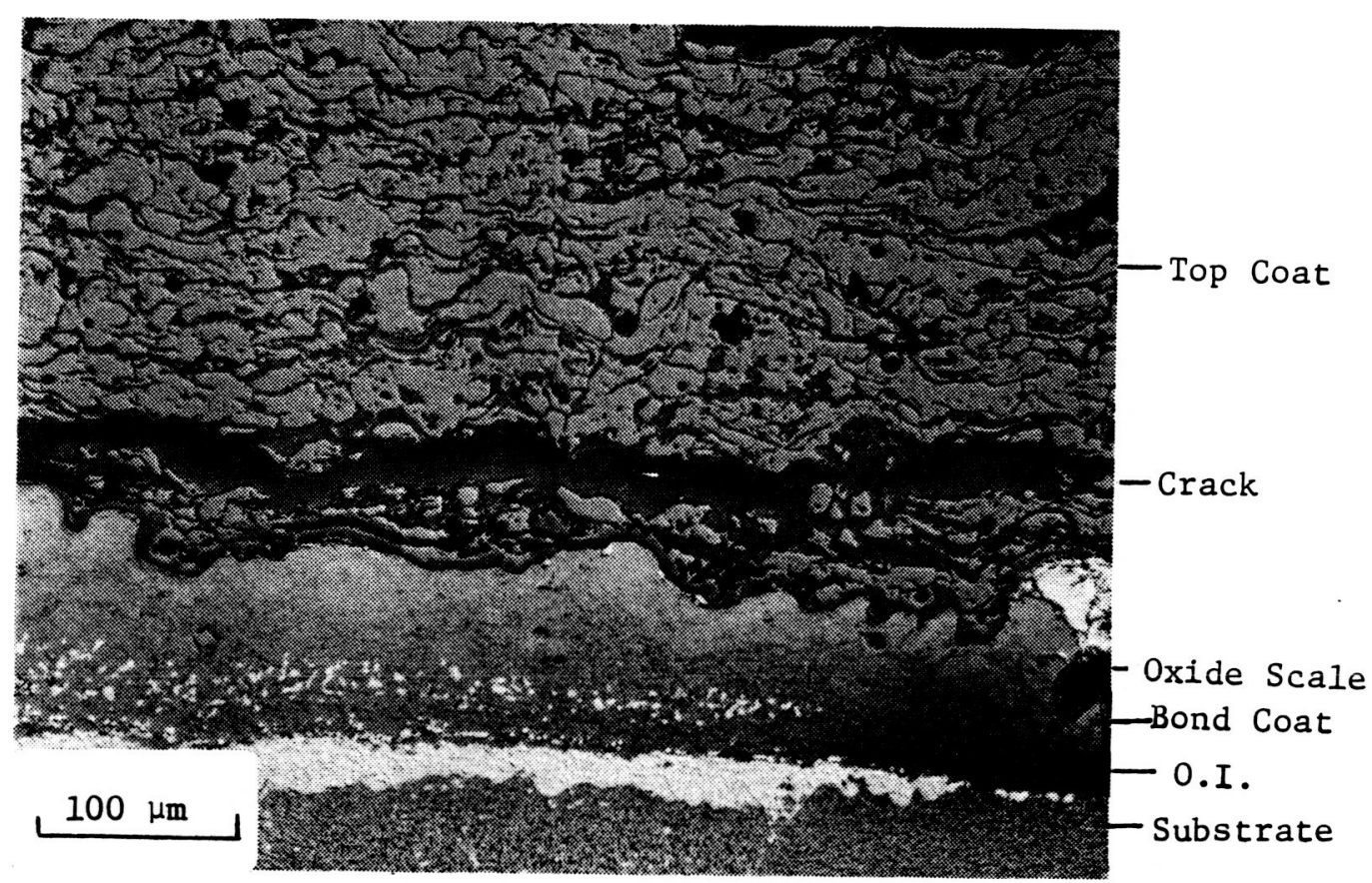

a) Low magnification

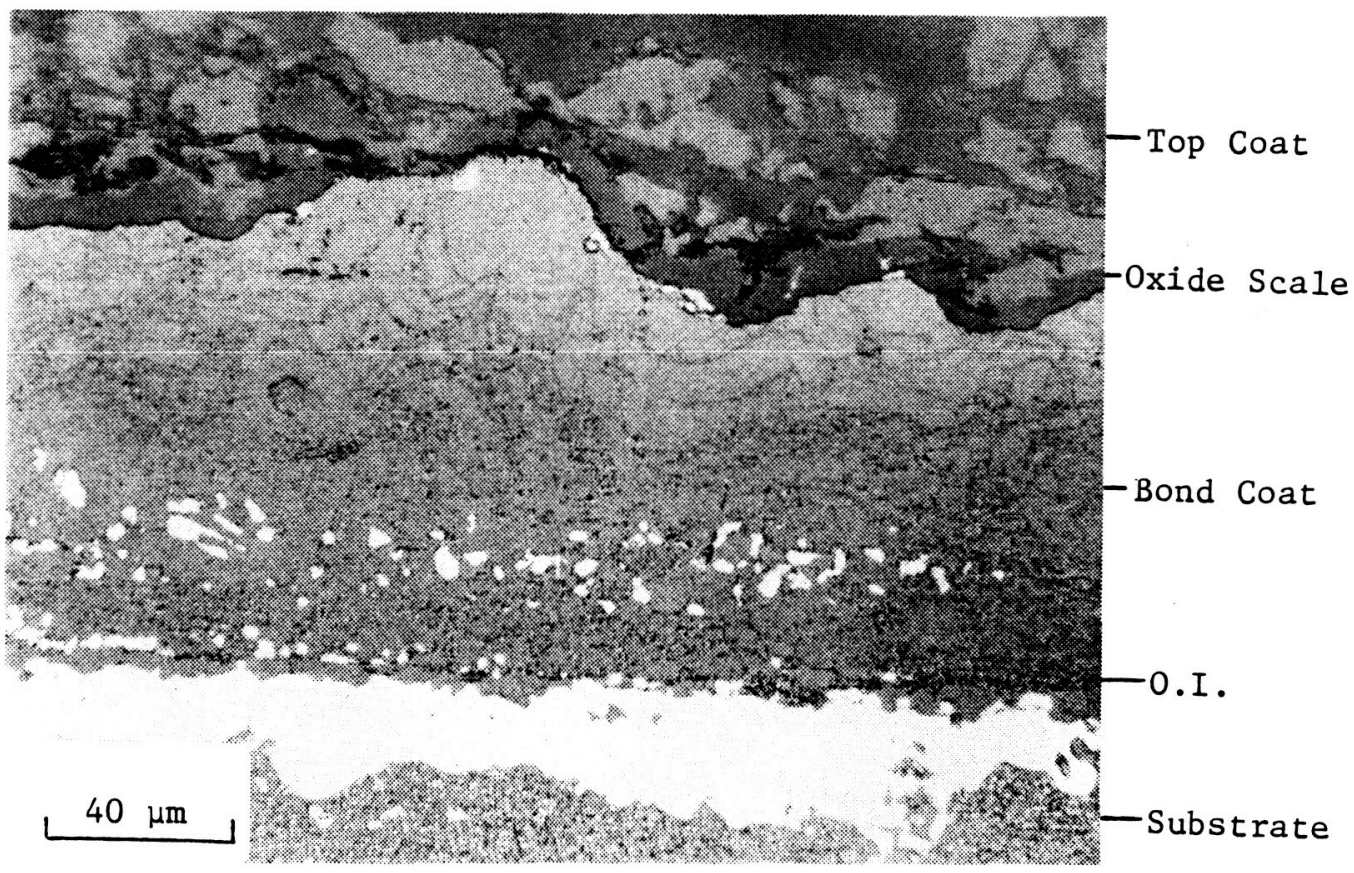

b) High magnification

Figure 11 Microstructure of specimens (no prior pre-exposure) at failure after thermal cycle testing in a unsealed canister $\left(94\right.$ cycles) in the $1093^{\circ} \mathrm{C}$ test 


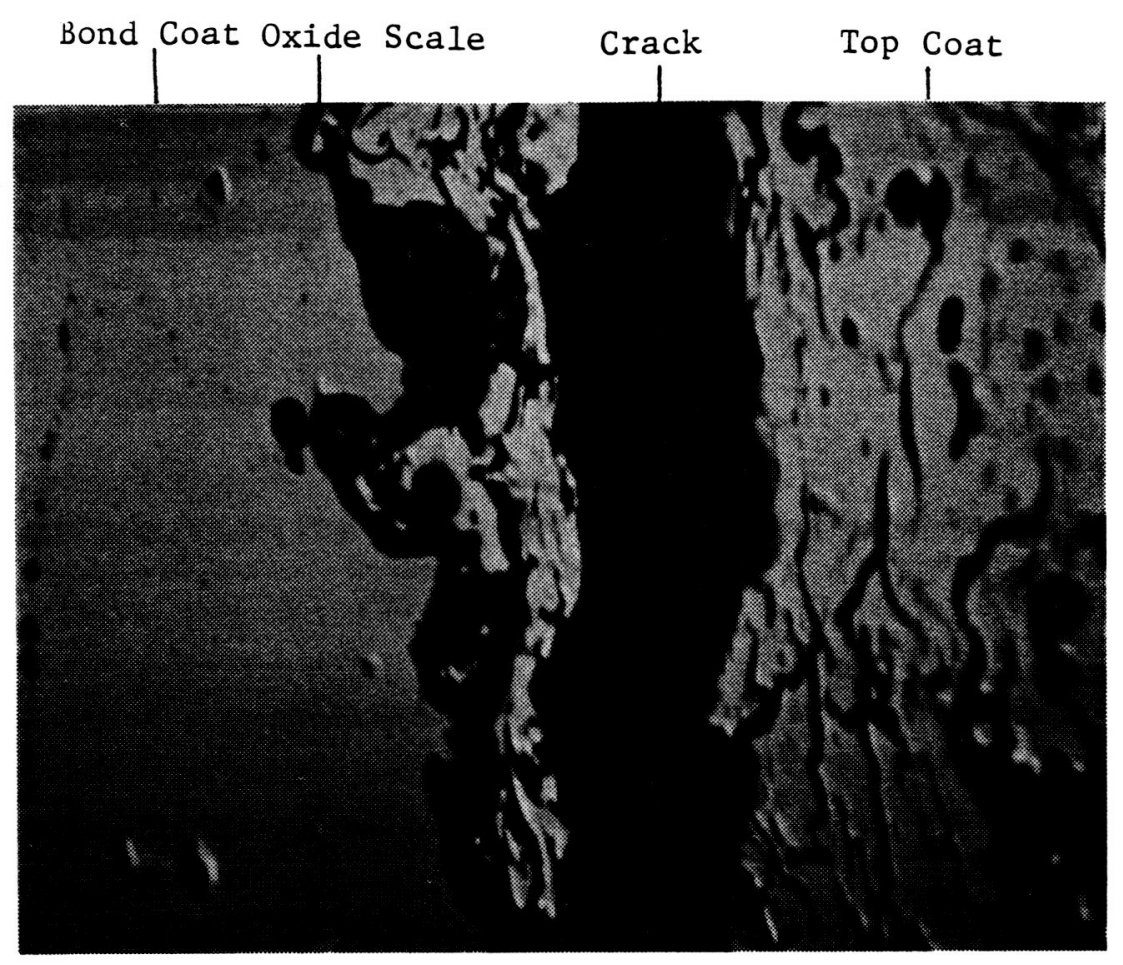

a) Backscatter Electron Image

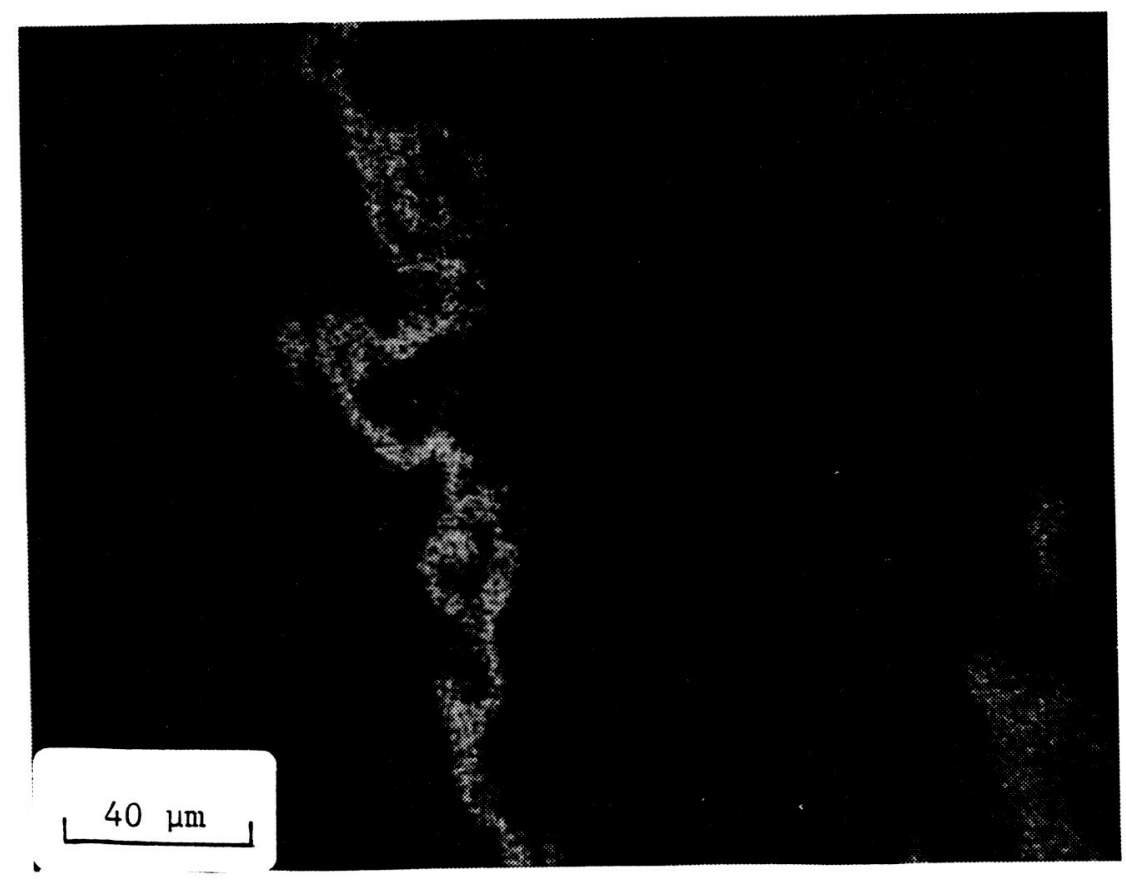

b) Electron microprobe map for Al

Figure 12 Electron microprobe map of specimen (no pre-exposure) thermally cycled in an unsealed canister in the $1093^{\circ} \mathrm{C}$ test (cont ${ }^{\prime} \mathrm{d}$ ). 


$$
\begin{aligned}
& \text { ORIGINAL pian is } \\
& \text { QE POOR QuAliti }
\end{aligned}
$$

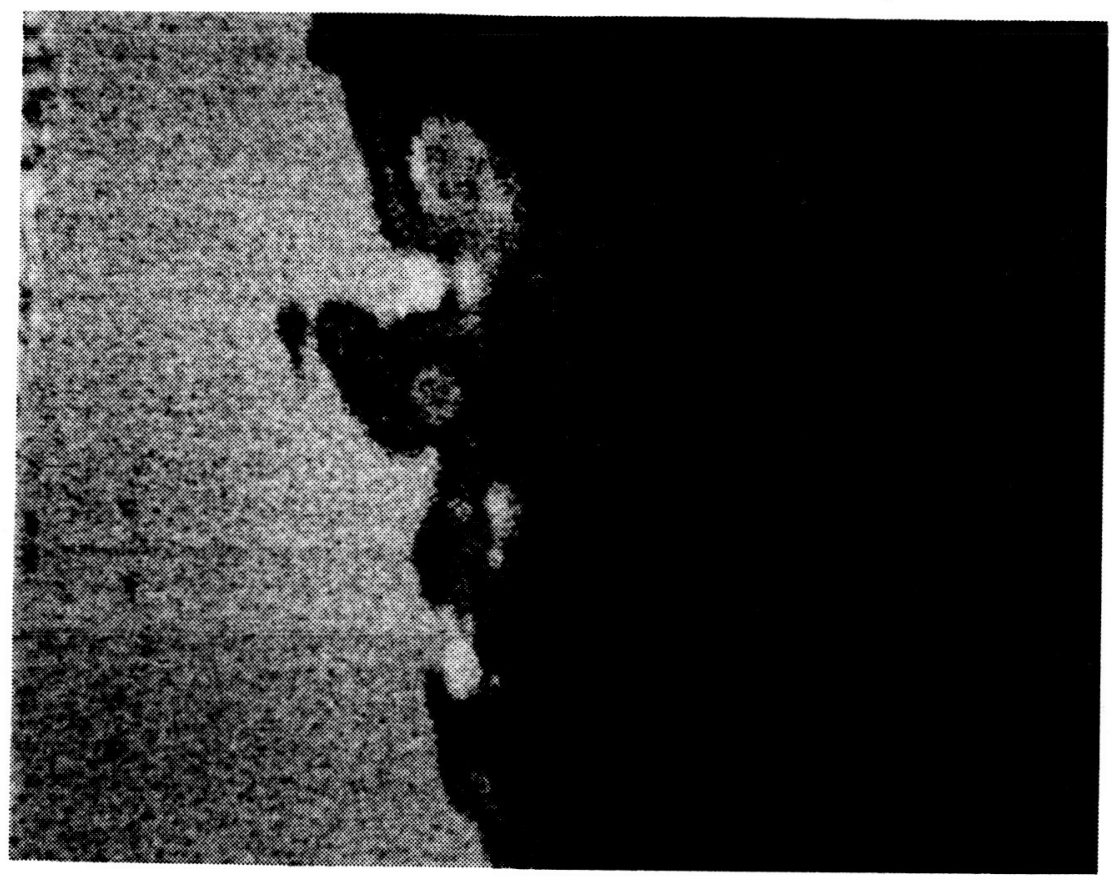

c) Electron microprobe map for $\mathrm{Cr}$

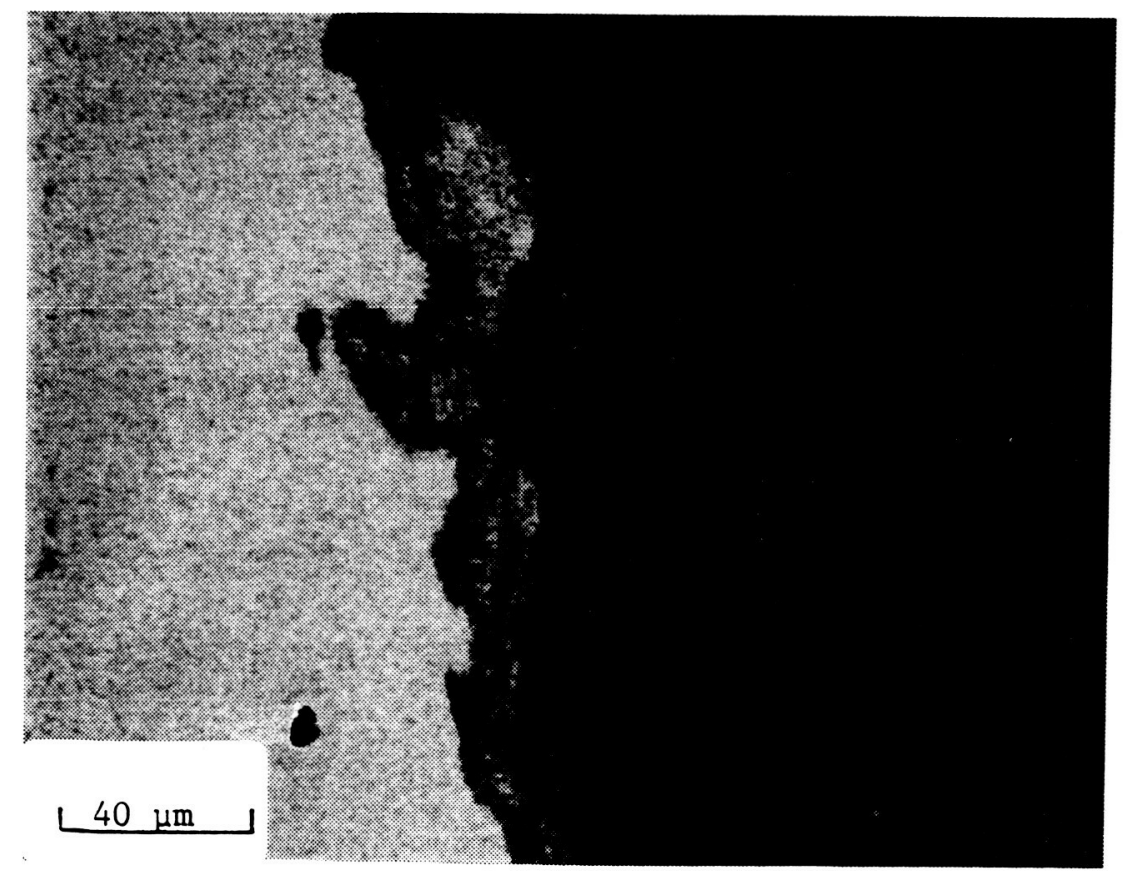

d) Electron microprobe map for Ni

Figure 12 Electron microprobe map of specimen (no pre-exposure) thermally cycled in an unsealed canister in the $1093^{\circ} \mathrm{C}$ test (cont'd). 


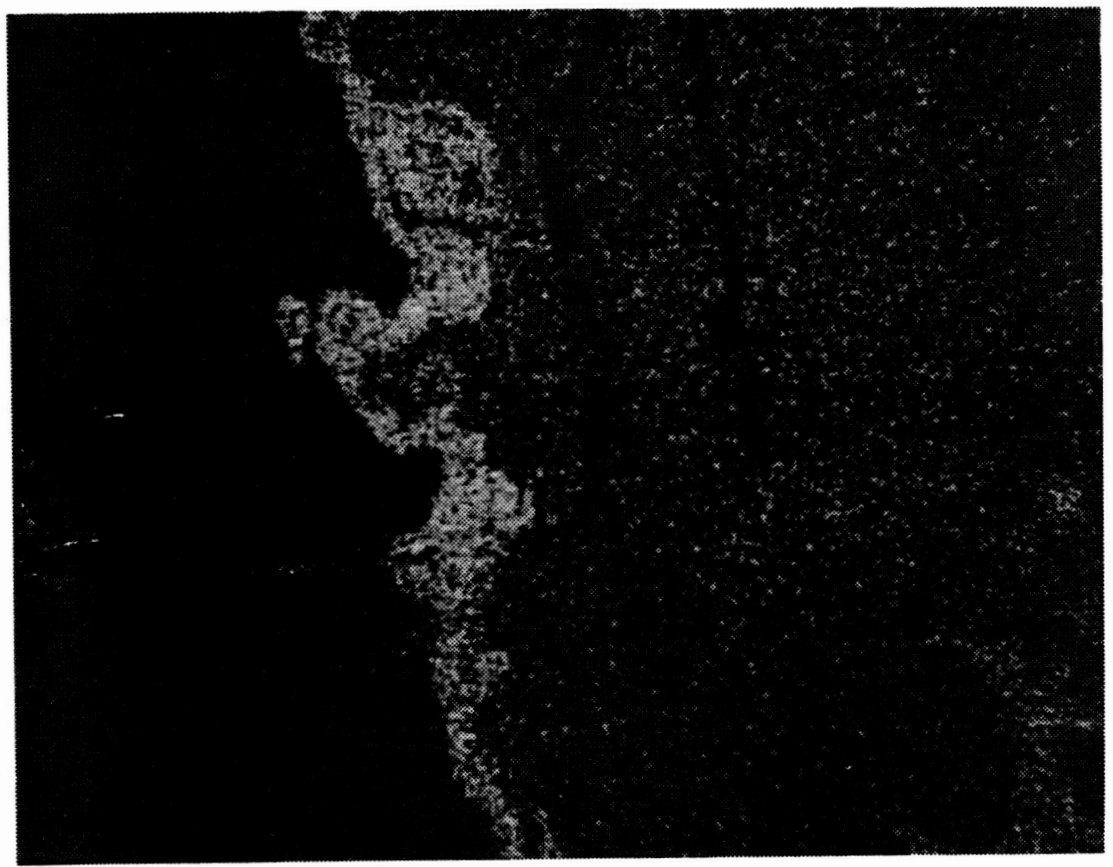

e) Electron microprobe map for 0

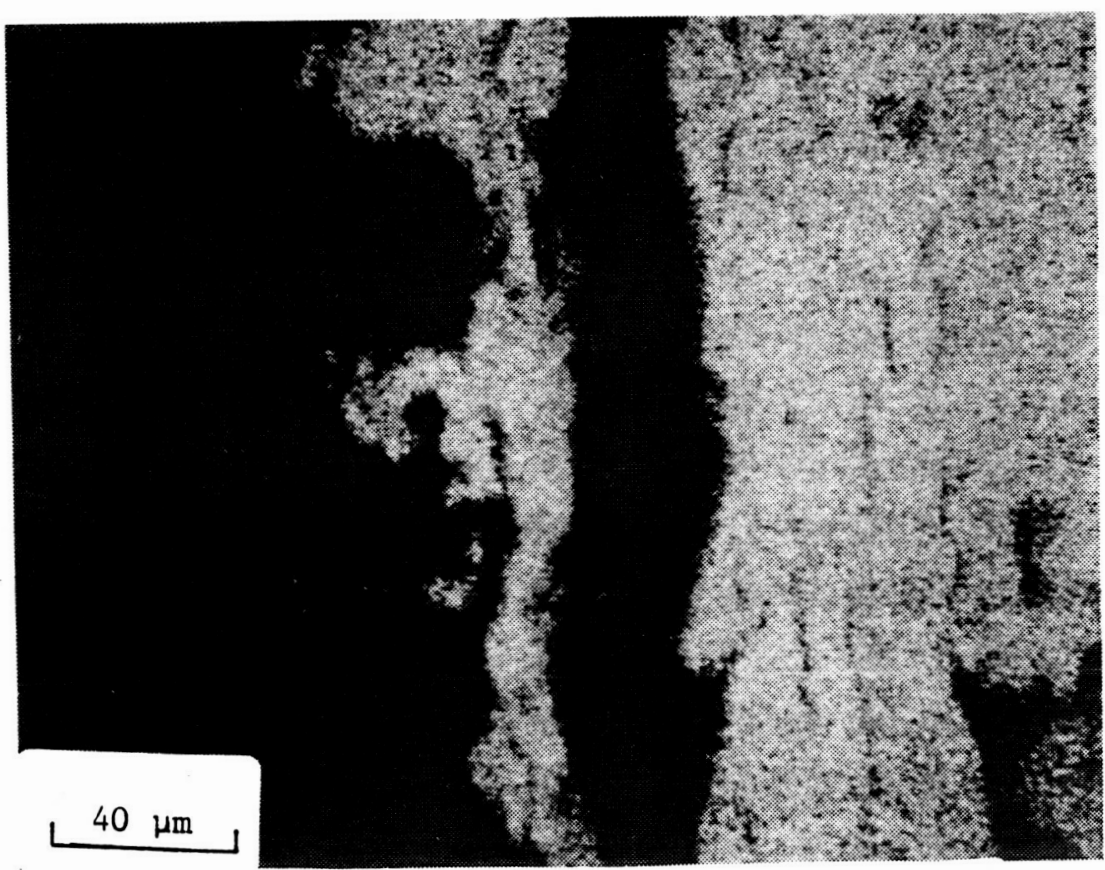

f) Electron microprobe map for $\mathrm{Zr}$

Figure 12 Electron microprobe map of specimen (no pre-exposure) thermally cycled in an unsealed canister in the $1093^{\circ} \mathrm{C}$ test 
These baseline sppecimens which normally last 400-450 cycles failed in only 60 cycles when tested in the canister. Significant frontal oxidation of the bond coat also occurred in these specimens. These results clearly demonstrate the importance of bond coat oxidation. In this case, thick $\mathrm{Cr}$ and $\mathrm{Ni}$ scales formed which resulted in significantly shorter thermal cycle life.

In the third experiment, an alternative method was used to evaluate bond coat oxidation and determine if the detrimental effect of argon could be more definitely traced to the bond coat or top coat changes. To accomplish this, combinations of pre-exposures in air and/or argon were performed before, and/or after the top coat application (Table $V$ ). This experiment was run concurrently with the second experiment in the same test furnace but without using the canister (the same, 30 minute cool down period was used). In this test, the specimens with no prior exposure had the expected thermal cycle life of approximately 400 cycles.

In one evaluation, specimens were given a 100 hour pre-exposure in both air and argon after the top coat application. One set of specimens received the air pre-exposure prior to the argon pre-exposure, while the other set of specimens received the argon pre-exposure first. The hypothesis was that if argon affects the top coat (stoichiometry), any reduction of the oxide state of the ceramic by the argon pre-exposure should be eliminated by the subsequent air pre-exposure. Similarly, by pre-exposing in air first, the more protective $\mathrm{Al}_{2} \mathrm{O}_{3}$ scale should form prior to the argon pre-exposure and provide a chemical bond similar to those normally observed. The specimens 
pre-exposed for 100 hours in argon followed by 100 hours in air had very short lives ( 14 cycles), while the specimens pre-exposed for 100 hours in air followed by 100 hours in argon had substantially longer lives (237 cycles), (Figure 13). Aš further evidence, x-ray diffraction analysis of specimens that were pre-exposed in air for 100 hours or pre-exposed in argon for 100 hours at $1093^{\circ} \mathrm{C}\left(2000^{\circ} \mathrm{F}\right)$ indicate that no major phase changes during the argon pre-exposure had occurred (Table VI). Hence, the results of this third experiment (Figure 9, right side), combined with the $x$-ray results and results from the second experiment, clearly indicate that the detrimental effect of argon primarily is associated with the bond coat oxidation.

As depicted in Table $V$, pre-exposures in argon prior to the top coat application were also examined. These tests were designed to further explore the effects of argon. Again, the argon pre-exposures significantly shortened thermal cycle life. The results also again indicate that the detrimental effect is associated with bond coat oxidation. 


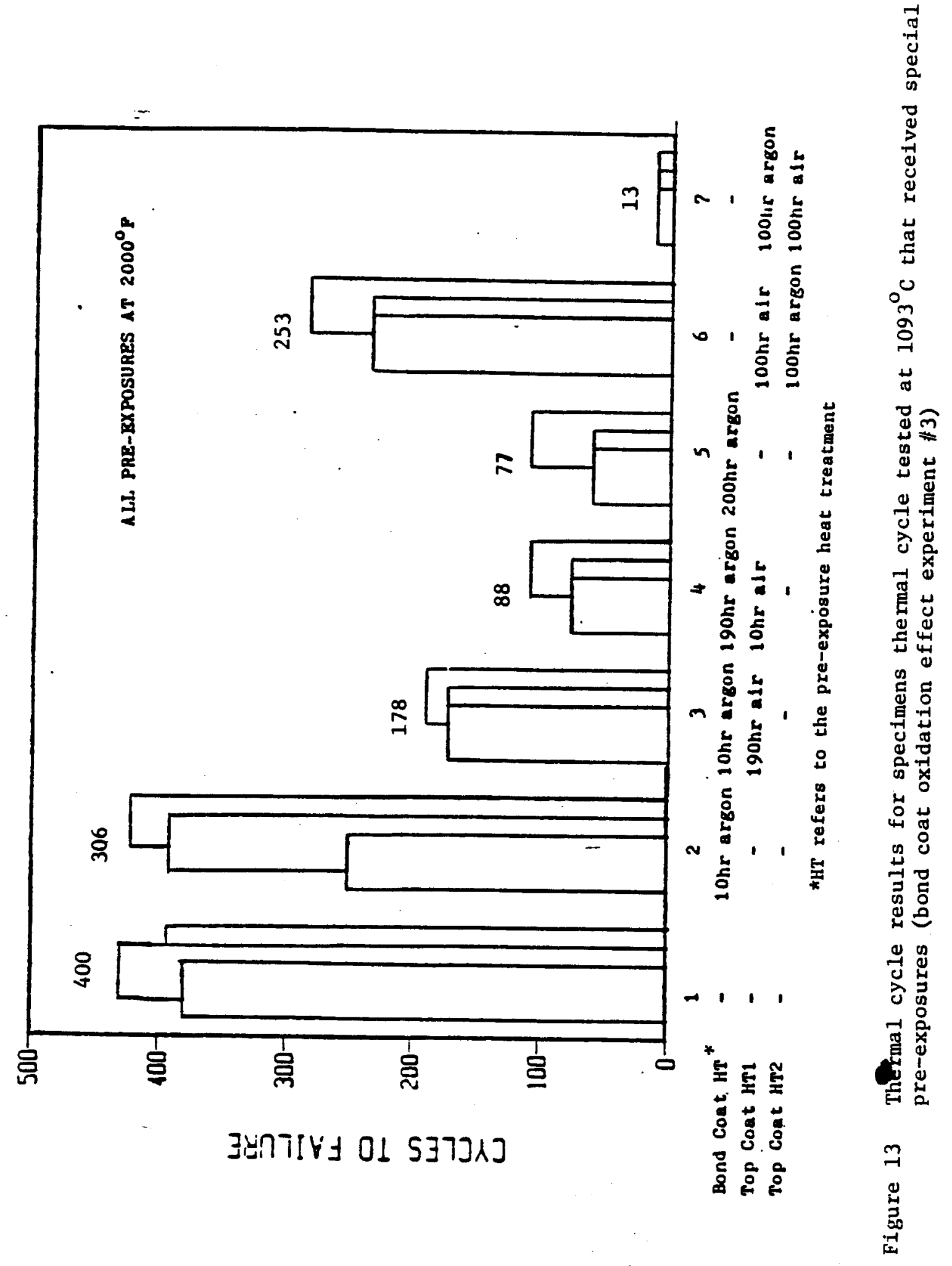


TABLE VI

TOP COAT X-RAY DIFFRACTION RESULTS*

Monoclinic Tetragonal Cubic

$\begin{array}{llll}100 \text { Hour Air Pre-Exposure } & 8.8 \% & 71.0 \% & 20.2 \% \\ 100 \text { Hour Argon Pre-Exposure } & 9.7 \% & 77.4 \% & 12.9 \%\end{array}$

* Performed by the University of Cincinnati 


\section{$=\quad$ Bond Coat Creep Effect Experiment}

The experiment to evaluate the effect of bond coat creep strength on thermal cycle life utilized four different bond coat alloys (Table VII) that have significantly different creep strengths. The modified NiCoCrAlY bond coats include various additions of Mo, Ta, W, Re, Hf, C, B, Si, Zr, and Ti. The bond coat layers on these specimens also received an aluminide (Codep) coating (Figure 14) before the ceramic layer was deposited in order to reduce the effect of any differences in oxidation resistance on thermal cycle life. All specimens were coated with the same $\mathrm{ZrO}_{2}-8 \% \mathrm{Y}_{2} \mathrm{O}_{3}$ ceramic layer. Six specimens of each TBC system were thermal cycle tested. Two specimens were exposed in argon for 100 hours at $1093^{\circ} \mathrm{C}\left(2000^{\circ} \mathrm{F}\right)$, two were exposed in air for the same time and temperature, and two specimens received no pre-exposure (Table VIII). The difference in thermal cycle lives should be a function of bond coat creep strength and pretest conditions. The intent of this experiment was to evaluate the effect of bond coat creep strength on TBC failure and to obtain a measure of its effect relative to that of oxidation. Tube specimens were utilized in this test. 
TABLE VII

BOND COAT CREEP EFFECT TBC SYSTEMS

Systems Substrate Bond Coating Over Coating Top Coating Bond Coat Creep (Laron/Miller

Parameter 03 KSI - rupture test

1 Rene'80 Bond Coating $1 '$ Aluminide $\mathrm{ZrO}_{2}-\mathrm{Y}_{2} \mathrm{O}_{3} \quad 39.0$

2 Rene'80 Bond Coating 2* Aluminide $\mathrm{ZrO}_{2}-\mathrm{Y}_{2} \mathrm{O}_{3}$

45.7

3 Rene' 80 Bond Coating 3* Aluminide $\mathrm{ZrO}_{2}-\mathrm{Y}_{2} \mathrm{O}_{3}$

47.0

4 Rene' 80 bond Coating 4* Aluminide $\mathrm{ZrO}_{2}-\mathrm{Y}_{2} \mathrm{O}_{3}$

48.4

- $\mathrm{Ni}-22 \mathrm{Cr}-10 \mathrm{Al}-0.3 \mathrm{Y}$

* Modified NiCoCrALY bond coats 


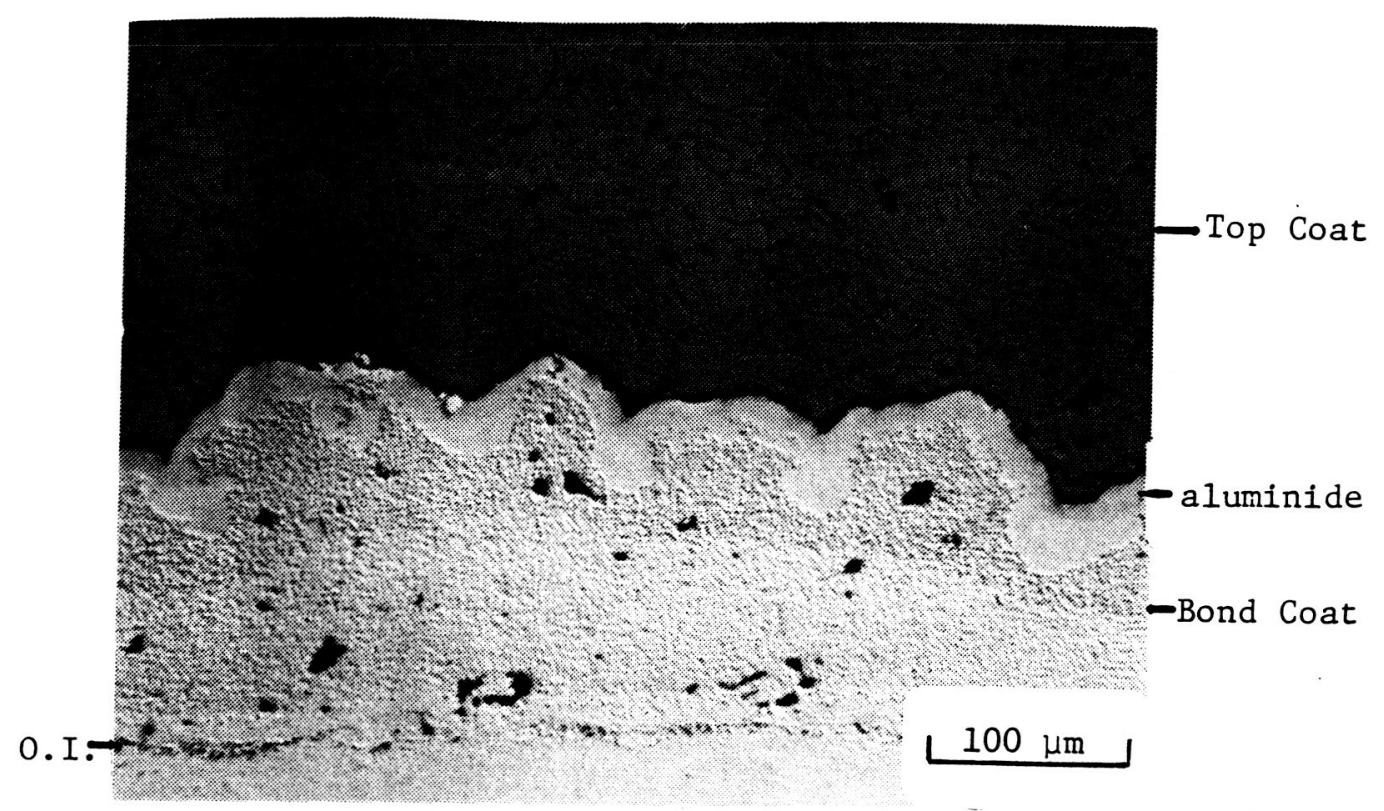

a) As-sprayed microstructure

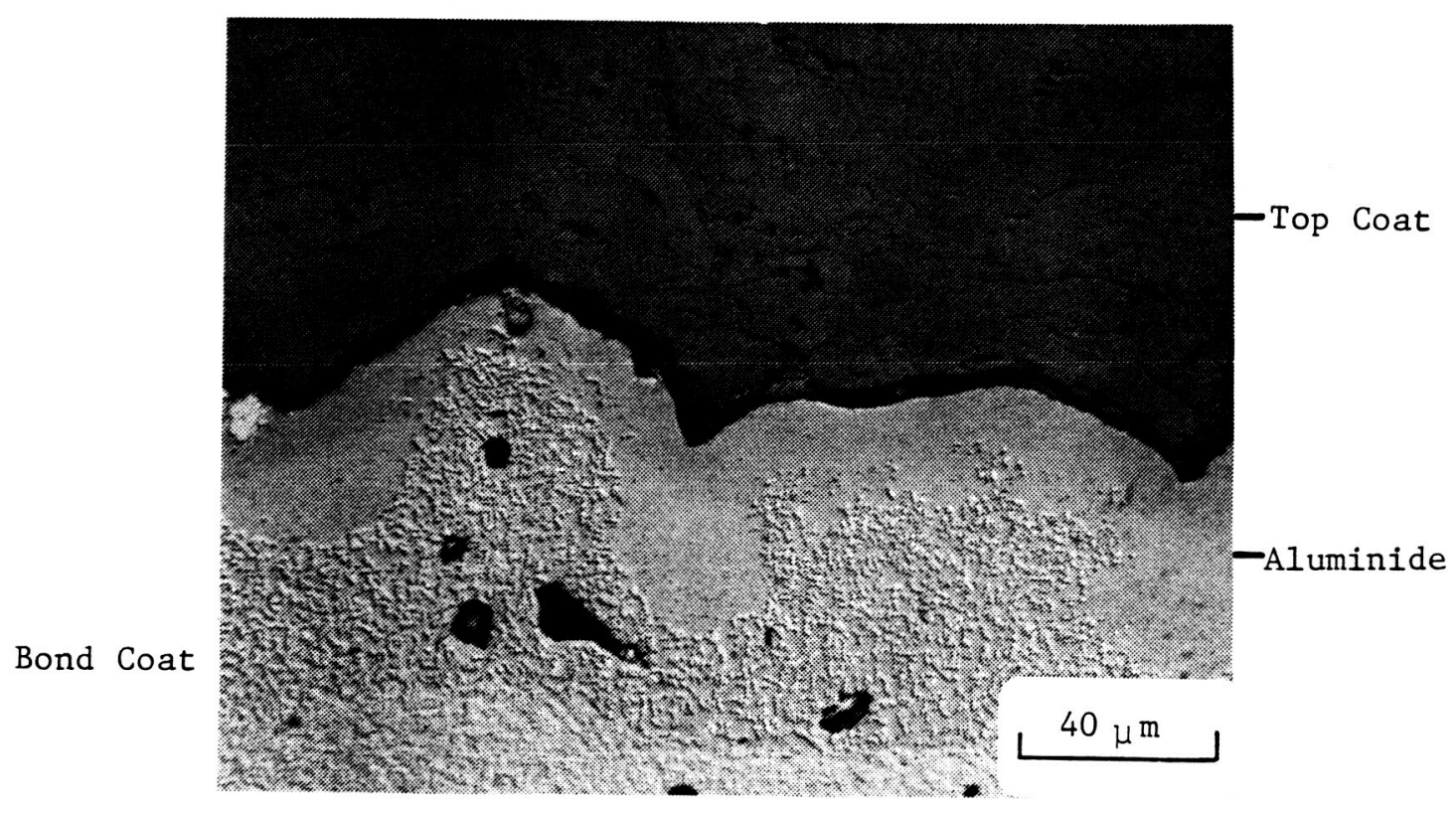

b) Bond coat/top coat interface

Figure 14 Microstructure of as-sprayed TBC with aluminide coated bond coat (Rene ' $80 / \mathrm{NiCrA1Y} / \mathrm{Aluminide/}$ $\mathrm{ZrO}_{2}-\mathrm{Y}_{2} \mathrm{O}_{3}$ ) 


\section{TABLE VIII}

PRE-EXPOSURE (1093C) TIMES FOR BOND COAT CREEP EFFECT SPECIMENS (THERMAL CYCLE TESTING IN AIR)

\begin{tabular}{|c|c|c|c|}
\hline $\begin{array}{c}\text { TBC } \\
\text { System } \\
\# \\
\end{array}$ & $\begin{array}{c}\text { Specimens } \\
\text { With No } \\
\text { Pre-Exposure }\end{array}$ & $\begin{array}{c}\text { Specimens } \\
\text { Pre-Exposed } \\
\text { in Argon } \\
\left(1093^{\circ} \mathrm{F}, 100 \mathrm{hrs}\right)\end{array}$ & $\begin{array}{c}\text { Specimens } \\
\text { Pre-Exposed } \\
\text { in Air } \\
\left(1093^{\circ} \mathrm{C}, 100 \mathrm{hrs}\right)\end{array}$ \\
\hline 1 & 2 & 2 & 2 \\
\hline 2 & 2 & 2 & 2 \\
\hline 3 & 2 & 2 & 2 \\
\hline 4 & 2 & 2 & 2 \\
\hline & 8 & 8 & 8 \\
\hline
\end{tabular}




\section{Results - Bond Coat Creep Effect Experiments}

\section{As-Sprayed Microstructure}

The as-sprayed microstructures (Figure 15) contain small differences in structure associated with the changes in composition. In all TBC systems, an aluminide overcoat is present and is clearly evident in the photomicrographs. Bond coat \#1, which is the baseline system, plus an aluminide overcoat, has a microstructure consisting of $\gamma^{\prime}+\beta+\gamma$. The aluminide coating produces a NiAl( $\beta$ ) coating at the surface of the bond coat. The other three bond coats, which contain numerous alloy strengthening additions, have a bond coat consisting of $\gamma^{\prime}+\gamma+$ carbides. The aluminide also produces a $N i A l(B)$ coating at the surface of bond coats $* 2, \# 3$, and $\# 4$.

\section{Pre-Exposures}

In all cases, a continuous $\mathrm{Al}_{2} \mathrm{O}_{3}$ scale formed at the bond coat/top coat interface in specimens that were pre-exposed in air for 100 hours at $1093^{\circ} \mathrm{C}\left(2000^{\circ} \mathrm{F}\right)(\text { Figure } 16)^{*}$, and the oxide scale thickness varied from 3 to $5 \mathrm{\mu m}$ for the four different bond coat systems that were pre-exposed in air for 100 hours (Table IX). The presence of a continuous carbide layer (presumably $\left.M_{23} C_{6}[y]\right)$ was also noted at the bond coat/substrate interface for the 

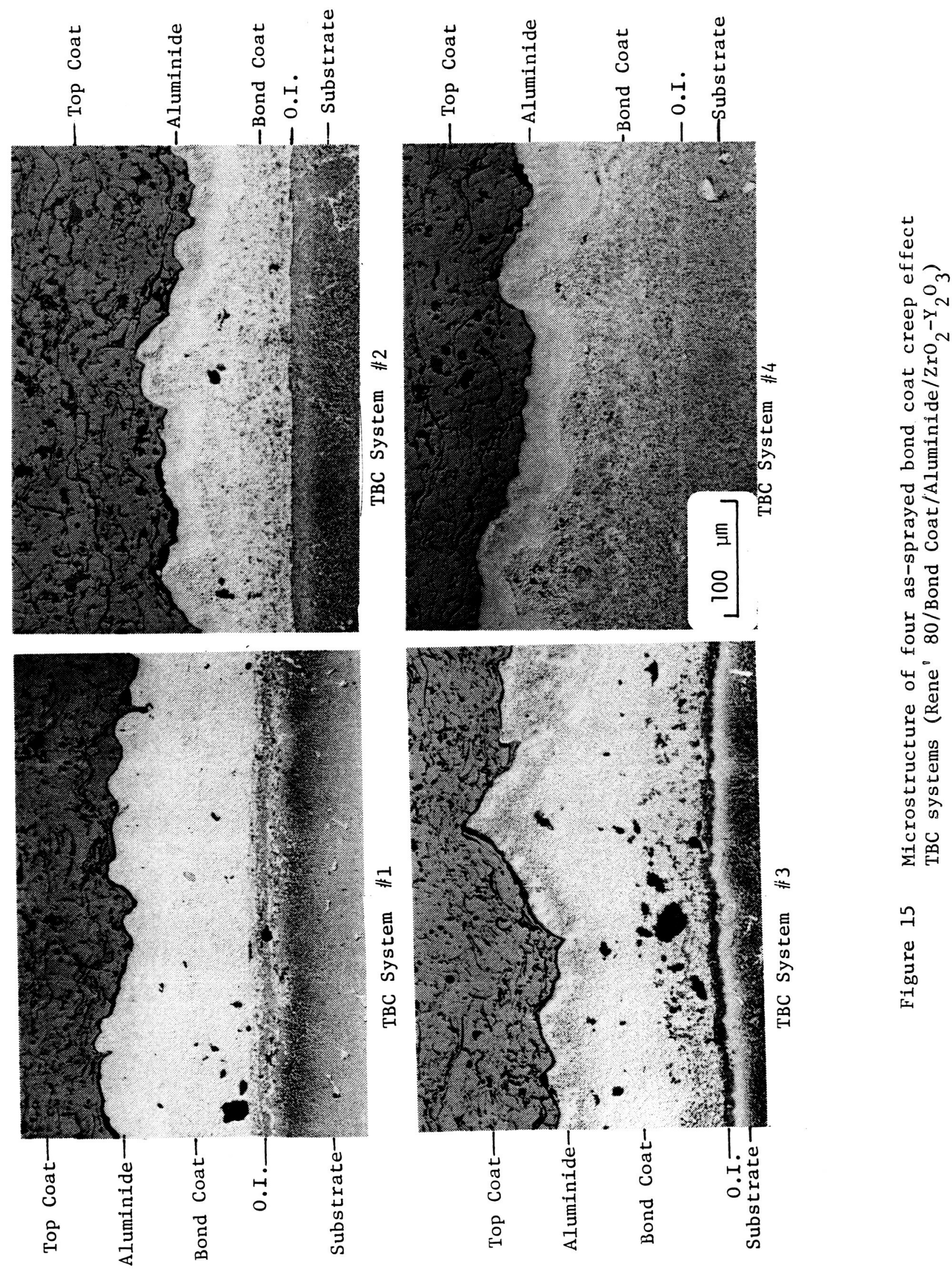

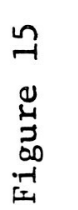




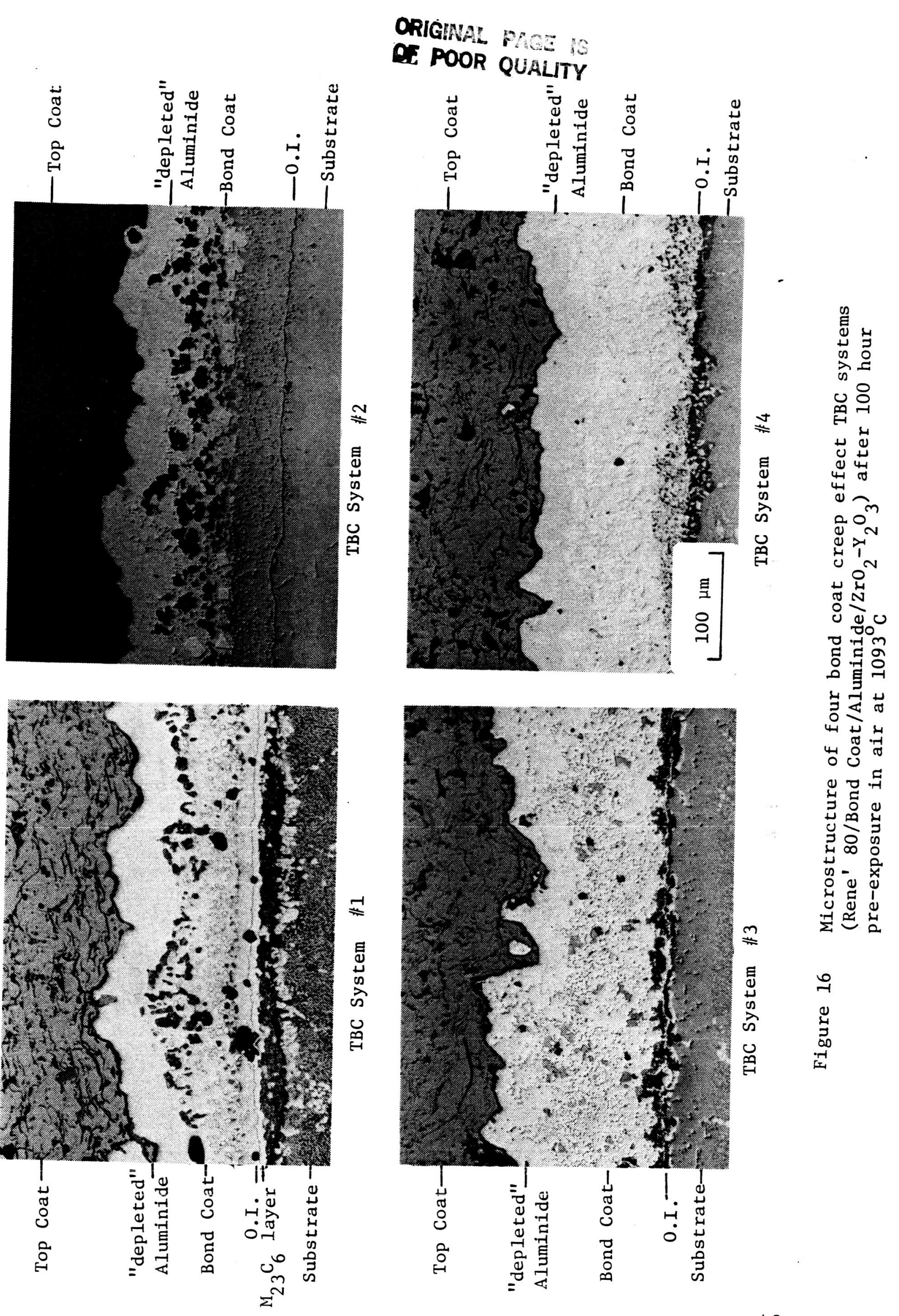


TABLE IX

\section{OXIDE SCALE THICKNESS AT BOND COAT/TOP COAT INTERFACE AFTER 100 HOUR AIR PRE-EXPOSURE (1093C) FOR THE BOND COAT CREEP EFFECT SPECIMENS}

Bond Coating

1

2

3

4
Oxide Scale Thickness ( $\mathrm{mm})$

3.0

5.3

2.8

4.3 
NiCrAlY + aluminide system (TBC System \#1). The aluminide in all cases was significantly depleted due to bond coat oxidation and bond coat/substrate interdiffusion. Bond coat \#3 also developed blocky carbides during the pre-exposure. Unique changes for each bond coat were expected due to the significant differences in bond coat compositions.

The use of canisters was again (6) very effective in retarding oxidation during argon pre-exposures at $1093^{\circ} \mathrm{C}\left(2000^{\circ} \mathrm{F}\right)$. In all cases, essentially no $\mathrm{Al}_{2} \mathrm{O}_{3}$ scale was detected at the bond coat/top coat interface by optical microscopy after pre-exposure (Figure 17). The aluminide in all systems did not appear depleted since little bond coat oxidation had occurred. Interestingly, a continuous carbide layer was not present at the bond coat/substrate interface in bond coat \#1 although the presence of significant quantities of presumably $\mathrm{M}_{23} \mathrm{C}_{6}$ carbides were noted at this interface following air pre-exposure. The presence of blocky carbides was again noted in bond coat \#3 following the argon exposure. 

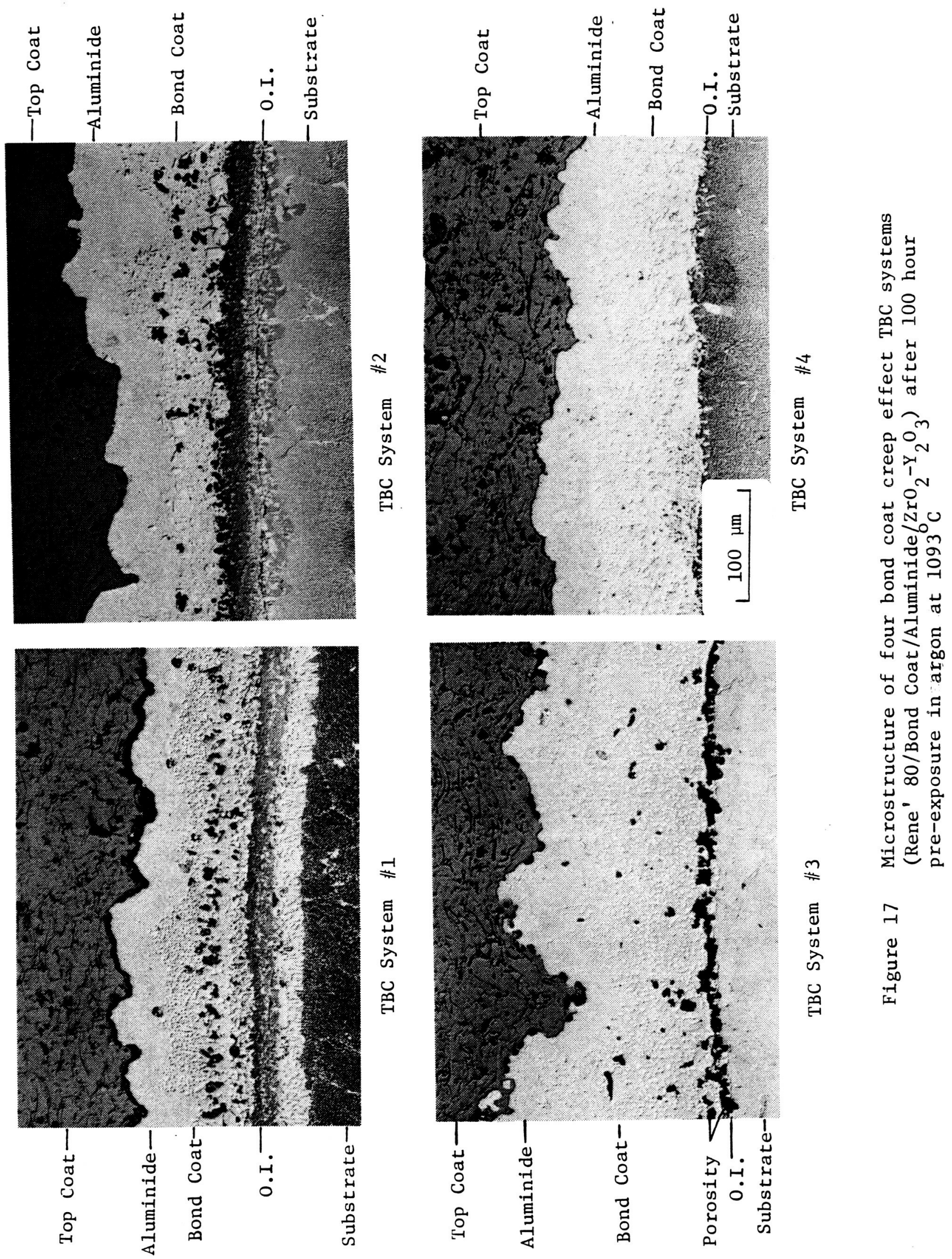

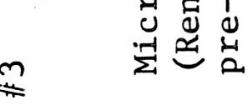

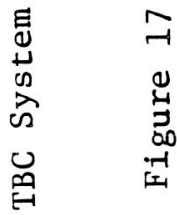




\section{Thermal Cycle Testing}

Test Results: Thermal cycle testing in air of specimens to evaluate the effect of bond coat creep strength on TBC thermal cycle life has been completed. These specimens had received pre-exposures at $1093^{\circ} \mathrm{C}\left(2000^{\circ} \mathrm{F}\right)$ either in air or argon for 100 hours, or no pre-exposure. As discussed, an aluminide overcoat was applied to all four bond coats to reduce any differences in oxidation resistance.

The results clearly show that the TBC specimens with the NiCrAlY + aluminide bond coat, which has the lowest creep strength, resulted in the shortest thermal cycle life for all pre-expsoure conditions (Figures 18 \& 19). However, the thermal cycle life differences for the other TBC systems appears to be minimal. The small differences may indicate that the bond coat creep strength differences (Table VII) were not large enough to offset the effect of other failure mechanisms (Nícraly is significantly lower in strength than the other three).

Interestingly, the 100 hour air pre-exposure did not significantiy affect the thermal cycle life of these systems with "high strength" bond coats $(2,3$, \& 4). This indicates that, as the thermal cycle life increases (due to increased life with increasing bond coat creep strength), the relative contributions of the pre-exposure to the overall oxidation of the bond coat is reduced. The data suggest that bona coat creep can play a significant role in overall TBC life. 


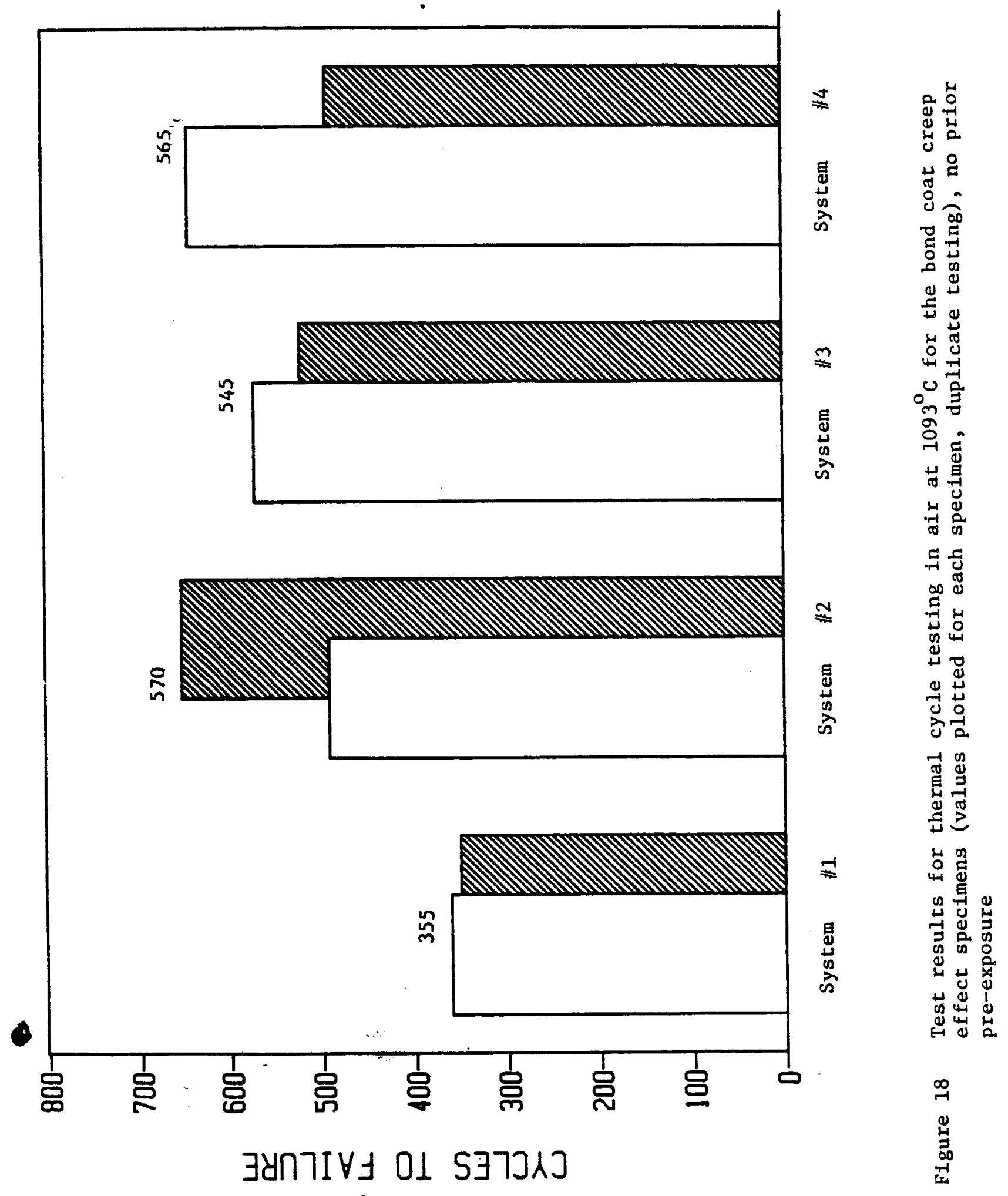




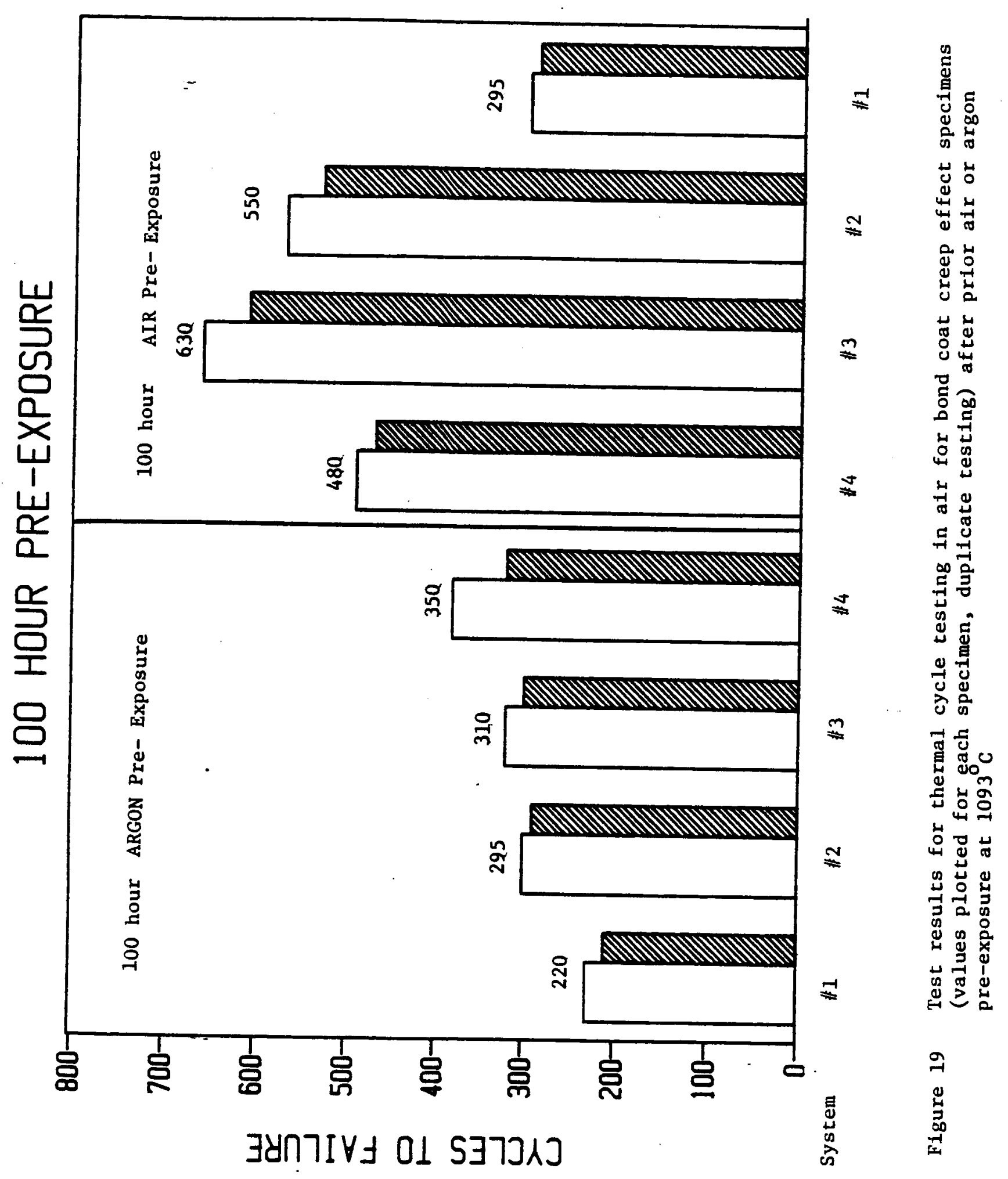


A weakness of this experiment was the potential of different interactions between the aluminide overcoat, and the different bond coats. To eliminate this effect, a recent study at GE (10) evaluated different bond coat creep strengths produced by applying various heat treatments to the same bond coat (Bond Coat \#4). In this study, bond coat \#4 was heated in vacuum at each of four temperatures, $1079^{\circ} \mathrm{C}\left(1975^{\circ} \mathrm{F}\right), 1148^{\circ} \mathrm{C}\left(2100^{\circ} \mathrm{F}\right), 1204^{\circ} \mathrm{C}\left(2200^{\circ} \mathrm{F}\right)$, and $1260^{\circ} \mathrm{C}\left(2300^{\circ} \mathrm{F}\right)$. The creep strength of bond coat $\# 4$ heat treated at these temperatures varies by approximately 5 Larson-Miller parameter units. The bond coat was also given the aluminide overcoat (after vacuum heat treatment) prior to the top coat application. The thermal cycle lives of these specimens and similar specimens not given the bond coat heat treatment are shown in Figure 20. The results indicate that $T B C$ thermal cycle test life increases with heat treatment temperature (and creep strength), indicating that creep strength of the bond coat does indeed influence TBC life. The beneficial effect was not observed on specimens treated at $1260^{\circ} \mathrm{C}\left(2300^{\circ} \mathrm{F}\right)$. This very high temperature may have resulted in rapid loss of strengthening elements from the bond coat by diffusion into the substrate, or incipient melting in the bond coat.

Specimen Appearance In all cases, initial spalling occurred at the top coat edges of the specimen with strong bond coats (Figure $21 \& 22$ ). These results are consistent with test results for the baseline NiCrAlY system ( 6 ). However, the NiCrAIY + aluminide bond coat was unique, in that while initial spalling occurred at the top coat edges, some spalling also occurred at the 


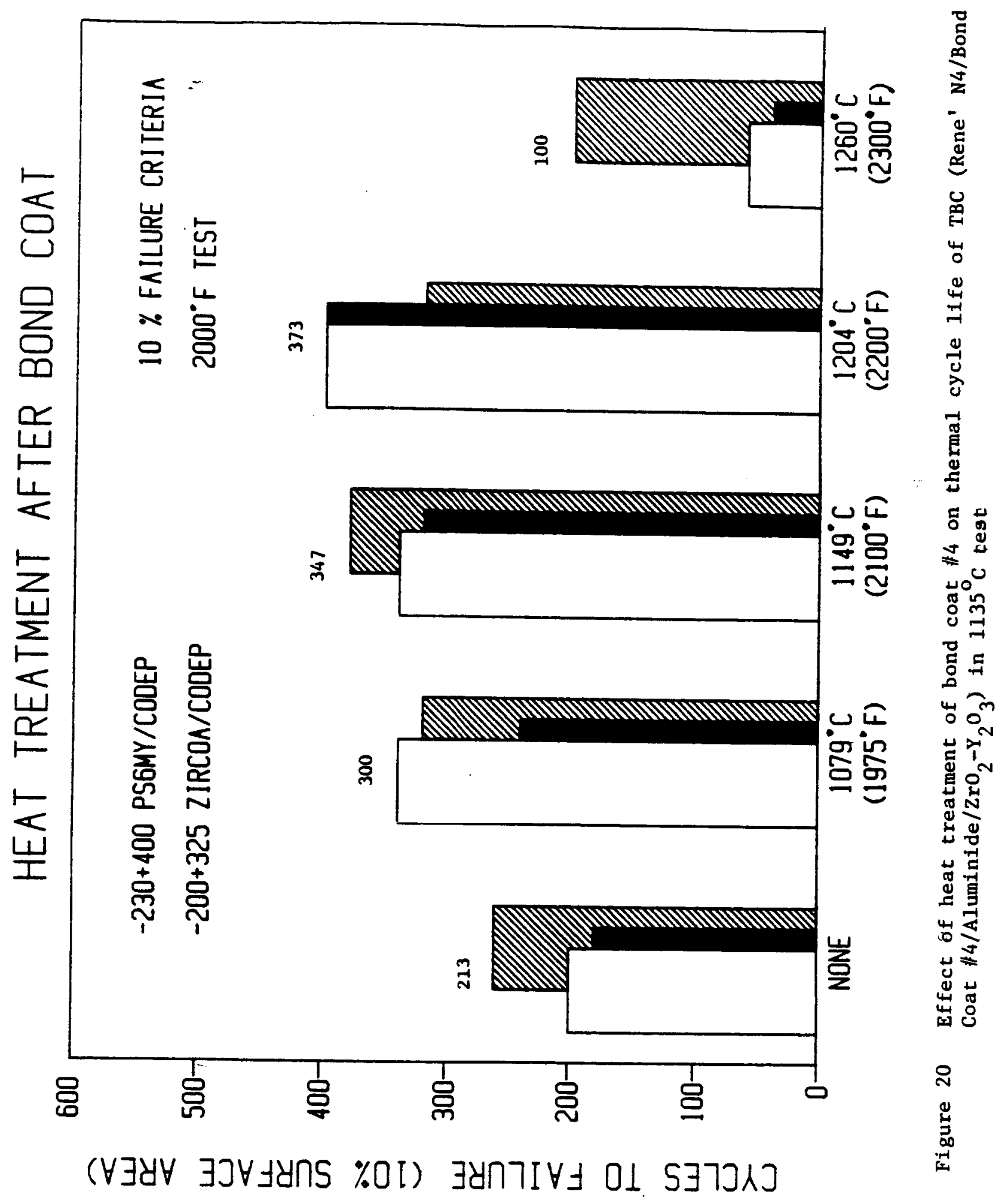


ORIGINAL PAOL HO

OF POOR QUALTY

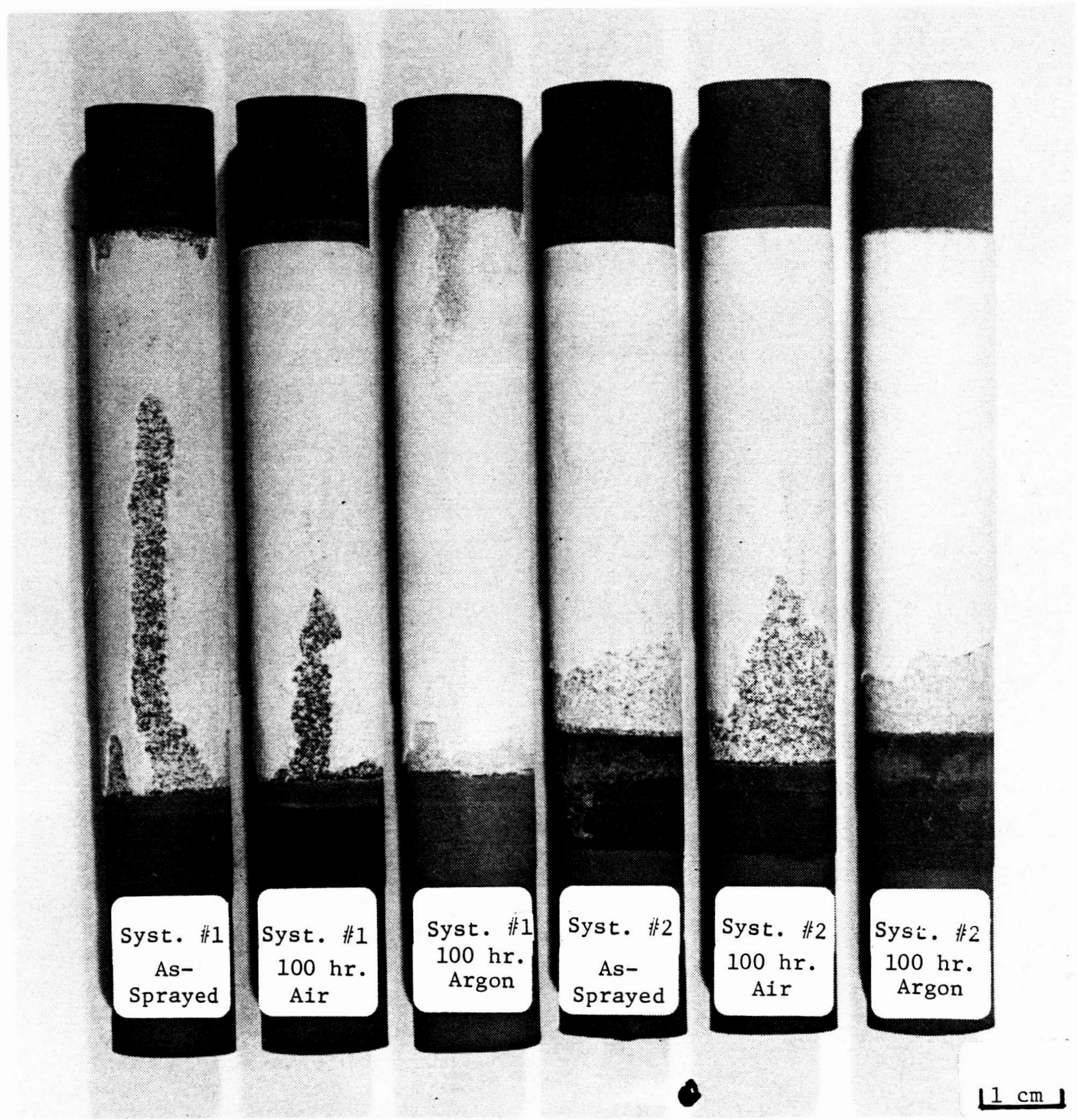

Figure 21 Failed TBC specimens after thermal cycle testing in air for TBC systems 非 1 and 非 (Bond Coat Creep Effect Experiment) 
ORICMAL PREZ is

OF POOR QUALTY

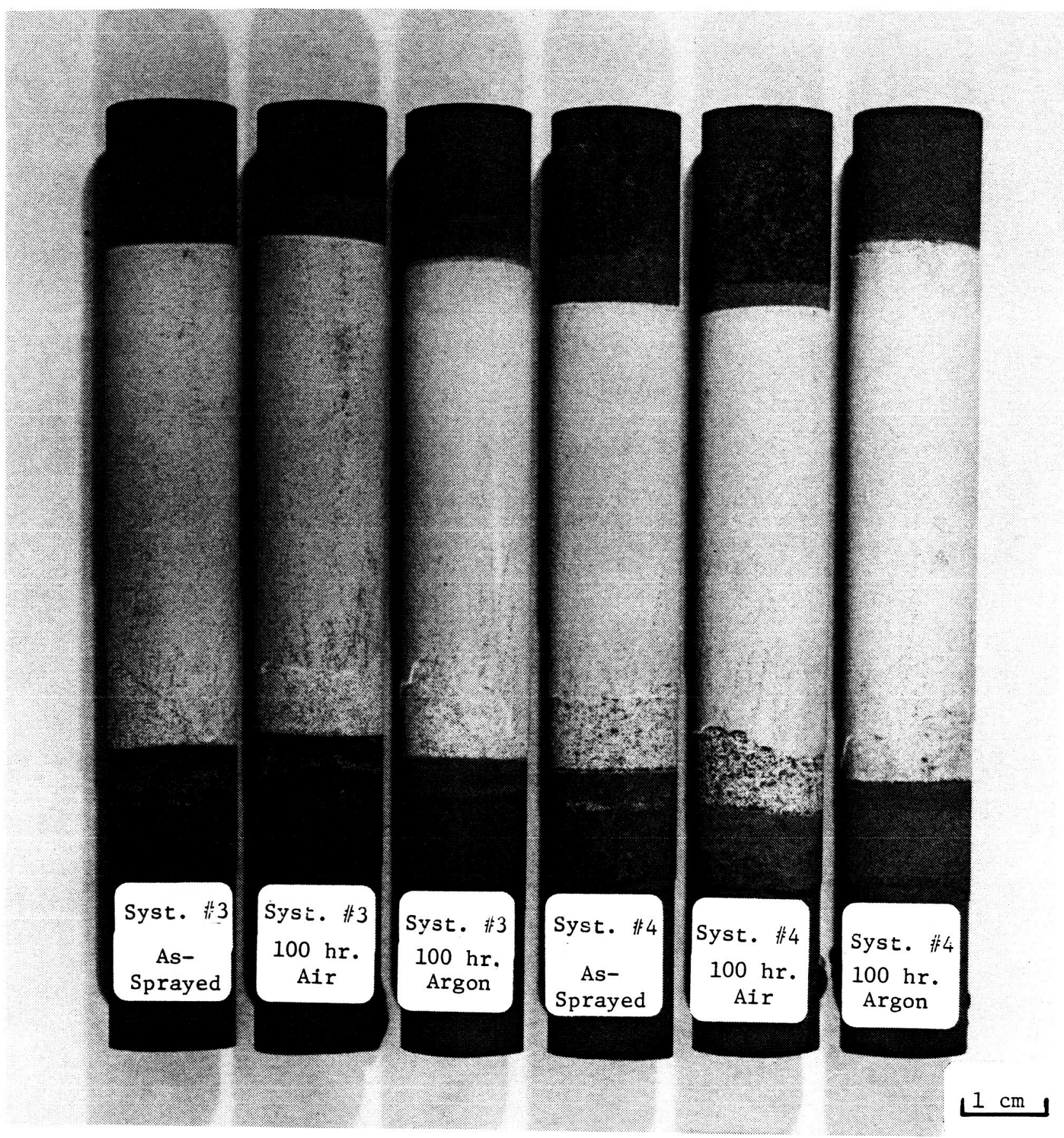

Figure 22 Failed TBC specimens after thermal cycle testing in air for TBC systems $\# 3$ and $\mathbb{\#} 4$ (Bond Coat Creep Effect Experiment) 
center of some specimens for all pre-exposure conditions. Spallation of these specimens also tended to be more catastrophic (true also for the baseline) than the TBCs with the higher creep strength bond coats. This phenomenon is consistent with other GE work and is under investigation.

Microstructure The microstructures after thermal cycle testing are shown in Figures 23, 24, and 25. In all cases, significant depletion of the bond coat had occurred through $\mathrm{Al}$ depletion via $\mathrm{Al}_{2} \mathrm{O}_{3}$ scale growth and bond coat/substrate interdiffusion. Coating/substrate interdiffusion had also resulted in the development of large $r$ layers in the bond coat and the substrate at this interface (for all three pre-exposure conditions) for bond coats \#2 and \#3. Bond coat \#1 ( NiCrAlY + aluminide) also includes a Ylayer in the bond coat with the presence of $M_{23} C_{6}$ precipitates in the substrate near the bond coat/substrate interface. Bond coat \#4 appears to have the smallest degree of microstructural change of the four different specimens for both the bond coat and the substrate. In all cases, significant changes have occurred in the bond coat for the four different systems due to thermal cycling. 
ORGRAL PrOS

OF POO? O A IT
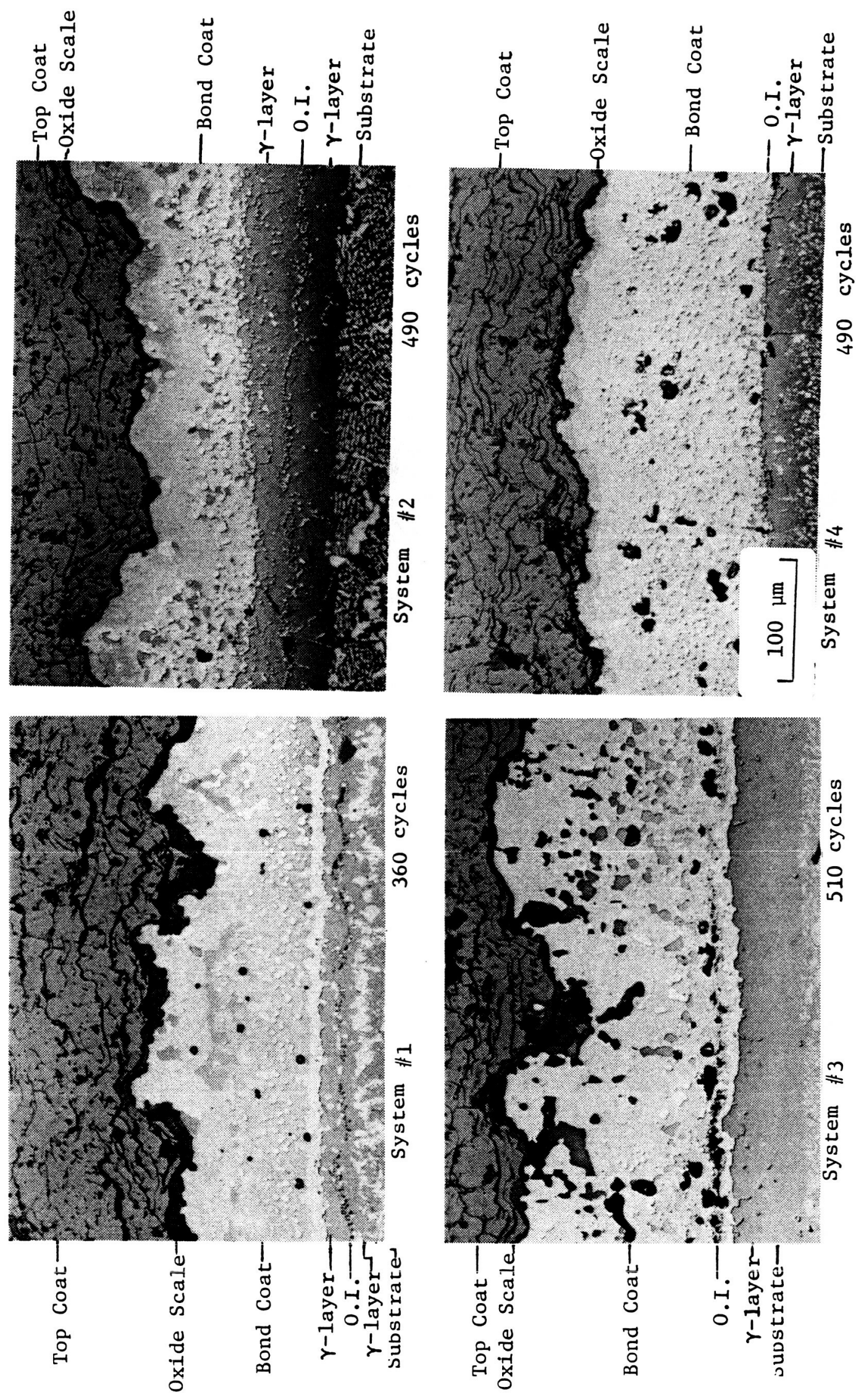

$\widehat{0}$
$\vdots$
0
0
0
$x$
0
1
0
0
0
4
0
-1
0
0
0

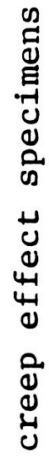

苋雚

ำ

胳

过

건

嵌

坣 䨔

氙

$+$

워

兵出

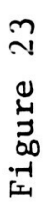



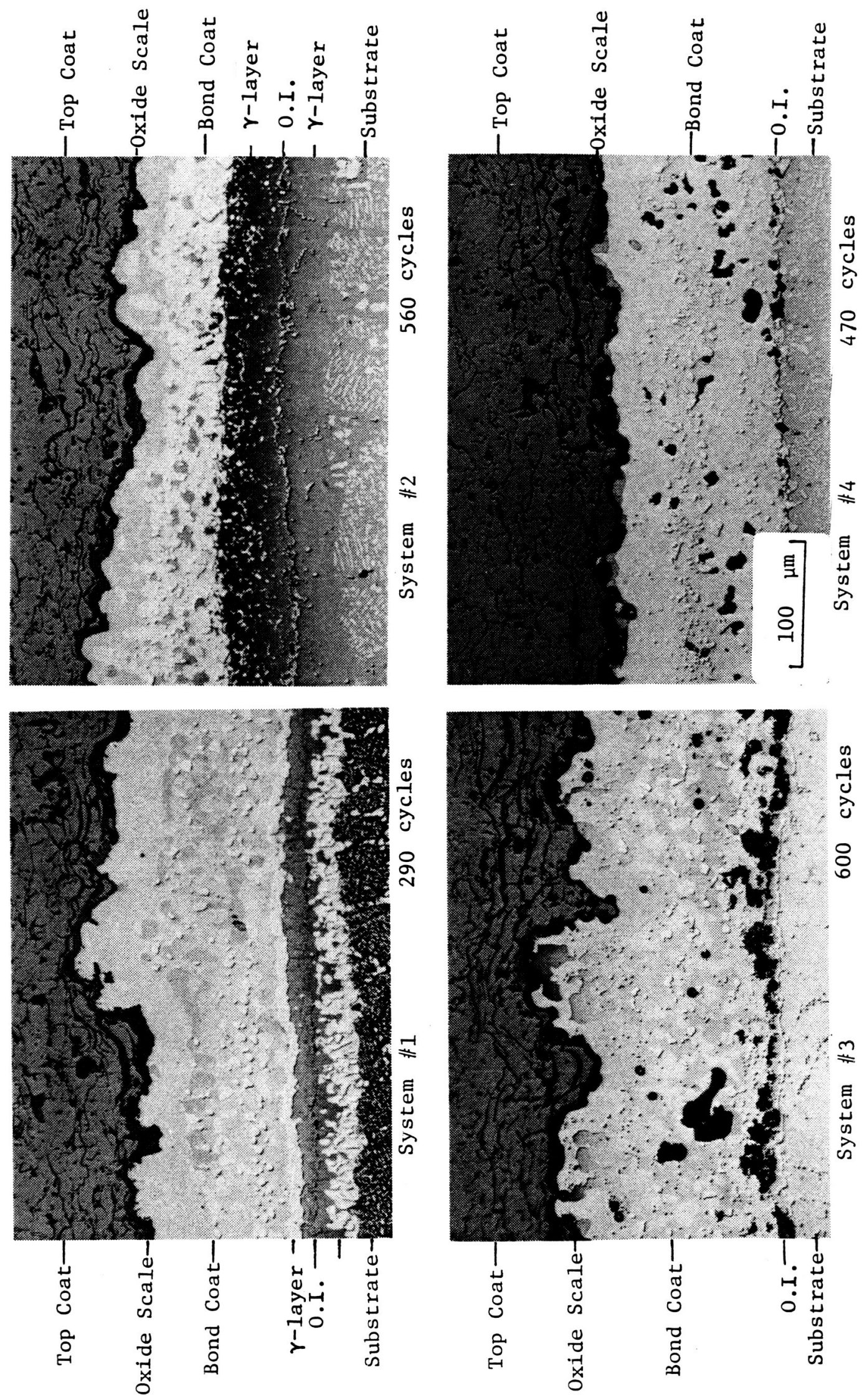

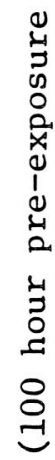

芩

峁

$\uplus_{4}^{\infty} \mathrm{m}$

4)

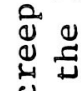

U.

崩

O

롱

प्-

峁先

गु

(1)

诜

षै

기음

ट्र

की

武

$\stackrel{+}{v}$

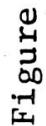




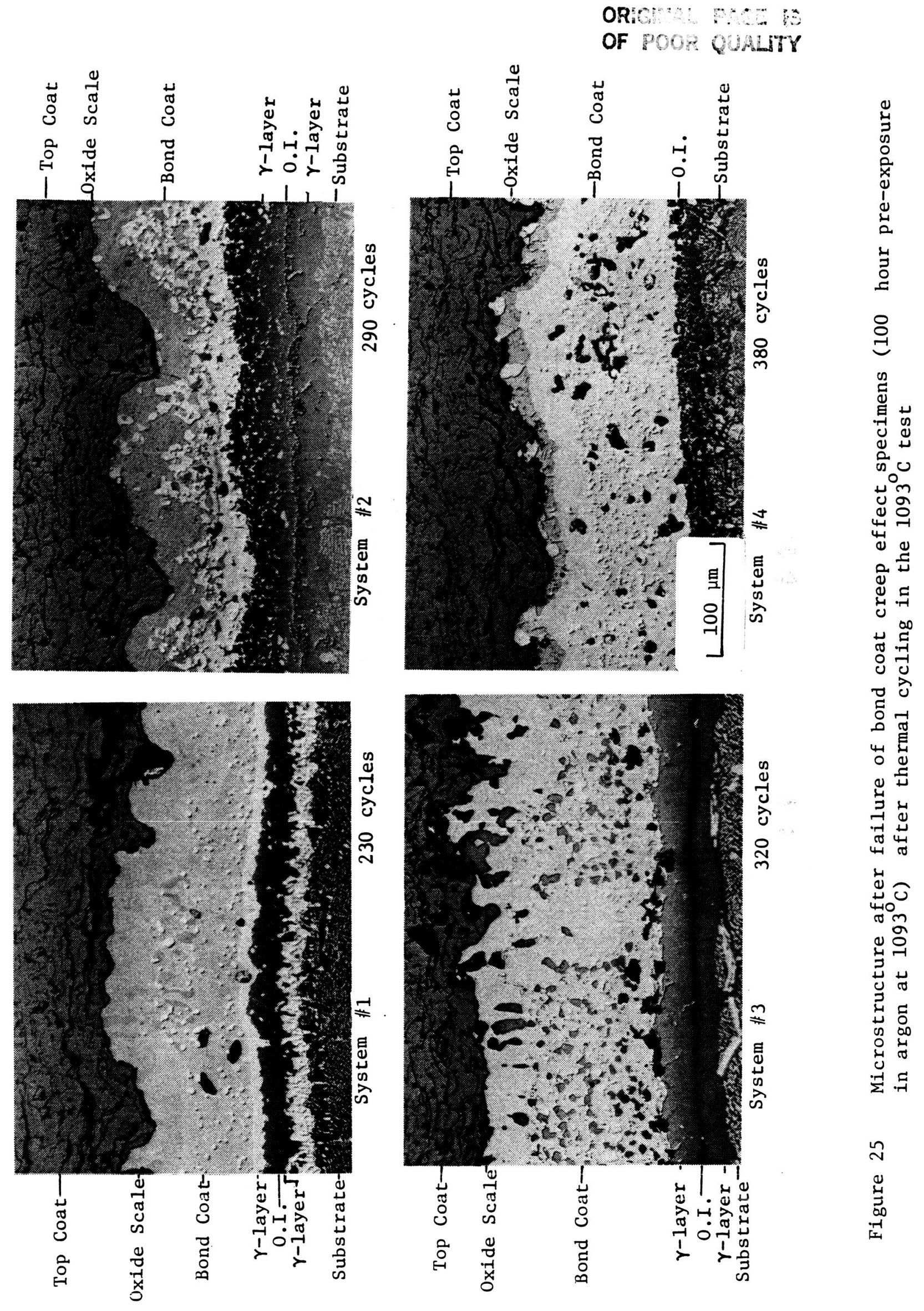




\section{Bond Coat Failure Criteria Experiment}

In this experiment, specimens were removed from thermal cycle testing prior to fajlure at various intervals (Table $X$ ). Microstructural examination of these specimens will allow examination of changes in the TBC prior to failure. Observation of the development and growth of cracks in the top coat are the primary goals of this effort. The data will be utilized to define failure criteria for TBC life prediction models. This examination will also yield the thermal cycle growth kinetics of the oxide scale at the bond coat/top coat interface. Tube specimens are being utilized in this experiment.

A11 testing has been completed and microstructural and scanning electron microscope examination of these specimens is underway. Their examination should be concluded early in the third year of this contract. 
TABLE $X$

$=$

EVALUATION OF TBC INTEGRITY VS. THERMAL CYCLES

SPECIMENS

3

3

3

3

3

3

3

3
PRE-EXPOSURE

None

None

None

None

None

None

None

None
THERMAL CYCLES*

1

10

30

50

75

100

110

115 (Failure)

*Thermal Cycle - 10 Minute Heat Up, 45 Minutes at $1093^{\circ} \mathrm{C}, 15$ minute Cool (Normal Inspection at 5 Cycles) 


\section{KEY PROPERTY DETERMINATIONS}

\section{Bond Coat Properties}

Tensile strength, Poisson's ratio, dynamic elastic modulus, and coefficient of thermal expansion were determined from room temperature to approximately $1093^{\circ} \mathrm{C}\left(2000^{\circ} \mathrm{F}\right)$. Standard testing procedures and test specimens (Figure 26) were utilized for the NiCrAlY bond coat specimens. These specimens were machined from $5.1 \mathrm{~cm}(2$ inch) by $15.2 \mathrm{~cm}(6$ inch) heat treated LPPS NiCrAlY billets of various heights. The as-sprayed billets received a four hour vacuum heat treatment at $1093^{\circ} \mathrm{C}\left(2000^{\circ} \mathrm{F}\right)$ to increase the machinability of the billets. The $1093^{\circ} \mathrm{C}$ heat treatment was chosen since this is the soak temperature utilized in thermal cycle testing.

Tensile Strength: Tensile strength was determined at room temperature, $538^{\circ} \mathrm{C}\left(1000^{\circ} \mathrm{F}\right), 760^{\circ} \mathrm{C}\left(1400^{\circ} \mathrm{F}\right), 982^{\circ} \mathrm{C}\left(1800^{\circ} \mathrm{F}\right)$, and $1093^{\circ} \mathrm{C}\left(2000^{\circ} \mathrm{F}\right)$. A summary of the test results is listed in Table XI. Some difficulties were encountered when testing at room temperature and at $538^{\circ} \mathrm{C}\left(1000^{\circ} \mathrm{F}\right)$. Unfortunately, NiCrAlY is extremely brittle at room temperature and two of the three test specimens failed in the grips and these results were not included in Table XI. At the $538^{\circ} \mathrm{C}$ test temperature, some slip of the extensometers was noted and although the data was included, these tests will be repeated and any differences noted in the final report. 

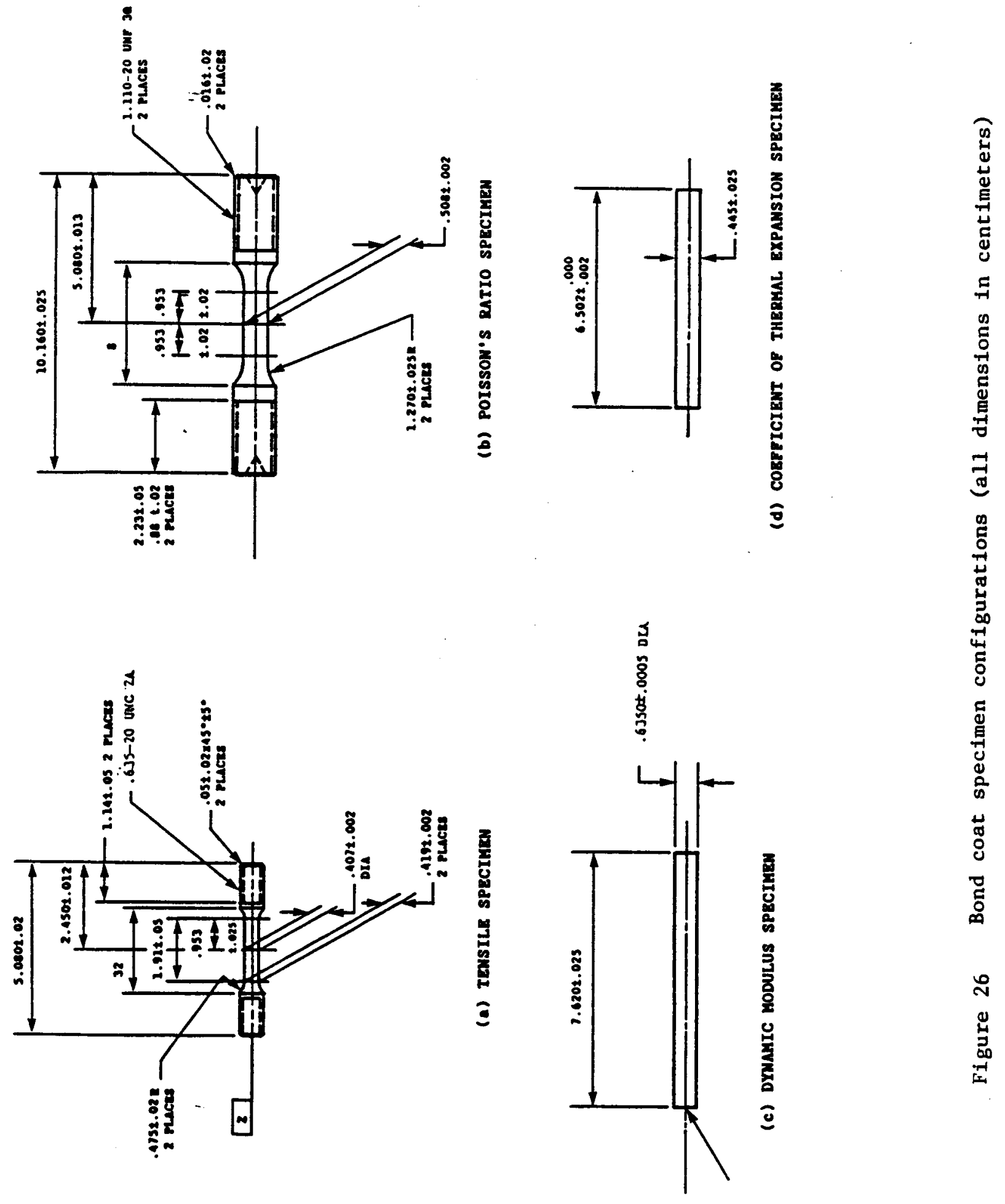

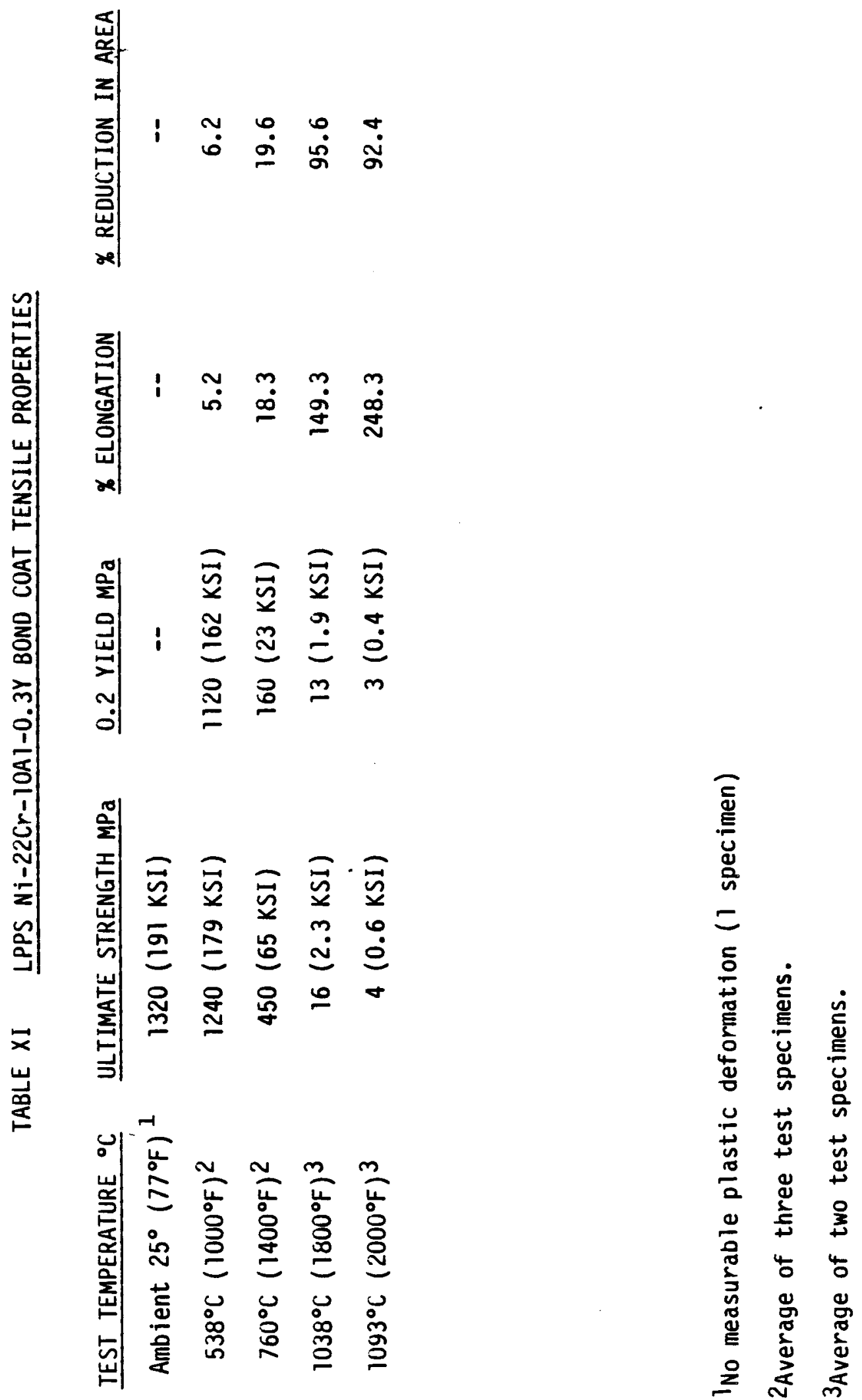
Poisson's Ratio: Poisson's ratio was determined at room temperature, $538^{\circ} \mathrm{C}\left(1000^{\circ} \mathrm{F}\right)$, and $760^{\circ} \mathrm{C}\left(1400^{\circ} \mathrm{F}\right)($ Table XII). Attempts were also made to obtain values at $982^{\circ} \mathrm{C}\left(1800^{\circ} \mathrm{F}\right)$, and at $1093^{\circ} \mathrm{C}\left(2000^{\circ} \mathrm{F}\right)$. However, due to the extremely ductile nature of the NiCrAlY material, the elastic region was not measurable at the elevated temperatures. A Poisson's ratio of 0.5 will be assumed for these temperatures, based on the laws of plasticity.

Dynamic Elastic Modulus: The dynamic elastic modulus was determined from room temperature to approximately $1075^{\circ} \mathrm{C}$ for two different specimens. A plot of the results for both specimens is shown in Figure 27 . The dynamic elastic modulus varies from $200 \mathrm{GN} / \mathrm{m}^{2}$ at R.T. to $20 \mathrm{GN} / \mathrm{m}^{2}$ at $1075^{\circ} \mathrm{C}$.

Coefficient of Thermal Expansion: Coefficient of thermal expansion was determined using the Chevenard dilatometer. The coefficient varies from approximately $11 \times 10^{-6} \mathrm{in} / \mathrm{in} / \mathrm{C}$ at R.T. to about $18 \times 10^{-6} \mathrm{in} / \mathrm{in} / \mathrm{C}$ at $1000^{\circ} \mathrm{C}$ (Figure 28 ). The same values were obtained when heating and cooling the specimens.

\section{Top Coat Properties}

Elastic modulus, shear modulus, Poisson's ratio, and coefficient of thermal expansion were determined for the top coat. These properties were 
TABLE XII

ELASTIC MODULI AND POISSON'S RATIO OF LPPS $\mathrm{Ni}-22 \mathrm{Cr}-10 \mathrm{Al}-0.3 \mathrm{Y}$

\begin{tabular}{|c|c|c|c|}
\hline Temperature ${ }^{\circ} \mathrm{C}$ & $E(A x i a l) \mathrm{GPa}$ & $E$ (Diametral) GPa & $\begin{array}{c}\text { Poisson's } \\
\text { Ratio } \\
\end{array}$ \\
\hline 20 (R.T.) & $206(29.9 \mathrm{MSI})$ & $696(100.8$ MSI $)$ & 0.30 \\
\hline $538\left(1000^{\circ} \mathrm{F}\right)$ & $180(26.1 \mathrm{MSI})$ & $602(87.3 \mathrm{MSI})$ & 0.30 \\
\hline $760\left(1400^{\circ} \mathrm{F}\right)$ & 101 ( $14.7 \mathrm{MSI})$ & $273(39.6 \mathrm{MSI})$ & 0.37 \\
\hline $982\left(1800^{\circ} \mathrm{F}\right)$ & -- & -- & $--\star$ \\
\hline $1093\left(2000^{\circ} \mathrm{F}\right)$ & -- & -- & $--\star$ \\
\hline
\end{tabular}

* No linear portion to stress/strain curves. 


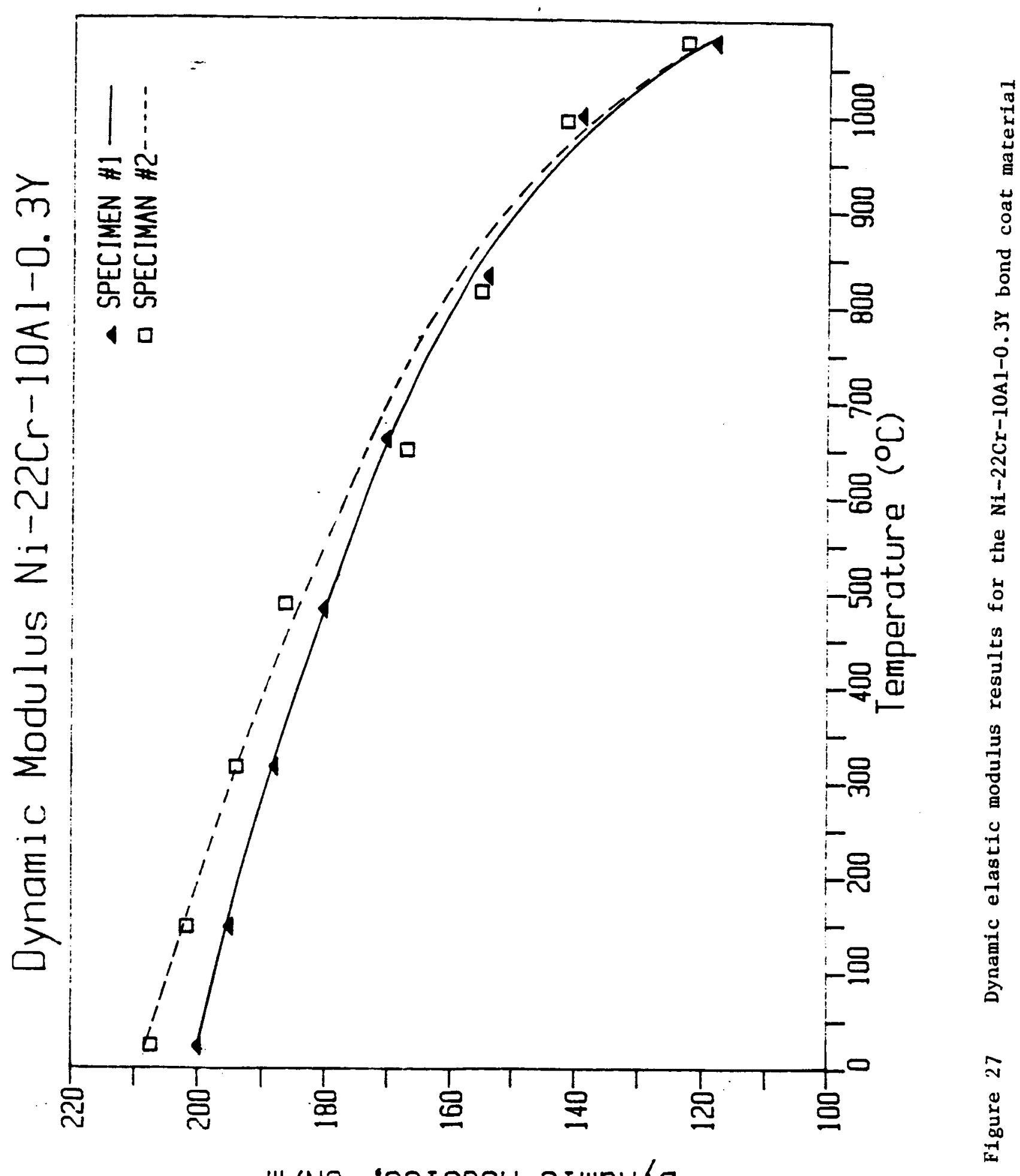

$\tau^{W / N J}$ 'sninpow otweuko 


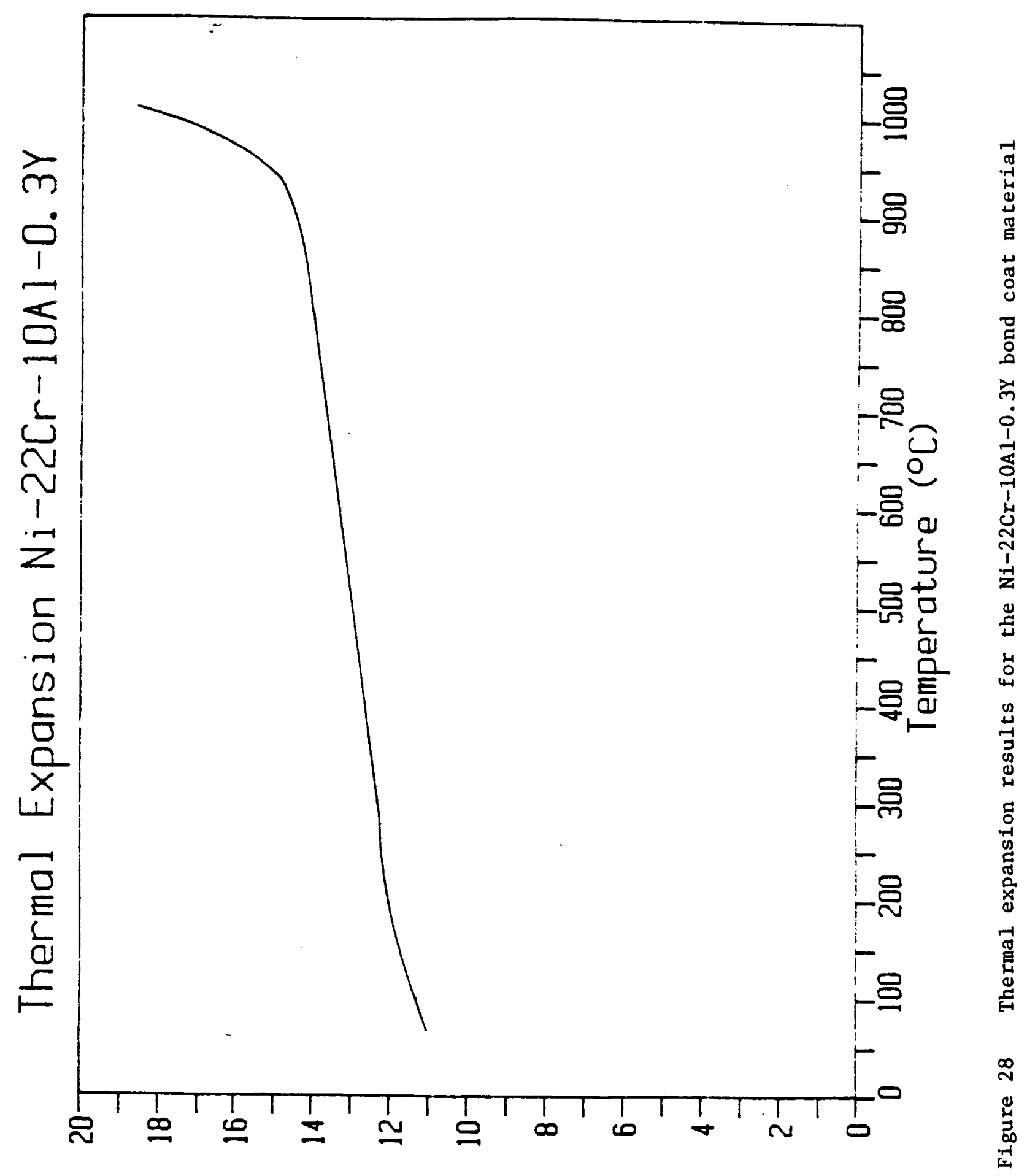

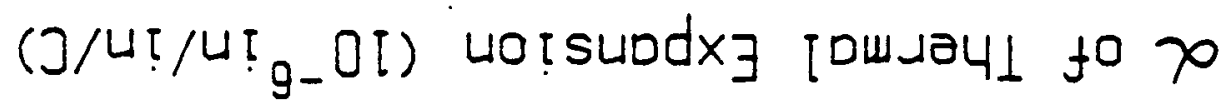


determined from-R.T. to approximately $1093^{\circ} \mathrm{C}\left(2000^{\circ} \mathrm{F}\right)$. In all tests, free-standing air plasma sprayed (APS) specimens were utilized. Free-standing specimens were produced by depositing the ceramic material on stainless steel substrates and inducing a thermal shock to cause spallation of the intact ceramic sheet. Some final machining was required to achieve the desired specimen configurations (Figure 29). These specimens also received a four-hour heat treatment in air at $1093^{\circ} \mathrm{C}\left(2000^{\circ} \mathrm{F}\right)$ prior to testing. The bend strength of similar free-standing specimens will also be determined in the trird year of this contract.

Elastic Modulus, Shear Modulus, and Poisson's Ratio - The apparatus and methodology used for measurement of elastic modulus, shear modulus, and Poisson's ratio of the ceramic specimen conform to that of Spinner and Tefft (11), the accepted standard of the industry.

The dynamic elastic and dynamic shear moduli were measured continuously from R.T. to $1093^{\circ} \mathrm{C}\left(2000^{\circ} \mathrm{F}\right) \star$ by a resonant frequency method. The free-standing ceramic specimen (Figure 30) was suspended in a furnace, and the flexural and torsional frequencies were measured as the furnace temperature was raised. A Pt wire or cotton thread was used to excite the specimens into its resonant frequency. The flexural resonant frequency was determined by 


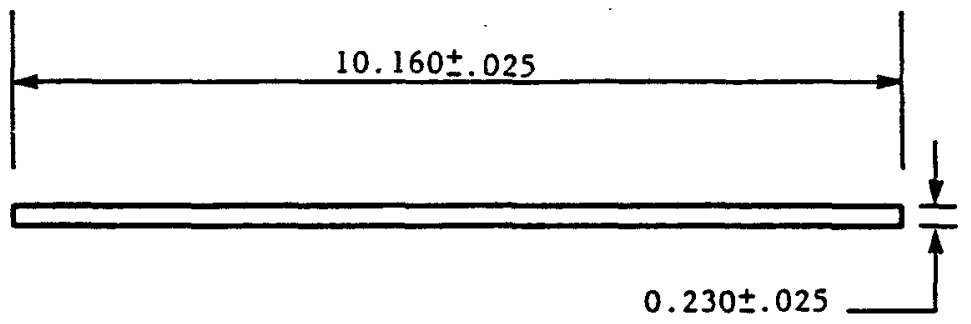

$2.540 \pm .025$

(a) DYNAMIC MODULUS AND POISSON'S RATIO SPECIMEN

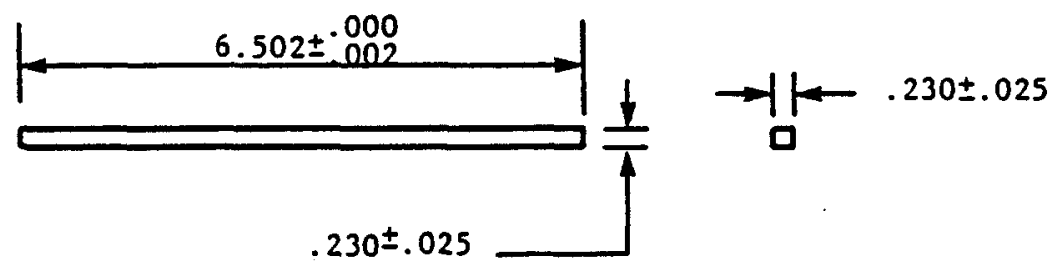

(b) COEFFICIENT OF THERMAL EXPANSION SPECIMEN
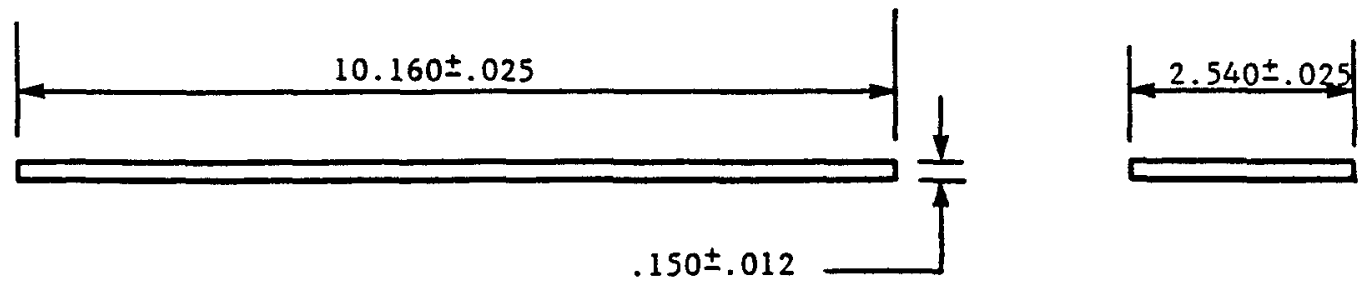

(c) BEND STRENGTH SPECIMEN

Figure 29 Top coat specimen configurations (all dimensions in centimeters) 


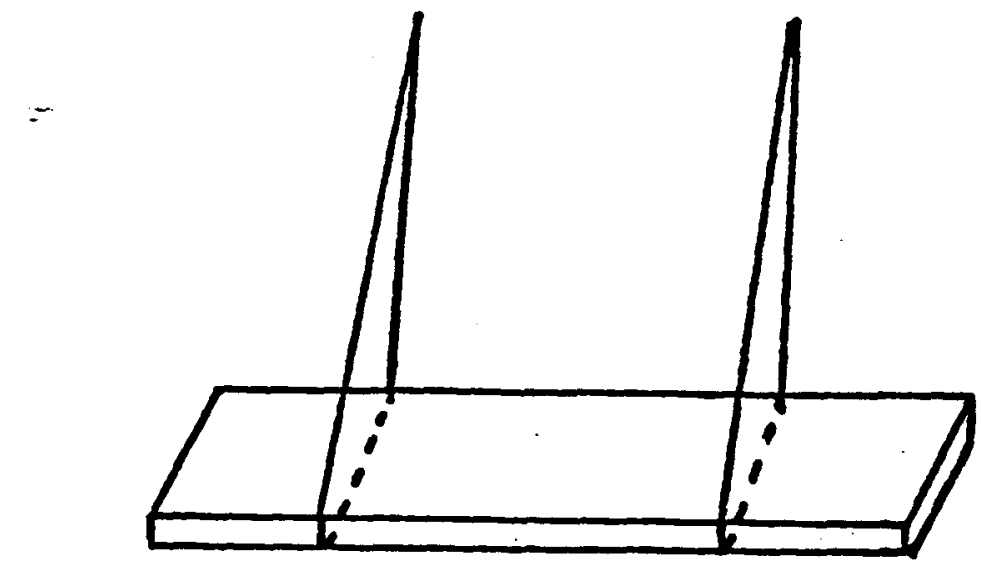

Flexura 1: Suspended Near Flexural Vibration Nodes

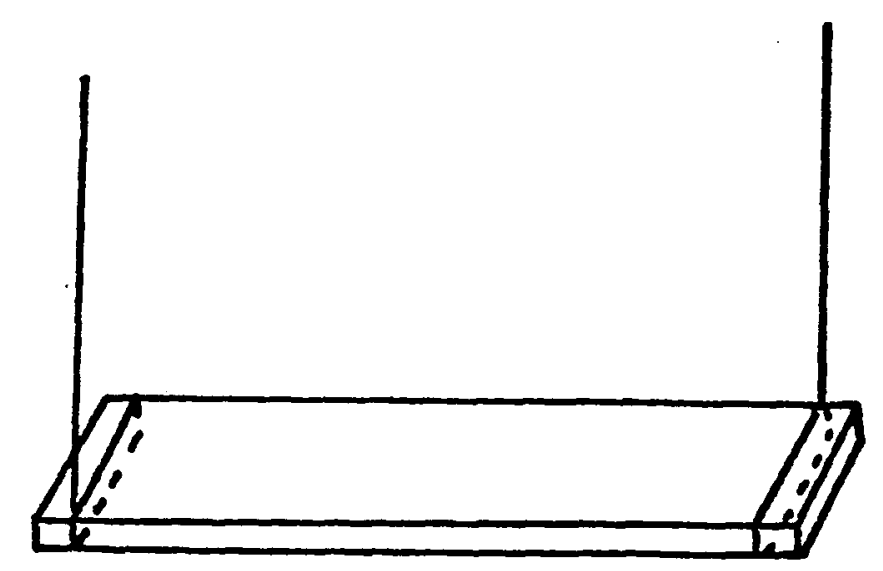

Torsional: From Opposite Corners

Figure 30 Method of suspending samples for flexural and torsional modes of vibration 
suspending the free-standing specimen from points just adjacent to the flexural nodal point, which permits detection of the resonant frequency. The elastic modulus was then calculated from the following relationship.

$$
E=\frac{0.94642}{386.09} \frac{P L^{4} f^{2} T}{t^{2}}
$$

where $E$ = Young's elastic modulus for flexural resonance of a prism of rectangular cross section, psi

$P=$ density, lb in. -3

$L=$ sample length, in.

$f=f$ lexural resonant frequency (fundamental mode), $\mathrm{Hz}$

$t=$ sample thickness, in.

$T=$ correction and shape factors given by Spinner and Tefft.

The specimen was then suspended at opposite corners, where torsional as well as flexural vibrations are induced. The shear modulus was then calculated from the measured torsional resonant frequency using the following relationship.

$$
G=\frac{4 f^{2} P R L^{2}}{386.09}
$$

where $G=$ shear modulus for torsional resonance, $p s i$

$f$ = torsional fundamental resonant frequency, $\mathrm{Hz}$

$R=$ shape factor

$L=$ sample length, in. 
Poisson's ratio $(\mu)$ was then calculated from the elastic and shear moduli using the following relationship.

$$
\mu=\frac{E-}{2 G}-1
$$

The cotton thread was used at $R$. $T$ to check the accuracy of the frequencies measured with the $\mathrm{Pt}$ wire. Two different specimens were evaluated at room temperature with the cotton thread. The average elastic modulus determined was $210 \mathrm{GPa}\left(30.5 \times 10^{6} \mathrm{psi}\right)$, while the average shear modulus was $91.2 \mathrm{GPa}$ $\left(13.2 \times 10^{6} \mathrm{psi}\right)$, (Table XIII). This compares to an elastic modulus of $208 \mathrm{GPa}\left(30.2 \times 10^{6} \mathrm{psi}\right)$, and a shear modulus of $90.3 \mathrm{GPa}\left(13.1 \times 10^{6} \mathrm{psi}\right)$ for specimen $\$ 2$ for the system utilizing the Pt wire. Since good correlation was observed between the two tests (cotton thread and $\mathrm{Pt}$ wire), the Pt wire was used for all measurements from R.T. through $1093^{\circ} \mathrm{C}$ on specimen \#2. The values measured for elastic modulus and shear modulus, and calculated for Poisson's ratio are shown in Table XV.

A four point (quarter flex) bend test was performed on specimen \#1 to allow comparison of elastic modulus values measured from this test to the values measured from the resonant frequency test. Specimen $\# 1$ was sectioned into three flex specimens $(0.635 \mathrm{~cm} \times 0.229 \mathrm{~cm} \times 0.635 \mathrm{~cm})$. The specimens were strain gaged and tested. The average elastic modulus determined from this test at.R.T. was $21 \mathrm{GPa}\left(3.0 \times 10^{6} \mathrm{psi}\right)$, (Table XIV). This average value is a factor of ten less than the values measured by the resonant frequency method. The difference is possibly associated with the presence of cracks, porosity, and splats decreasing the apparent modulus in the bend test. These factors should play a smaller role in the resonant frequency method. These results will be further evaluated and elaborated on in the final report. 
TABLE XIII

VALUES FOR ROOM TEMPERATURE MEASUREMENTS OF ELASTIC MODULUS ANO SHEAR MODULUS OF APS $2 \mathrm{rO}_{2} \mathrm{BY}_{2} \mathrm{O}_{3}$ (ON COTTON THREAD)

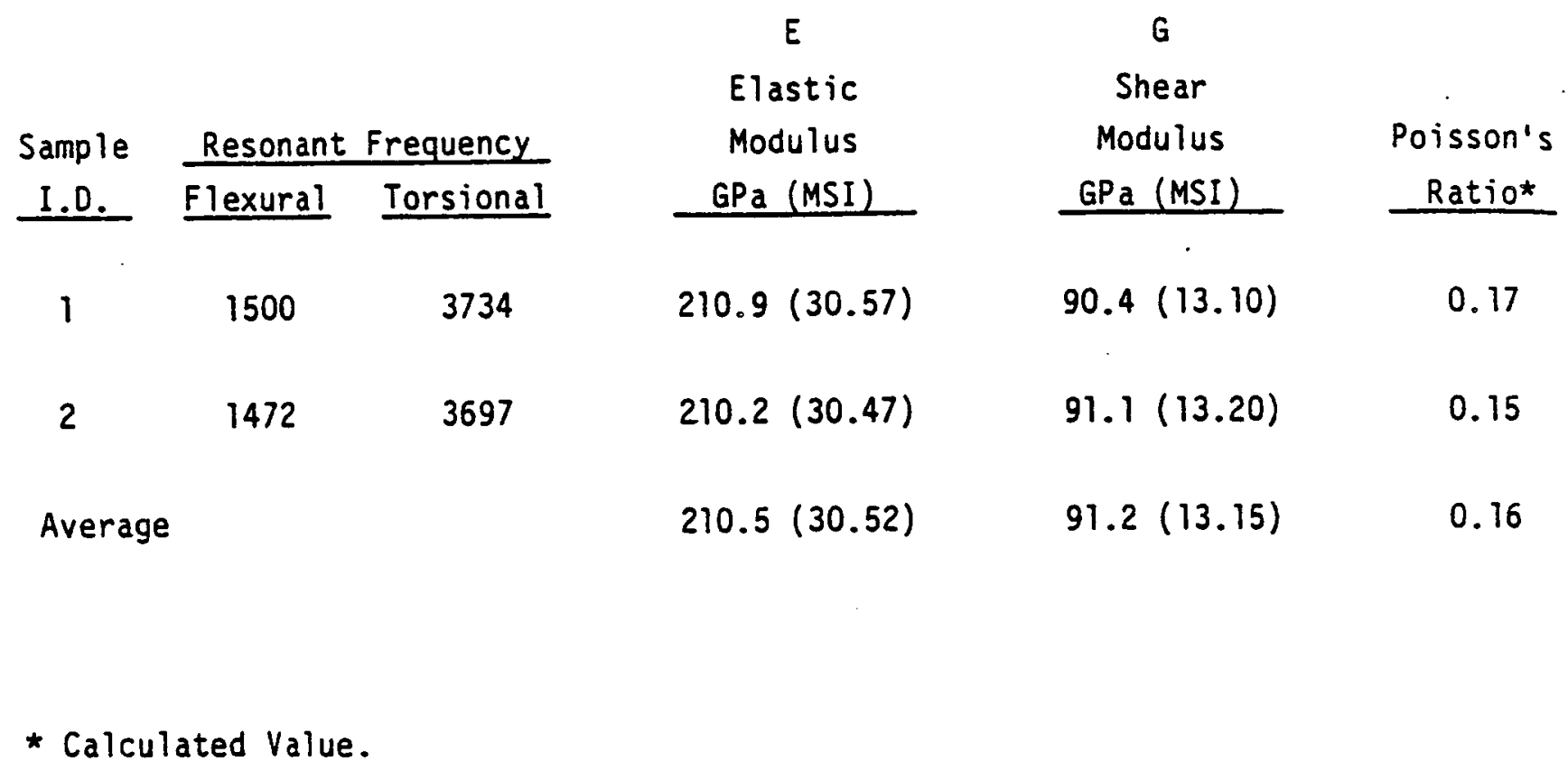




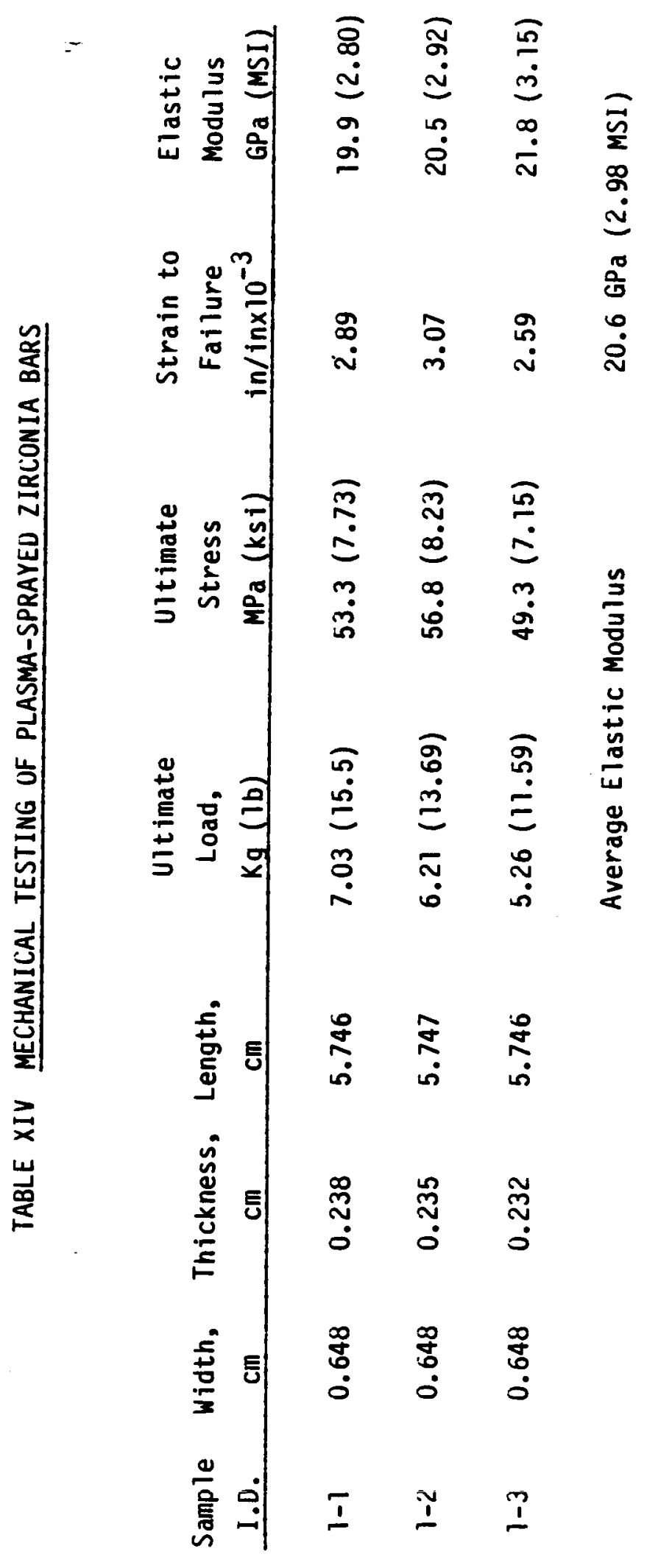


TABLE XV

ELEVATED TEMPERATURE DETERMINATION OF ELASTIC MODULUS, SHEAR MODULUS, AND POISSON'S RATIO OF APS $\mathrm{ZrO}_{2}-8 \mathrm{Y}_{2} \mathrm{O}_{3}$

\begin{tabular}{|c|c|c|c|c|c|}
\hline $\begin{array}{c}\text { Temp., } \\
{ }^{\circ} \mathrm{C}\end{array}$ & $\frac{\text { Resonan }}{\text { Flexural }}$ & $\frac{\text { requency }}{\text { Torsional }}$ & $\begin{array}{l}\quad \text { E } \\
\text { Elastic } \\
\text { Modulus } \\
\text { GPa (MSI) }\end{array}$ & $\begin{array}{l}\quad G \\
\text { Shear } \\
\text { Modulus } \\
\text { GPa (MSI) }\end{array}$ & $\begin{array}{l}\text { Poisson's } \\
\text { Ratios }\end{array}$ \\
\hline $25 \star$ & 1472 & 3697 & $210(30.5)$ & $91(13.2)$ & 0.15 \\
\hline 25 & 1466 & 3672 & $208(30.2)$ & $90(13.1)$ & 0.16 \\
\hline 100 & 1453 & 3630 & $205(29.7)$ & $88(12.8)$ & 0.16 \\
\hline 150 & 1444 & 3610 & $202(29.3)$ & $87(12.6)$ & 0.16 \\
\hline 200 & 1436 & 3573 & $200(29.0)$ & $86(12.4)$ & 0.17 \\
\hline 300 & 1425 & 3443 & $197(28.6)$ & $79(11.5)$ & 0.24 \\
\hline 400 & 1412 & 3343 & $193(28.0)$ & $75(10.8)$ & 0.29 \\
\hline 450 & 1411 & 3325 & $193(28.0)$ & $74(10.7)$ & 0.31 \\
\hline 500 & 1401 & 3299 & $190(27.6)$ & $72(10.5)$ & 0.31 \\
\hline 538 & 1395 & 3281 & $189(27.4)$ & $72(10.4)$ & 0.31 \\
\hline 600 & 1387 & 3265 & $187(27.1)$ & $71(10.3)$ & 0.31 \\
\hline 700 & 1375 & 3209 & $184(26.6)$ & $69(10.0)$ & 0.33 \\
\hline 800 & 1360 & 3160 & $179(26.0)$ & $67(9.7)$ & 0.34 \\
\hline 900 & 1342 & 3135 & $175(25.3)$ & $66(9.5)$ & 0.33 \\
\hline 982 & 1340 & 3122 & $175(25.3)$ & $65(9.4)$ & 0.34 \\
\hline 1000 & 1362 & 3147 & $179(26.1)$ & $66(9.6)$ & 0.36 \\
\hline 1038 & 1374 & 3163 & $183(26.5)$ & $67(9.7)$ & 0.37 \\
\hline 1093 & 1342 & 3185 & $175(25.3)$ & $68(y .8)$ & 0.29 \\
\hline
\end{tabular}

* Specimen suspended on cotton thread, all others suspended on Pt wire. 
Coefficient of Thermal Expansion: Coefficient of thermal expansion was determined using the Chevenard dilatometer from R.T. to $1073^{\circ} \mathrm{C}$. Interestingly, the coefficient was essentially constant (Figure 31) over this temperature regime with a value of approximately $9 \times 10^{6} \mathrm{in} / \mathrm{in} / \mathrm{C}$. These results will be compared to other published results in the final report.

Bend Strength Testing: Bend testing of the free-standing ceramic will be completed in the third year of this contract. Delays in procuring the necessary fixtures to run this test in-house, have resulted in the plan to perform these tests at Southern Research Institute. 


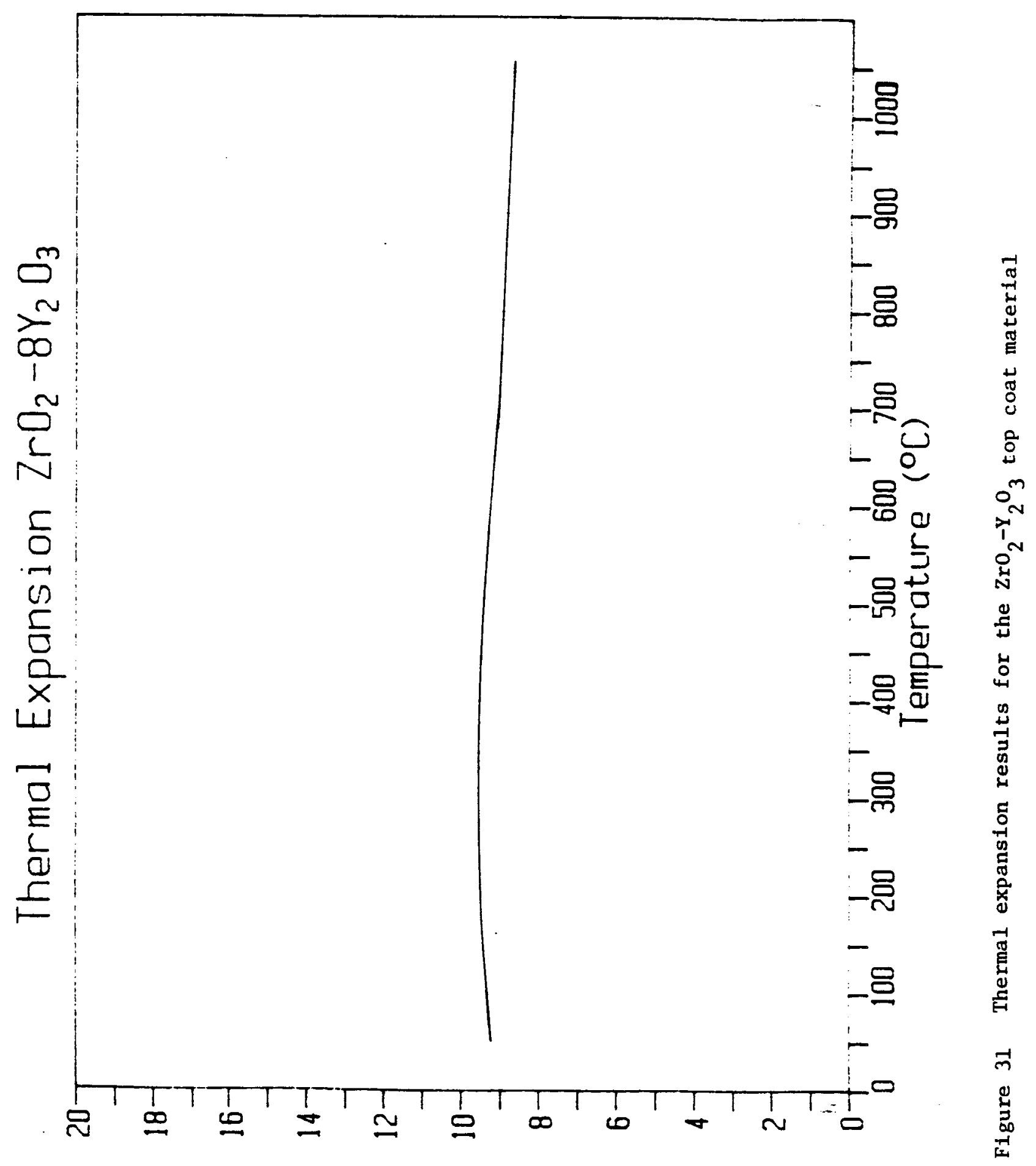

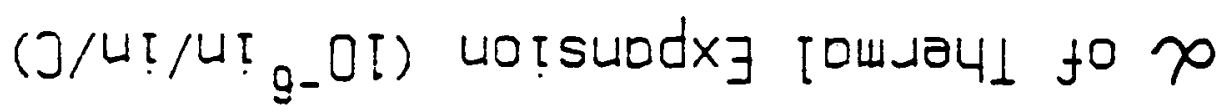




\section{- TASK II - MAJOR MODE LIFE PREDICTION MOOEL}

The objective of this task is to develop life prediction models for TBCs. To accomplish this goal, finite element analysis is being performed on the $T B C s$, and thermomechanical experiments are being utilized to evaluate the thermomechanical characteristics of TBCs. The TBC Analytical Modeling Program (finite element modeling) includes evaluation of five analytical tasks, each dealing with a particular aspect of the TBC failure regimes, while three thermomechanical experiments are aimed at determining the strains induced by thermal cycling. The TBC life prediction model will be created by combining the results of the TBC Analytical Program, the results of the thermomechanical experiments, and the results of the failure criteria examinations of Task I. 


\section{Finite Element Modeling}

The CYANIDE finite element program (GE in-house program) is being utilized to analyze thermal barrier coatings. Initial use of this program will consider the material's time independent behavior only. The time-dependent deformation will be included in the third year of this contract. A brief description of how the CYANIDE program handles inelastic behavior is described below.

CYANIDE is a two-dimensional finite element program which can handle either plane stress, plane strain, or axisymmetric deformation. The program can analyze structures subjected to any complex cyclic thermomechanical loading conditions including concentrated loads, pressure loads, thermal loads, and centrifugal loads. CYANIDE accounts for both time-independent plastic flow and time-dependent creep deformation.

Plasticity is accounted for by using a modified Besseling subvolume method with multilinear stress-strain curves which are temperature dependent. A typical stress-strain representation for one temperature is shown in Figure 32. This method automatically reproduces certain aspects of real-material behavior important in the analysis of engine components. These include the Bauschinger effect, cross hardening, and memory. In addition to 


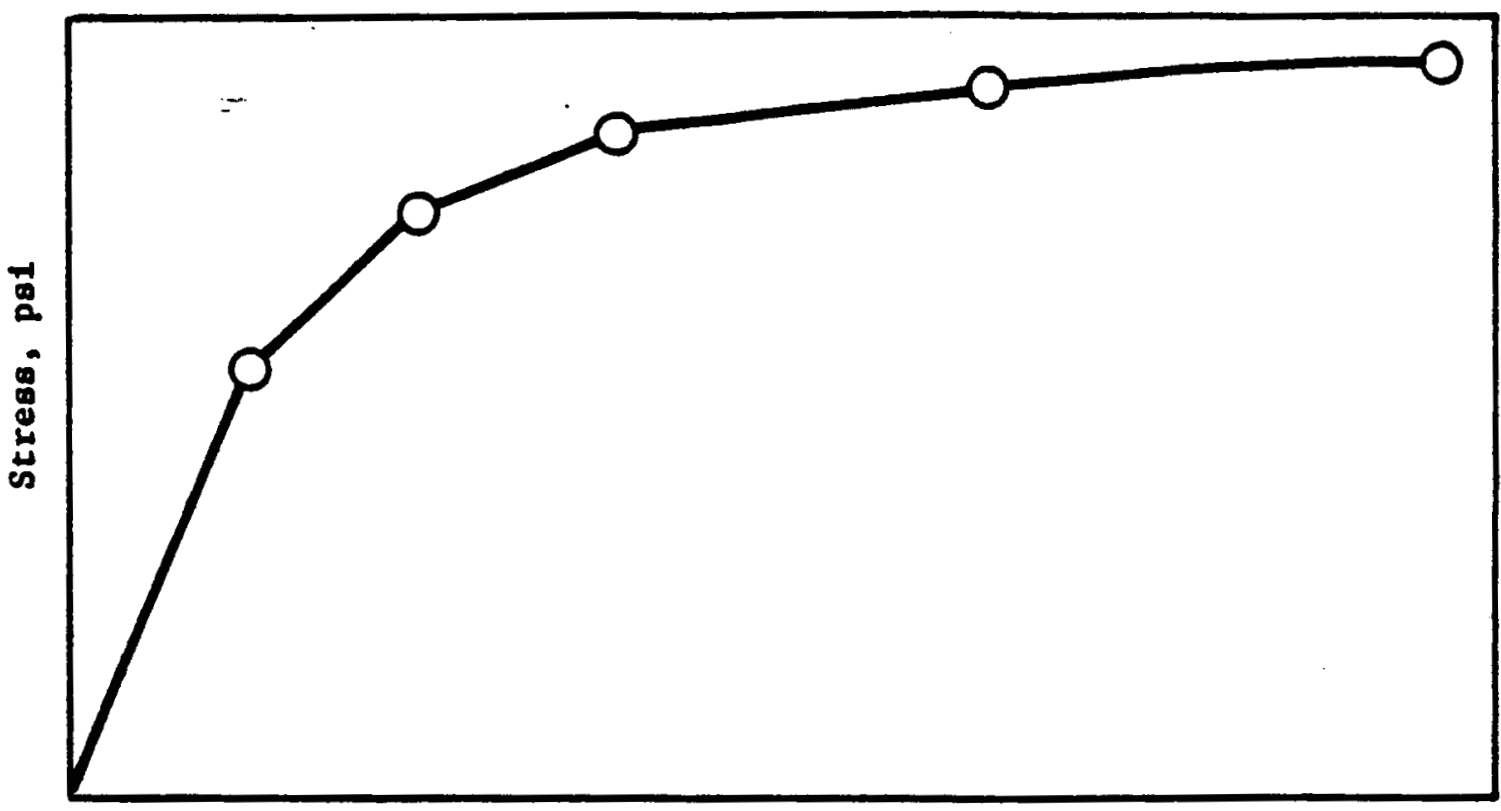

Strain ( $\varepsilon)$, In.in.

Figure 32 Point by point stress-strain curve representation

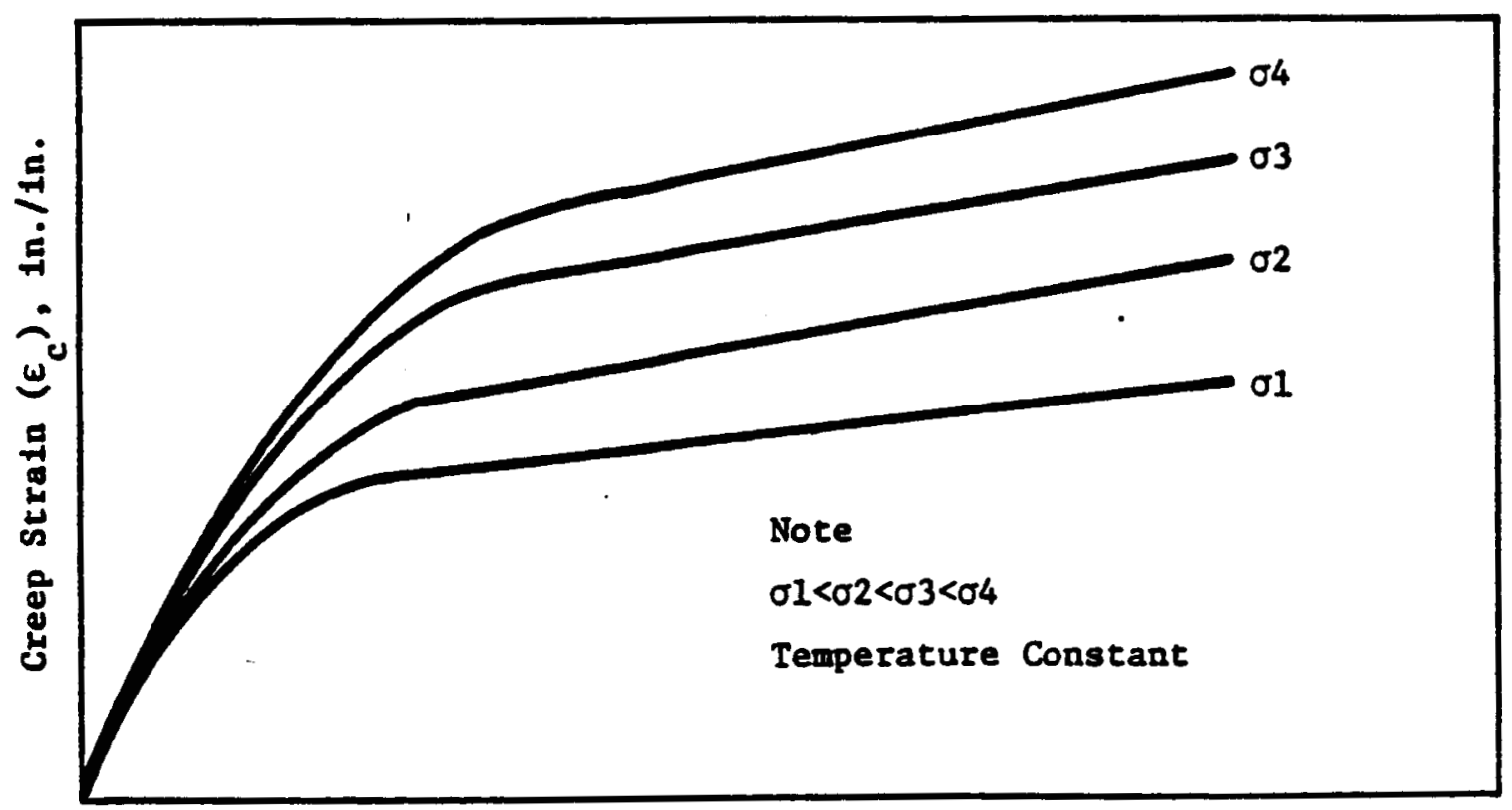

Time, hours

Figure 33 Creep curve representation for constant temperature 
simulating the material response very closely, Besseling's method is also more economical than other methods. Implementation of the method involves revising the force vector by computing plastic forces which account for the plastic flow:

$$
\begin{aligned}
& {[K][\delta]=[F]+\left[F_{p}\right] \text { where } K \text { is the elastic stiffness, }} \\
& \delta \text { is the incremental displacement, } \\
& F \text { is the applied force and } \\
& F_{p} \text { is the plastic force. }
\end{aligned}
$$

Since the method does not require modification of the stiffness matrix in the plastic iterations, it is consequently very economical.

The creep analysis utilizes one of two possible creep representations. When tertiary creep is not considered to be of importance, the equation used is:

$$
e_{c}=k \sigma_{e}^{-n_{t}^{m}}+q \bar{\sigma}_{e}^{-r}
$$

where

$$
\bar{\sigma}_{e}=\sigma_{e} / 100000, \sigma_{e}=\text { effective stress }
$$

and

$k, m, n, q, \dot{r}=$ material-dependent and temperature-dependent creep coefficients.

This type of response is shown for one temperature in Figure 33. 
When the material exhibits a significant amount of tertiary creep capability, an alternate representation is used. Primary creep is represented by the Bailey-Norton law.

$$
\varepsilon_{c}^{P}=A_{1}{ }^{\bar{\sigma}} e^{A_{2}} t^{A_{3}}
$$

Secondary creep is modeled with the expression proposed by Marine, Pao, and Cuff (12)

$$
\varepsilon_{c}^{S}=A_{4}{ }_{\sigma_{e}}^{-A_{5} t+A_{6}} \bar{\sigma}_{e}^{-A_{7}}
$$

Tertiary creep is represented with an equation of the form

$$
\varepsilon_{c}^{\top}=A_{8} \exp \left(\begin{array}{ll}
A_{9} & \bar{\sigma}_{e}^{A_{10}}
\end{array}\right)
$$

$A_{1}, A_{2} \ldots A_{10}=$ material-dependent and temperature-dependent

creep coefficients. This type of response is shown for one temperature in Figure 34.

CYANIDE also contains an orthotropic creep formulation. The creep strain rate is assumed to be given by

$$
\varepsilon i j=9_{i j k l} \sigma k l
$$




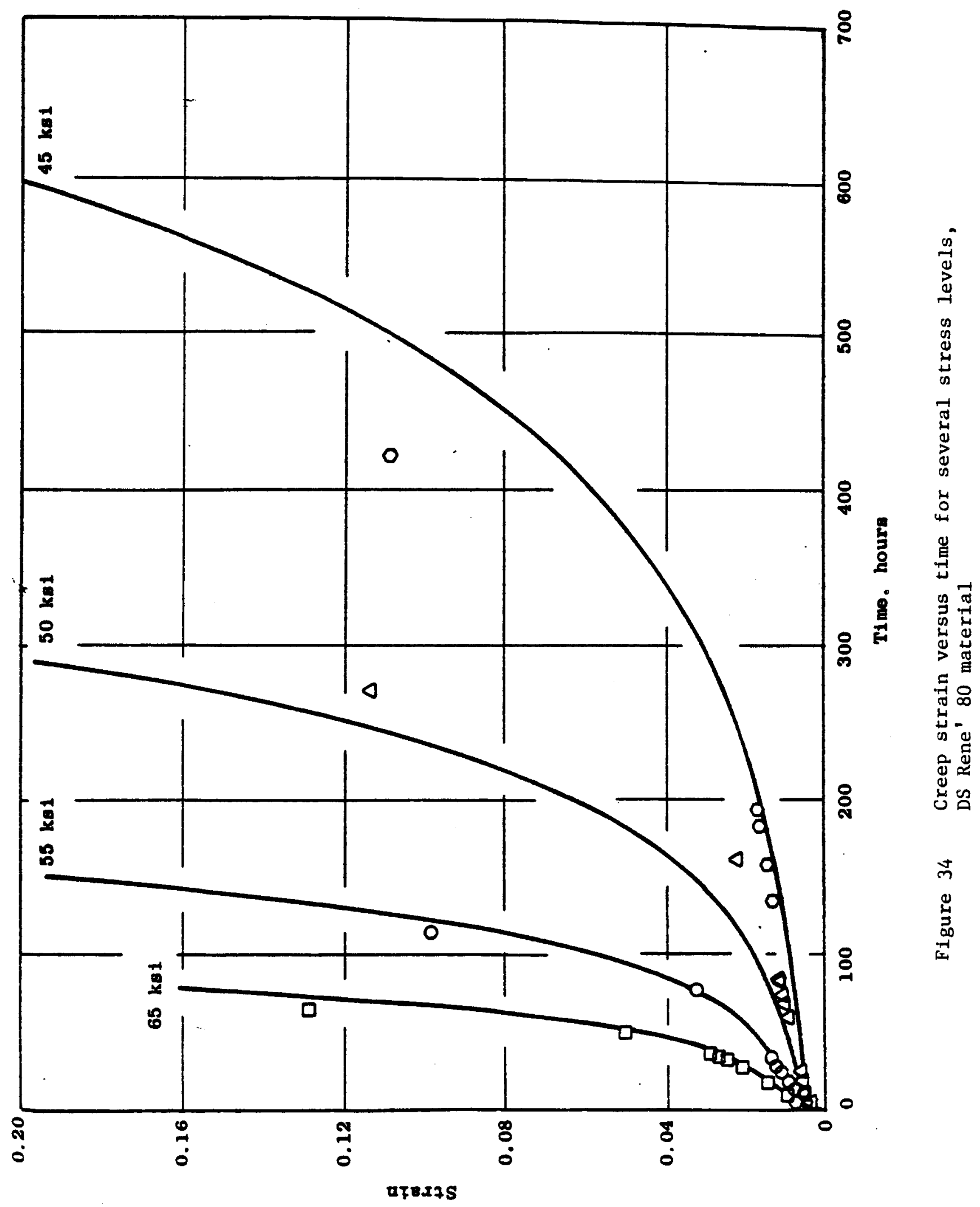


where

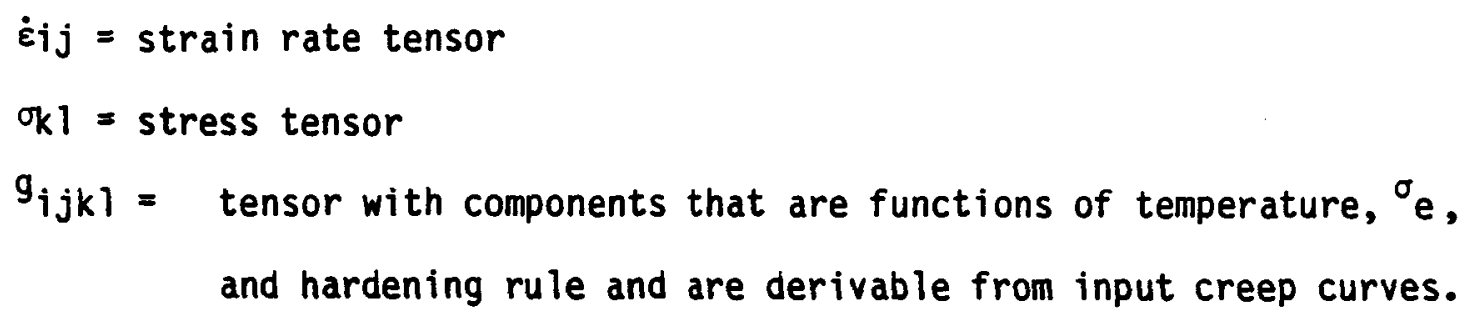

The user can select from time hardening, strain hardening, or life fraction creep rule, depending on the actual material characteristics. Strain hardening is ordinarily adequate for describing hardening behavior, providing that stress reversals do not occur. A stress reversal is considered to occur when

$$
\varepsilon_{i j} c \text { oij }<0
$$

where $\varepsilon i j^{C}$ is creep strain measured from the current origin. When a reversal occurs the origin is changed, and the analysis proceeds (13). 
The combination of general creep equations and creep rule makes the program very general in application to structures which undergo time-dependent inelastic deformation. A solution is done for each time step using an iterative technique to predict incremental creep strain components and revise the right side of the basic structural stiffness matrix equation by adding a plastic force vector to account for the creep effects

$$
[K]\{\delta\}=\{F\}+\left\{F_{P_{C}}\right\}
$$

in a manner similar to that used in the Besseling technique for time-independent plasticity. Again, this method is very efficient; very large problems can be solved economically, and convergence has been shown to be very rapid. The benefits of the CYANIDE finite element program will be more evident when creep relationships are introduced later in this TBC analys is effort. 


\section{TBC Analytical Modeling Program}

Five different analytical tasks, each dealing with a particular aspect of the TBC failure regimes, are being investigated. All five tasks will utilize finite element analysis. The first three tasks involve an axisymmetric model of a multilayer cylinder, while the fourth task examines a disk model, and the fifth task is intended to combine finite elements models with simple crack and diffusion models. The specific conditions of each task are discussed below.

Task a. In this evaluation, the same temperature will be assumed at the inner and outer surfaces of the specimen (i.e. no gradient across the TBC coated tubular specimen). The GE cyclic temperature rig's cycle (10-minute heat up, 45-minute exposure at $1093^{\circ} \mathrm{C}, 15$-minute cooling, Figure 35) will be modeled. This model will be compared to a free thermal expansion experiment planned to measure the axial displacement of the specimen.

Task $b$. A temperature distribution which is a function of space rather than time will be modeled (i.e., a gradient across the TBC cooled tubular specimen). The work will model the effect of the large gradients $\left(100-150^{\circ} \mathrm{C}\right)$ developed across the ceramic. In this case, no time dependent boundary conditions will be applied. 


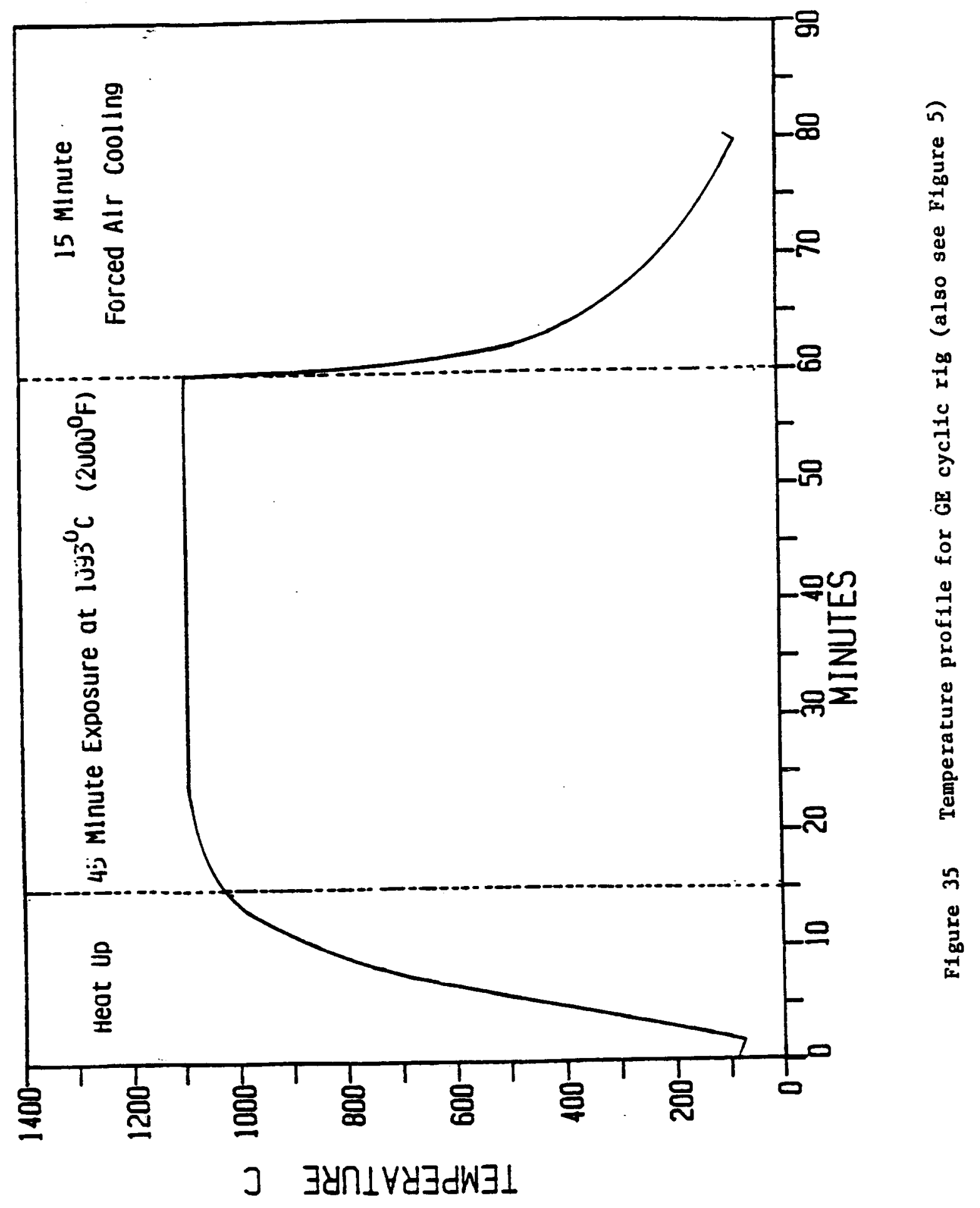


Task c. In this evaluation, cracks will be "placed" along the bond coat/top coat interface, thereby producing a ring crack. One or more cracks perpendicular to the free surface will then be added. The goal is to examine crack tip driving forces to determine any changes resulting from accommodations of displacements by the multiple cracks. Small submodels involving a number of cracks may be studied applying perturbation approaches (localized crack changes). The conditions for this modeling will be based on the results of the first two tasks described above.

Task d. The importance of edge effects in multilayer specimens (disks) will be briefly evaluated. This is an area of active research, so the task analysis will draw on published results. Since most GE TBC applications contain edges, it is important to examine how these edges may affect thermal cycle life by evaluating the stress state at these edges.

Task e. In this task, the above finite element model results, along with some simple elastic crack models, thermal mismatch strains, a diffusion model (e.g., \& \& Dt), and a hydrostatic pressure will be used to further examine crack tip driving force. Being elastic, there is a limit as to how far this model can be pushed, but it may produce significant insight on cracking in the ceramic. 
In the first four tasks of the modeling work, emphasis will be placed on extracting stress and displacement data as a function of time and location under changes in geometry and boundary conditions. In cases where sufficient material data is available (crack initiation, propagation, or failure data), quantities predicted by the models will be compared to this data for failure information.

The final task is the least defined and is the most difficult. Similar problems have been examined involving cracks perpendicular to the interface, but analysis of coating spallation has not been attempted. This is further complicated as a result of the presence of pore pressure and large amounts of thermal strain mismatch in the ceramic. However, the potential benefits of this examination are significant and warrant the investigation. 


\section{- Results - TBC Analytical Program}

Two dimensional finite element models are being used to determine the stress and deformation fields in the TBC specimens. Several finite element models were examined and an axisymetric model was selected to evaluate the fields. These results will provide the basis for the development of TBC life prediction models.

For the axisymmetric model, a longitudinal slice of a multilayer cylinder (Figure 36 ) is being examined. In this case, the assumption is made that the specimen is sufficiently long that the cross-sectional planes (perpendicular to axis) remain planar after deformation. For this geometry, two different axisymmetric models were investigated. The first has two layers in the axial direction (Figure 36b), with the elements in the right layer set to be extremely rigid to resist the axial and shear deformation. The second model (Figure 36c) has many layers in the axial direction, with the last layer very long (10:1 aspect ratio, not shown) in the axial direction. In both models, the goal is to enforce the uniform axial deformation. 

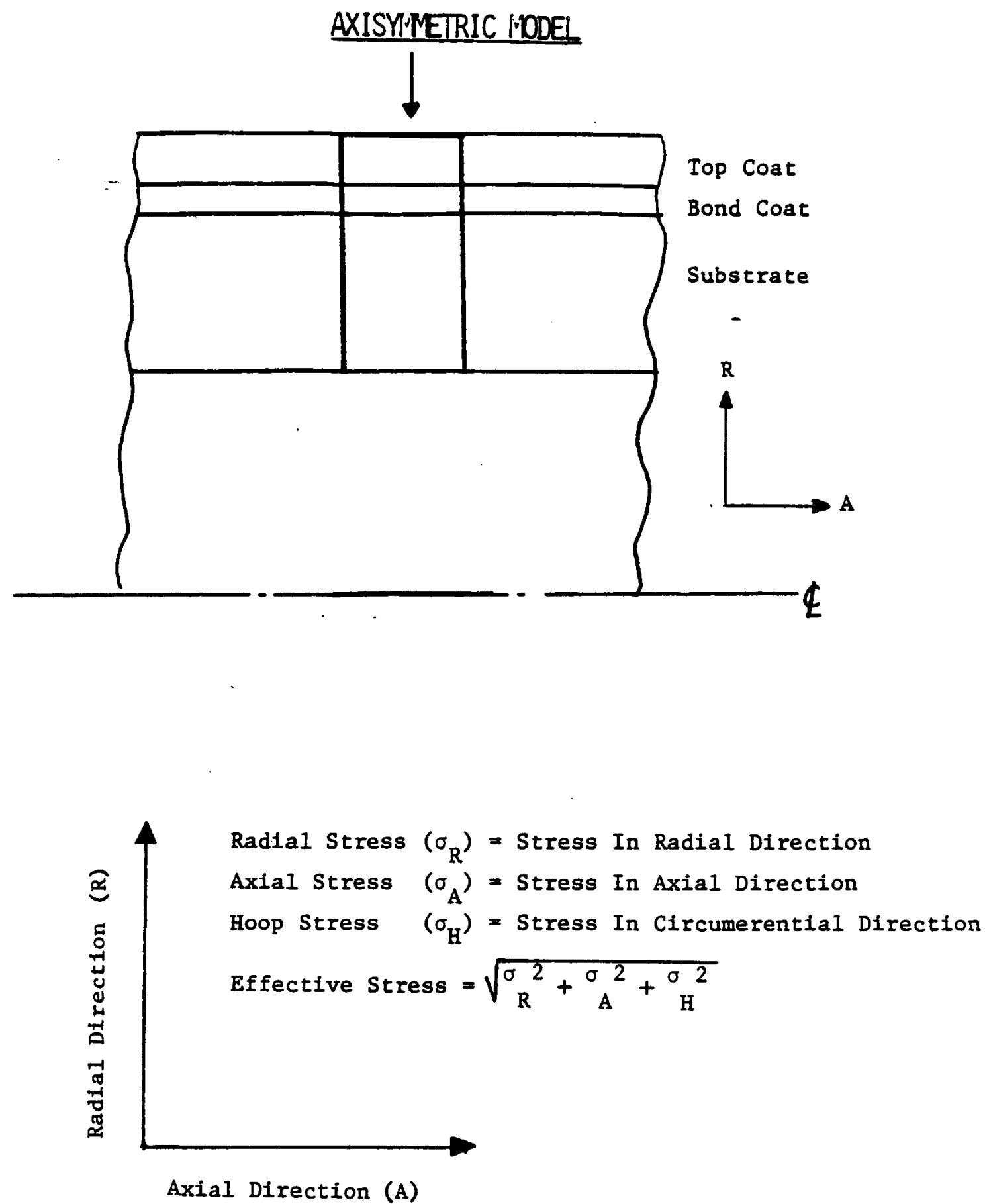

a)

Figure 36 Axisymmetric Mode1

a) Longitudinal slice of multilayer cylinder 


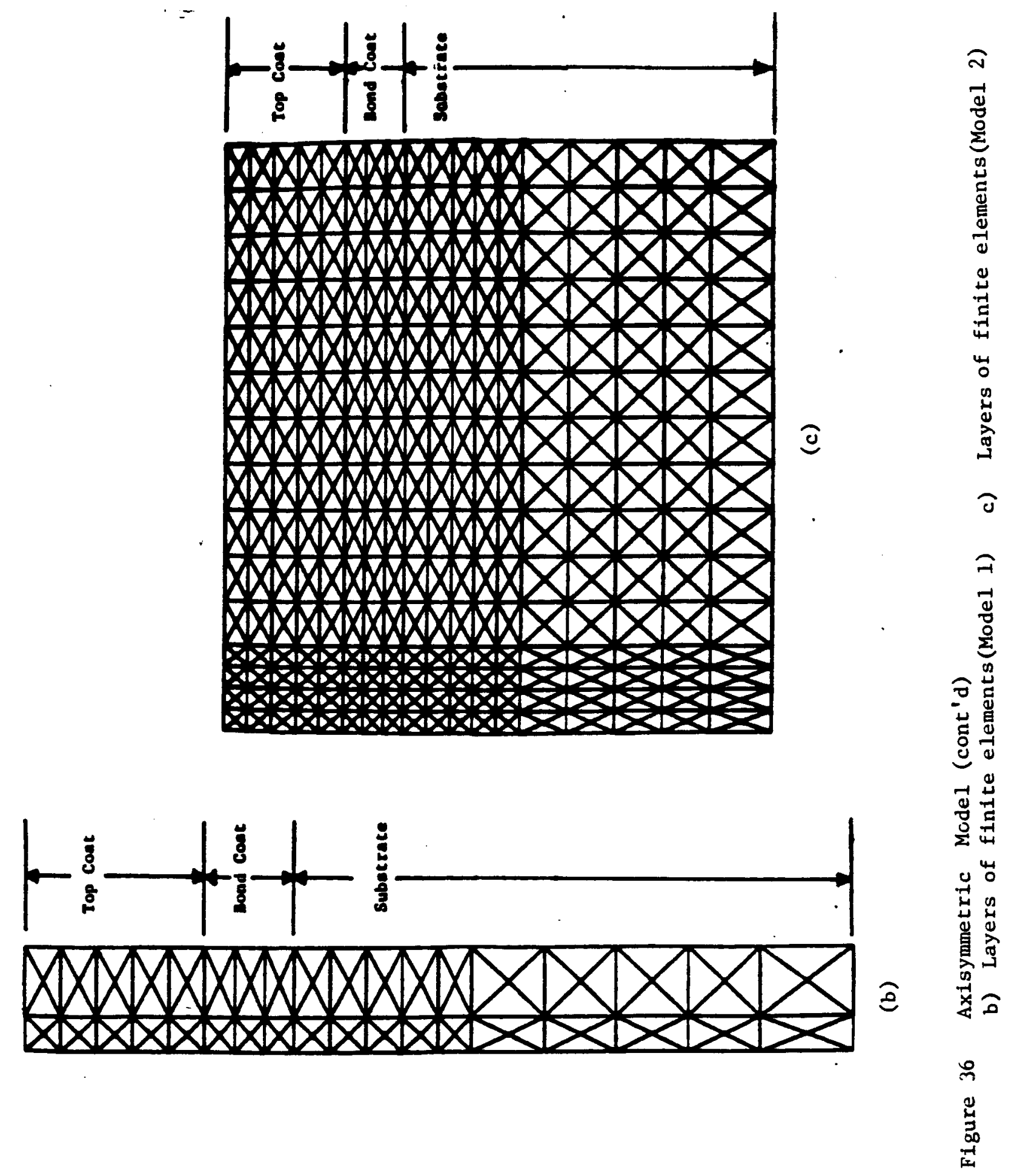


The evaluation of both types of models has allowed initial cross checking of data generated from the models. However, after careful examination, the decision was made to utilize the second axisymmetric model (Figure $36 \mathrm{c}$ ).

The axisymmetric finite element program (Figure 36a and 36c) has been applied to the first two analytical tasks. The bond coat stress free temperature was assumed to be $982^{\circ} \mathrm{C}\left(1800^{\circ} \mathrm{F}\right)$, while the top coat stress free temperature was assumed to be $204^{\circ} \mathrm{C}\left(400^{\circ} \mathrm{F}\right)$. These are the temperatures of the substrate during application of these coatings. The material properties utilized in the model are listed in Appendix III. Stresses, which include effective, radial, axial, and hoop, have been determined across the top coat, the bond coat, and the substrate in the radial direction. In the analysis both elastic and plastic deformation was included, but no plasticity developed for the temperature conditions selected (time at temperature was not included). Analysis of the results for the first two analytical tasks is discussed below.

In Task $a$, the specimen was assumed to undergo the thermal cycle of $21^{\circ} \mathrm{C}-1093^{\circ} \mathrm{C}-21^{\circ} \mathrm{C}$ in the cycling rig. Since this is a quasistatic test, the entire specimen was assumed to be at a given temperature. Effective, radial, axial, and hoop stresses versus distance in the radial direction are plotted in Figure 37 for four different temperatures $\left[21^{\circ} \mathrm{C}\left(70^{\circ} \mathrm{F}\right), 204^{\circ} \mathrm{C}\right.$ $\left(400^{\circ} \mathrm{F}\right), 982^{\circ} \mathrm{C}\left(1800^{\circ} \mathrm{F}\right)$, and $1093^{\circ} \mathrm{C}\left(2000^{\circ} \mathrm{F}\right) \mathrm{J}$. As indicated, the stress free temperature for the top coat is $204^{\circ} \mathrm{C}\left(400^{\circ} \mathrm{F}\right)$, therefore, zero stress is found in the top coat at this temperature. However, since the top coat was applied to the bond coat, $982^{\circ} \mathrm{C}\left(1800^{\circ} \mathrm{F}\right)$ is no longer the bond coat stress free 
temperature. Therefore, small stresses due to the top coat application develop in the bond coat at this temperature.

As observed in all plots, the model predicts extremely large stresses in the bond coat and top coat at $1093^{\circ} \mathrm{C}\left(2000^{\circ} \mathrm{F}\right)$. The high stresses in the top coat would probably be relieved by microcracking. The results also indicate that large compressive stresses do develop in the ceramic upon cooling. This is consistent with most theories associating TBC failure with the large compressive stresses that develop in the ceramic upon cooling. Further comment on the significance of the values will be made as experimental data becomes available in subsequent work on this program.

In the Task $b$, a temperature distribution across the TBC system was modeled. In this examination, the surface of the ceramic was set at $1093^{\circ} \mathrm{C}$ $\left(2000^{\circ} \mathrm{C}\right)$, the bond coat/top coat interface was set at $943^{\circ} \mathrm{C}\left(1730^{\circ} \mathrm{F}\right)$, the bond coat/top coat interface was set at $941^{\circ} \mathrm{C}\left(1725^{\circ} \mathrm{F}\right)$, and the inner wall of the tube was set at $927^{\circ} \mathrm{C}\left(1700^{\circ} \mathrm{F}\right)$. These results (Figure 38) were plotted and compared with the results present when the system was at $21^{\circ} \mathrm{C}\left(70^{\circ} \mathrm{F}\right)$. Interestingly, the largest effective stress is present in the ceramic near the bond coat/top coat interface which is the typical failure location for thermal barrier coatings. Future plans include evaluating the effect of temperature gradients at lower temperatures, closer to temperature at which TBCs are believed to fail. Comparison of the results of deformation behavior for Tasks $a$ and $b$ (Figures 37 and 38 ) indicate how significantly the presence of thermal gradients can affect the stress state present in TBCs. 


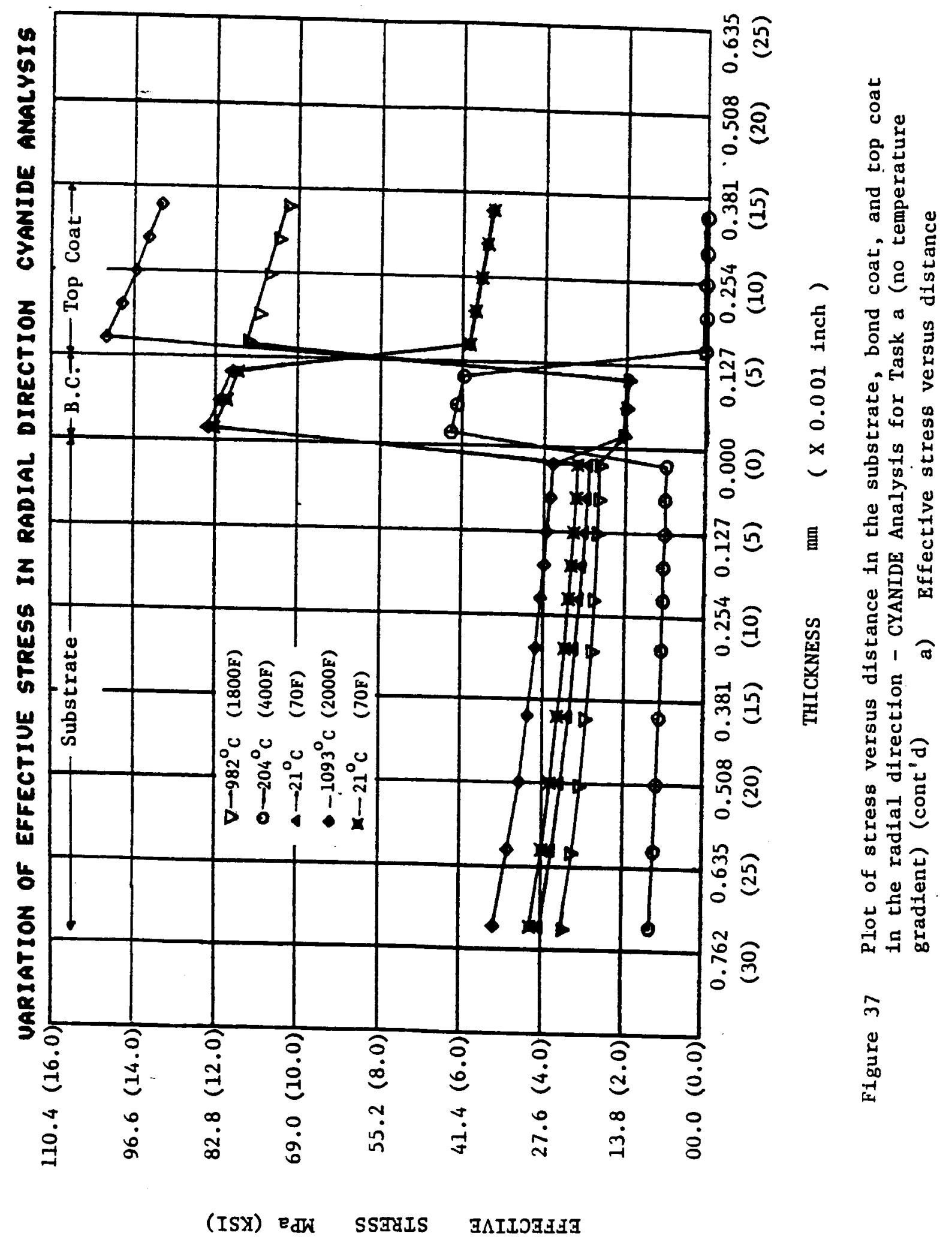




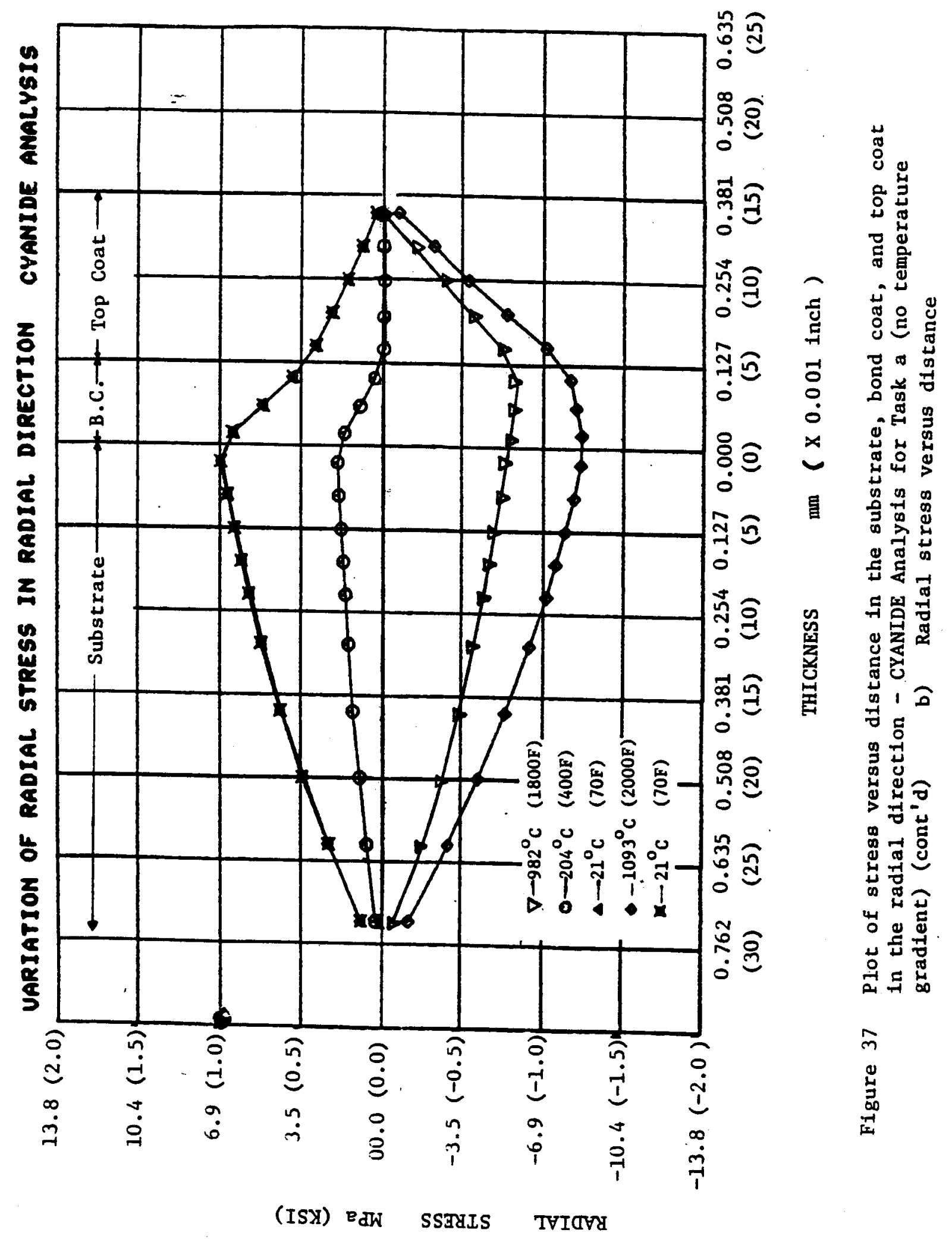




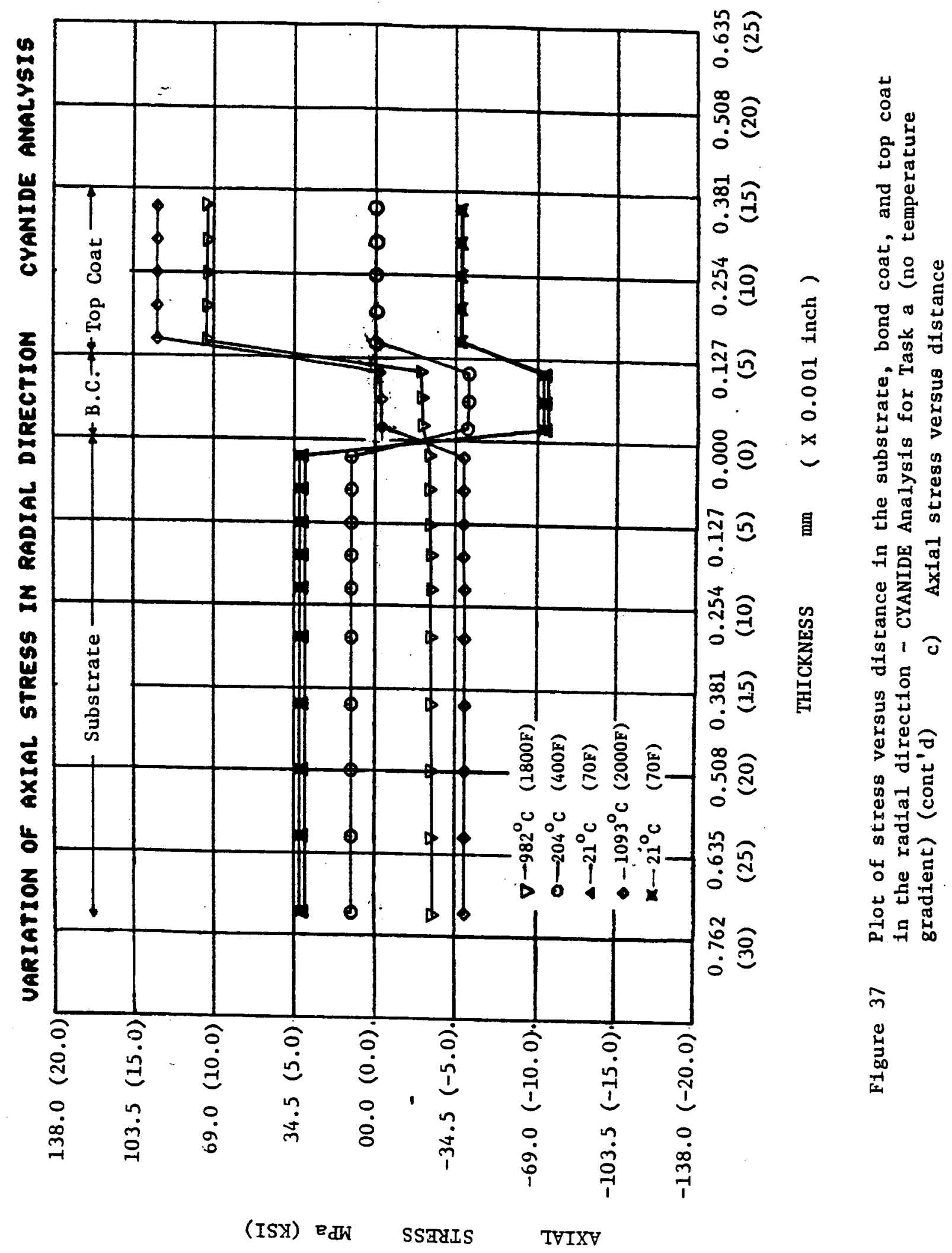




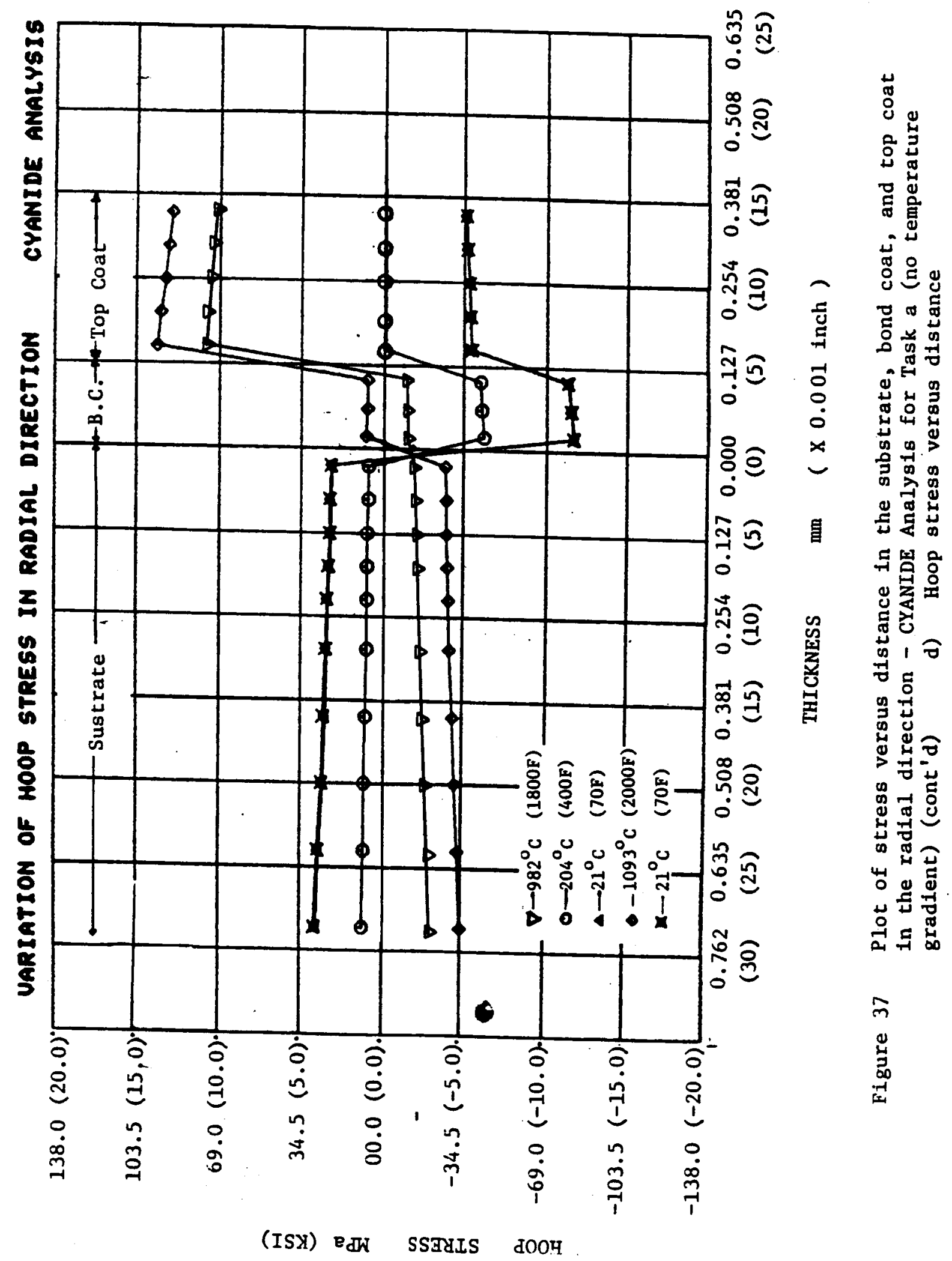




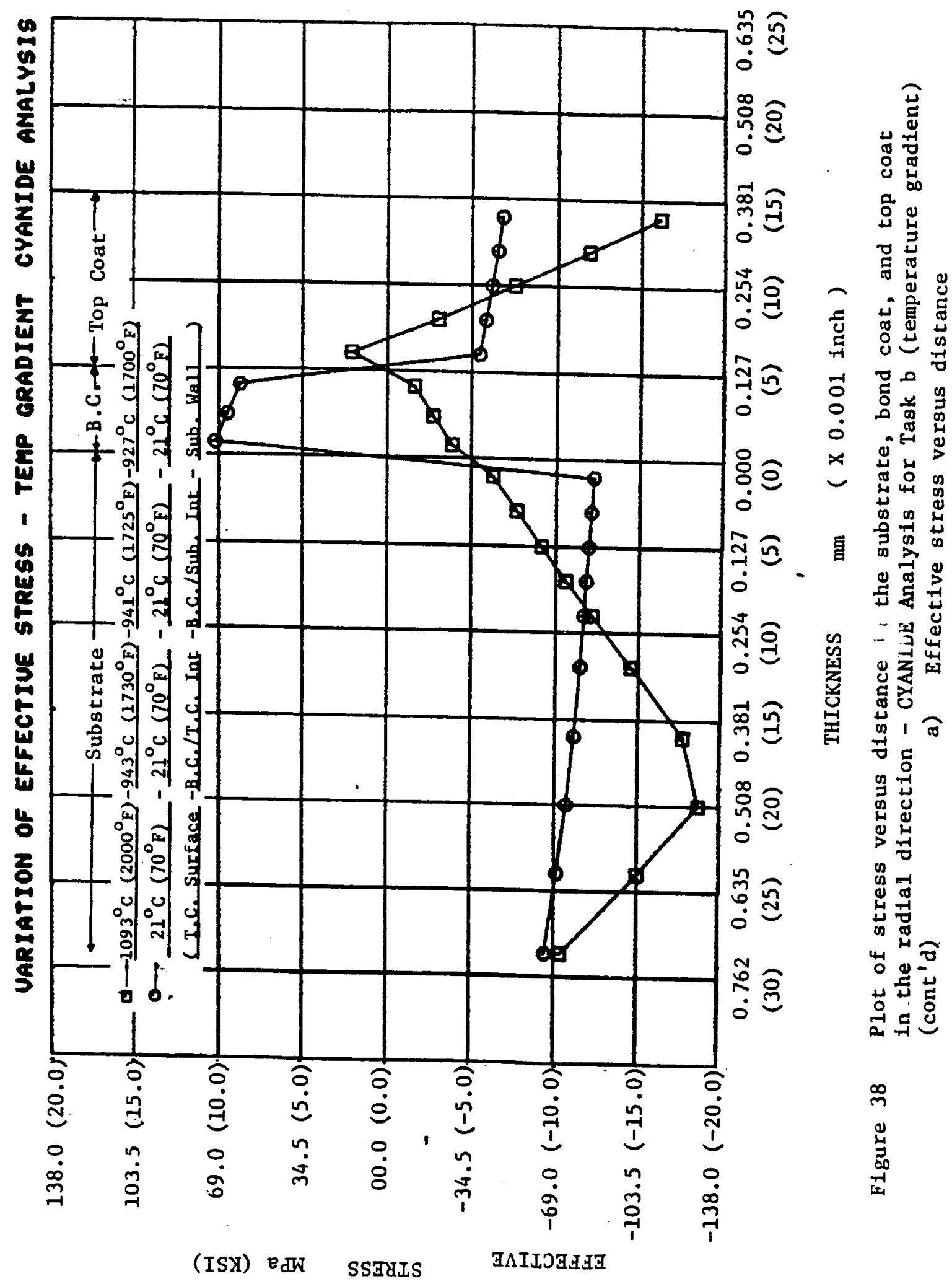




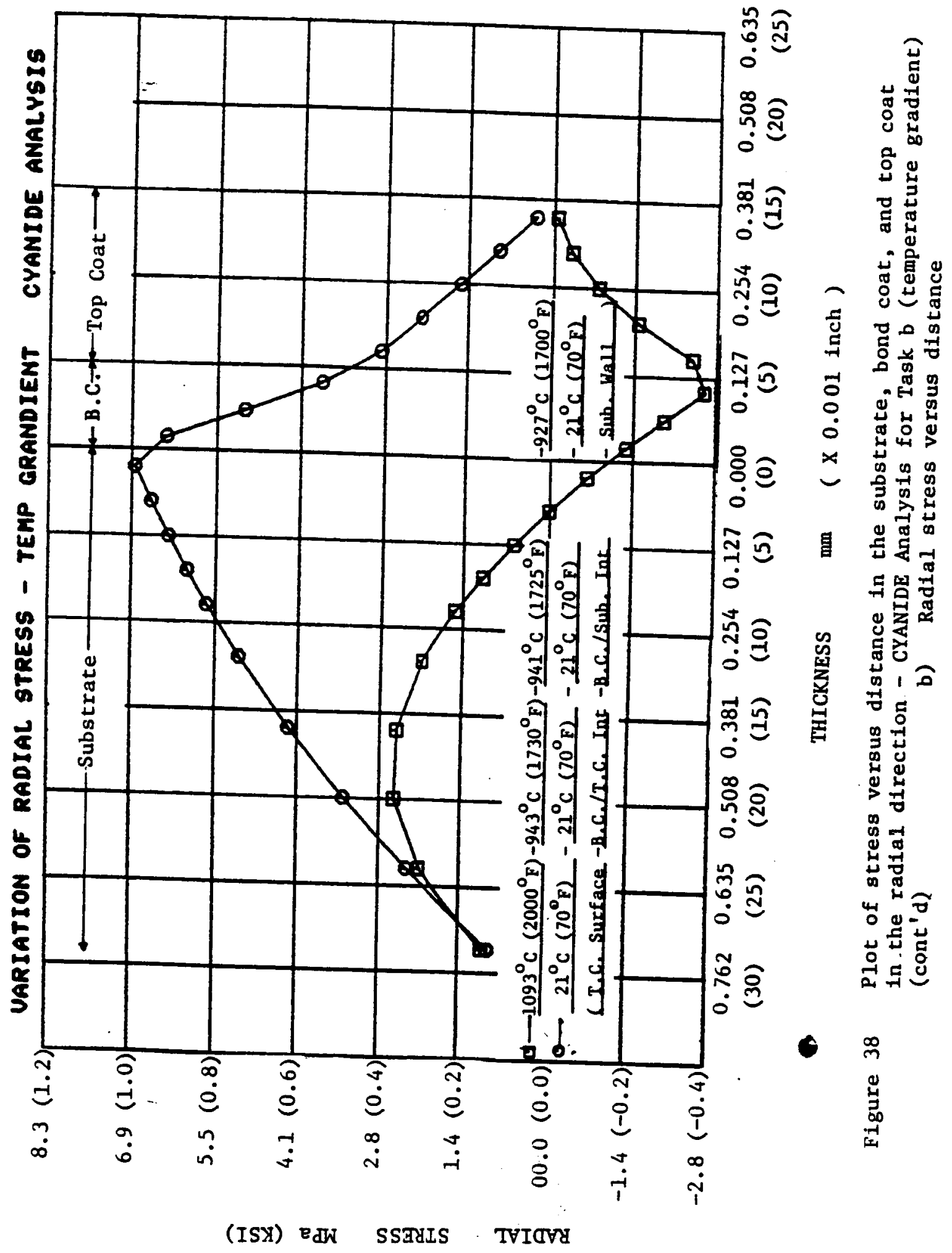




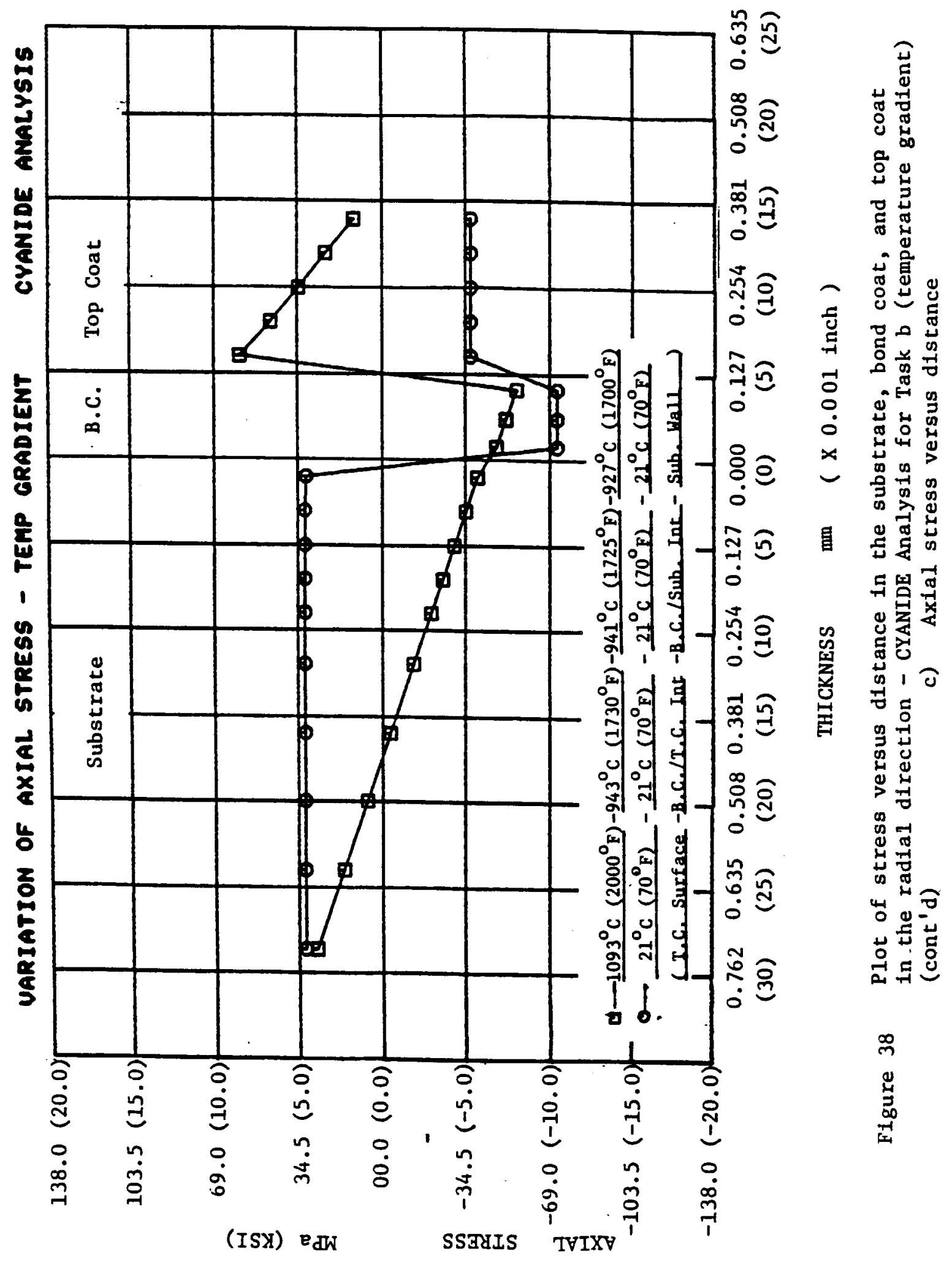




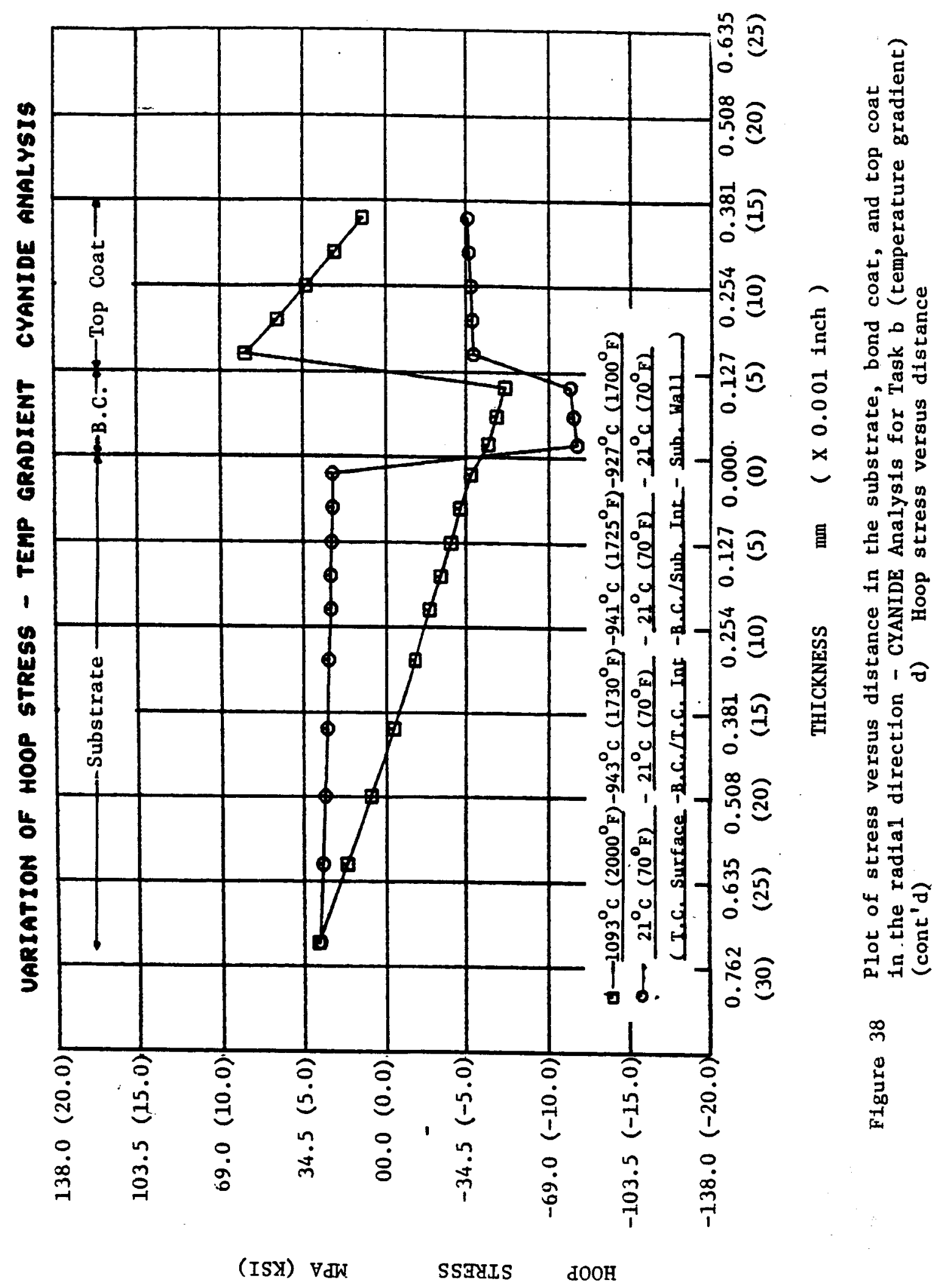




\section{Thermomechanical Experiments}

Three different thermomechanical experiments have been planned to evaluate the thermomechanical characteristics of TBCs. The primary goal of these examinations is to measure the strains induced during thermal cycling of TBCs, and to relate these strains to the observed failure modes.

In the first experiment (Experiment 1), a thermal barrier coated LCF tube specimen (Figure 39) will be thermally cycled using an induction system and a forced air cooling system. The thermomechanical nature of two different thermal cycles will be evaluated. The first thermal cycle will be as close to the GE cyclic temperature rig's cycle (Figure 35 ) as possible. The conditions of the second cycle will be based on the results of the first cycle. A laser interferometer displacement gage, which has a higher level of sensitivity than an extensometer, will be used to measure surface displacements (axial direction) of both the substrate and the ceramic top coat during thermal cycling. The possibility of placing microstrain gages beneath the coating is also being investigated. To accomplish measurement of both the substrate and top coat simultaneously, the tube specimen will be masked during both the bond coat and top coat applications so that a strip in the gage section is not coated with the ceramic. Lasers will be positioned on both the ceramic top coat and the metal substrate (masked region). No mechanical load will be applied to these specimens. 

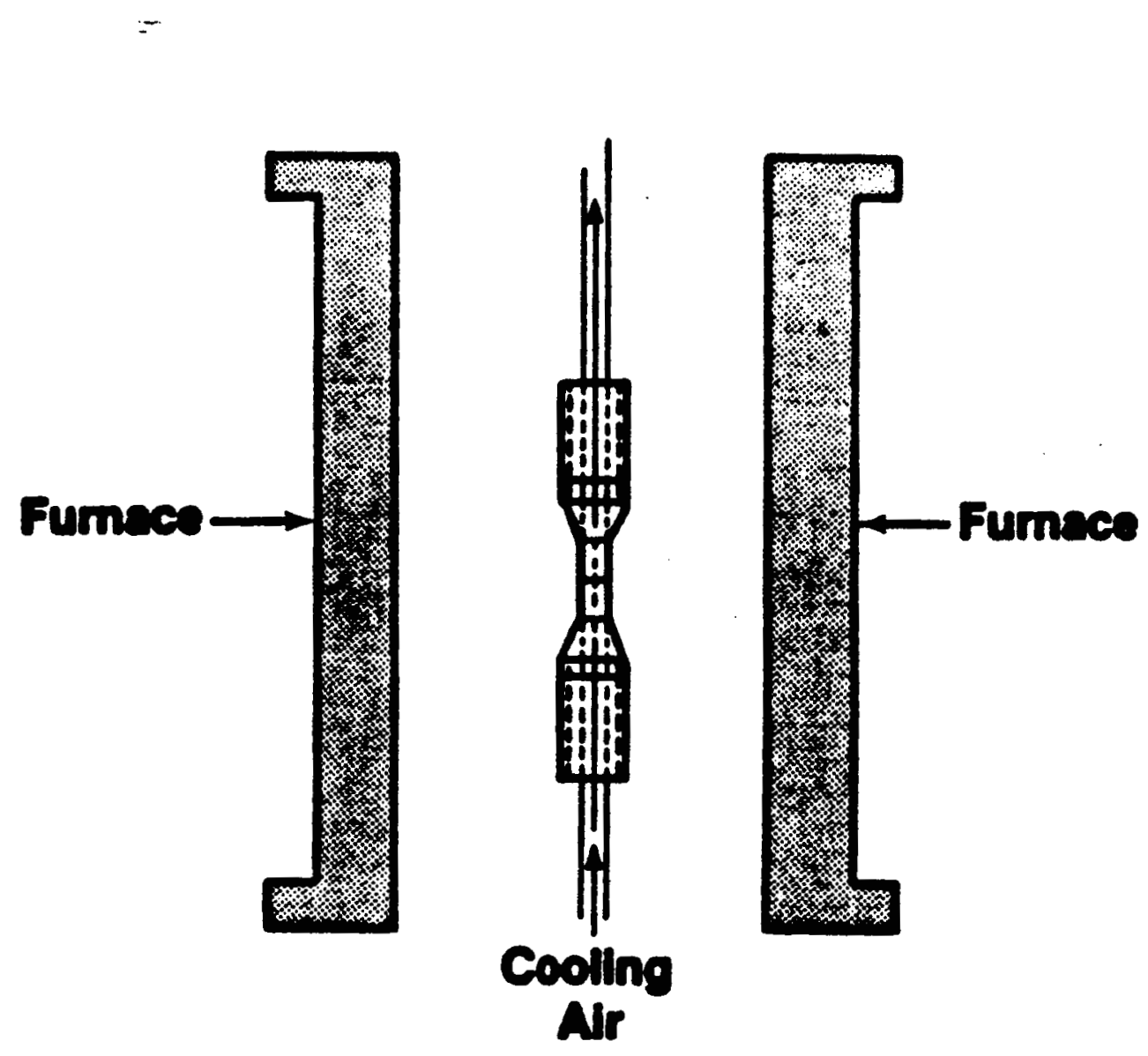

Figure 39 Sketch of furnace system for thermomechanical experiment 非 
This experiment (Experiment 1) is aimed at determining the magnitude of strains induced by thermal cycling of the TBC specimen under essentially zero mechanical load. The experiment will attempt to determine if any phasing exists between the strains observed for the substrate and the ceramic, or if the ceramic just follows the displacement of the metal substrate.

In the second experiment (Experiment 2), a thermal barrier coated specimen will be thermally cycled in a thermomechanical fatigue (TMF) rig. An induction heating system and a forced air cooling system will be used to thermally cycle the specimens. Three different thermal cycles will be evaluated. One of the three thermal cycles will be as close to the GE temperature rig's cycle (Figure 35 ) as possible. For one (or several, depending on results) thermal cycle, a tensile load will be applied to keep the strains (axial direction) in the top coat from becoming compressive. The final part of this experiment will be to apply tensile, compressive, and zero loading to three TBC specimens. These specimens will be thermal cycled to failure under these conditions for at least one of the thermal cycles.

This experiment (Experiment 2) is also aimed at determining the relationship of the strains induced by thermal cycling of TBC specimens to the failure mode. However, in this case, tensile loads (axial direction) will be applied to balance the compressive strains developed due to thermal cycling. By applying tensile loads, the goal is to determine the magnitude of the compressive strains. The experiment will also evaluate whether longer thermal cycle life can be achieved if the stress in the coating is not allowed to become compressive. 
In the thiro experiment (Experiment 3), the thermal barrier coating will be applied to thin Rene' 80 (substrate) strips. These specimens will be heated and cooled using induction heating and forced air cooling. Extensometers will be used to measure the displacements of the metal back side and the ceramic front side of the specimen. One thermal cycle, selected on the basis of Experiment 1 and 2 results will be evaluated. An uncoated Rene ' 80 strip and a free-standing ceramic strip will also be tested.

This experiment is also aimed at determining the magnitude of strains induced by thermal cycling. It is anticipated that the thin Rene' 80 strips and their TBC coatings will bend measurably during thermal transients because of the stresses induced by thermal expansion differences. Permanent deformations may occur as the result of creep and/or oxide scale formation on the bond coat. Observation of curvature changes during coating deposition and during subsequent thermal transients will be compared to predicted curvatures based on known properties of Rene' 80 and the coating materials. This data, in conjunction with data from the uncoated Rene' 80 strip and free-standing ceramic strip, should provide insight on the behavior of coated specimens and thus contribute to a better understanding of failure mechanisms. 


\section{Results - Thermomechanical Experiments}

The thermomechanical specimens (tubular LCF specimens) have received the $\mathrm{NiCrAIY}$ bond coat and the $\mathrm{ZrO}_{2}-\mathrm{Y}_{2} \mathrm{O}_{3}$ top coat. Three different types of specimens were produced by masking during the top coat and/or the bond coat application. Masking was employed to allow measurement of displacements by extensometers and/or lasers of both the ceramic top coat and the bond coat or substrate simultaneously. Type 1 specimens utilized masking during the application of both the bond coat and the top coat. The result was the presence of a thin strip of substrate on the gage section that received no bond coat and no top coat (Figure $41 \mathrm{a}$ ). Type 2 specimens utilized masking during the application of the top coat. The result was the presence of a thin strip of bond coat that received no top coat (Figure $41 \mathrm{~b})$. No masking was utilized for type 3 specimens. The result was complete coverage of the gage section with TBC (Figure 41c). The presence of uncoated regions in some specimens allows direct measurement of displacements in these regions.

Thermocouples (TC's) have aiso been embedded* between the substrate and the bond coat in two tubular LCF specimens. These TC's have been embedded in five different locations along the gage section of the specimen (Figure 42). These specimens will be used to calibrate the thermal cycle rigs for experiments 1 and 2 to obtain accurate temperature data.

* Five 0.020" diameter grooves, 0.015" deep, were EDM wire cut in the substrate surface (axial direction). Five 0.020" diameter TC's were embedded in the substrate prior to the bond coat and the top coat applications. 

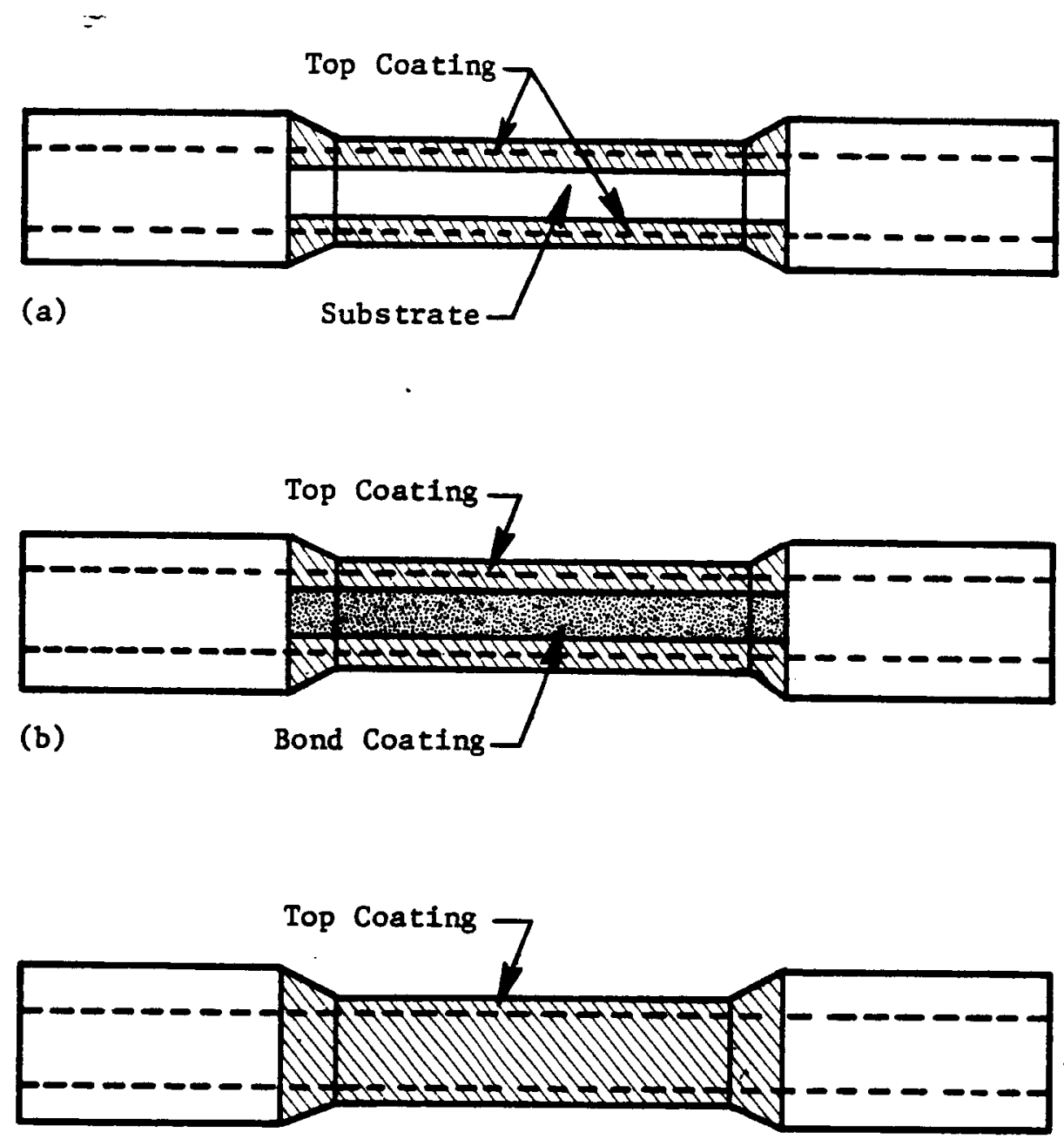

(c)

(a) Type 1 - Uncoated Substrate on Gage Section

(b) Type 2 - Uncoated Bond Coat Strip on Gage Section

(c) Type 3 - Fully Coated Gage Section

Figure 40 Three Types of Masking for Thermomechanical Specimens. 


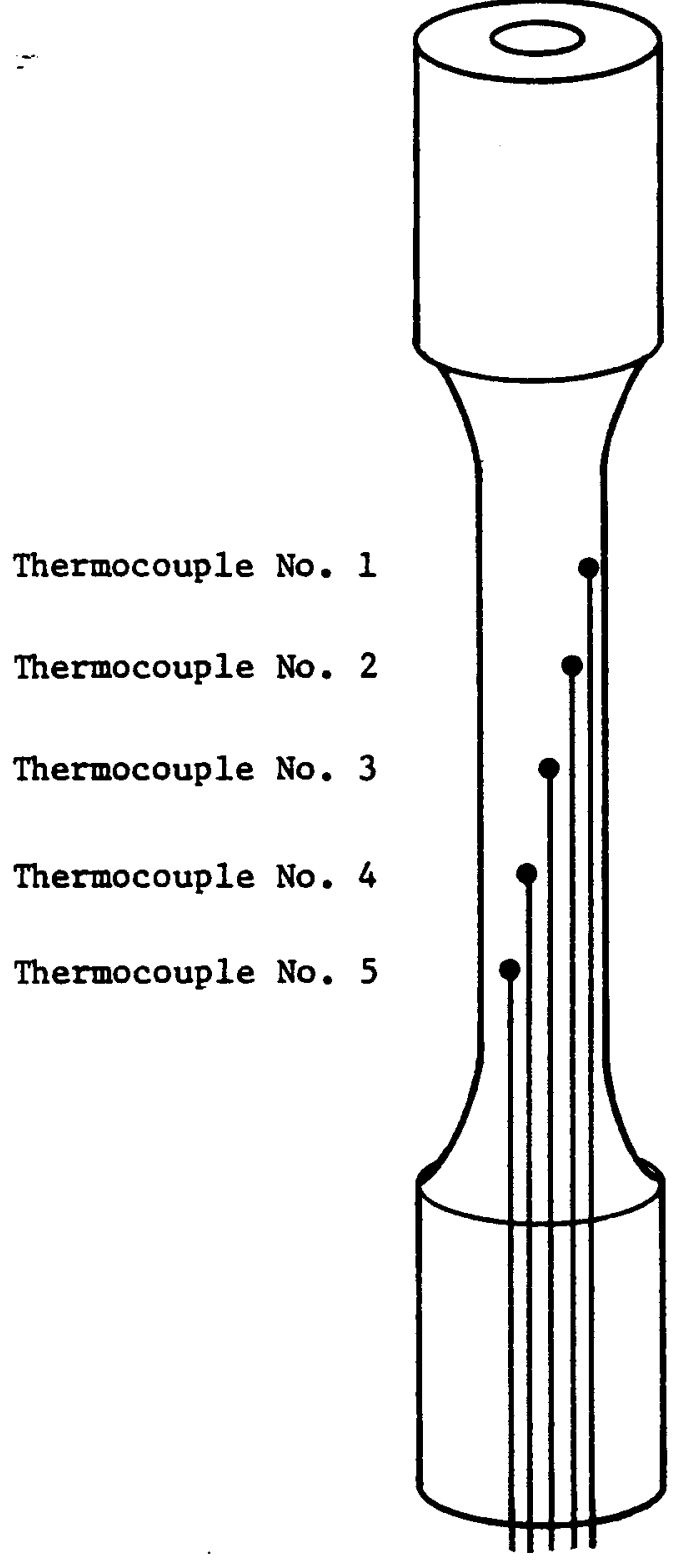

Thermocouple Leads

Figure 41 Locations of Embedded Thermocouples in Thermomechanical Test Specimens. 
The final preparations for the thermomechanical experiments are nearing completion. The actual testing should be initiated early in the third year of this contract. 


\section{CONCLUSIONS}

The first task of the study involves the determination of TBC failure mechanisms and key properties of both the bond coat and the top coat. The second task of the study involves the development of finite element models for TBCs and determination of thermomechanical properties of the TBCs. The information determined from Tasks $\# 1$ and \#2 will be utilized to develop TBC life prediction models

Three experiments aimed at evaluating the effects of bond coat oxidation were completed. The three experiments indicate that bond coat oxidation is a significant contribution to an overall TBC failure mechanism. Unexpectedly, the test data indicate that pre-exposures in argon are more detrimental to thermal cycle life (shorter thermal cycle life) then pre-exposures in air for TBCs. Analysis has indicated that the detrimental effects of argon are probably associated with bond coat oxidation effects.

The experiment aimed at evaluating bond coat creep was completed. The results indicate that bond creep is a contributor to TBC failure and that TBC life increases with increasing bond coat creep strength. 
Key properties for the bond coat and the top coat were determined. Tensile strength, dynamic elastic modulus, Poisson's ratio, and coefficient of thermal expansion were determined for the bond coat. Poisson's ratio, dynamic elastic modulus, dynamic shear modulus, and coefficient of thermal expansion were determined for the top coat. Bend strength for the top coat will be determined in the third year of this contract.

Finite element models were developed for TBCs and applied to two analytical examinations. These two models were applied to the first two analytical tasks.

The specimens for the thermomechanical experiment have been prepared, and final preparations prior to testing are nearing completion. These experiments will be utilized to examine the thermomechanical characteristics of TBCs. 


\section{APPEMDIX I, POWDER CHARACTERISTICS}

$=$

TABLE XVI POWDER MANUFACTURERS

Manuf acturer

Alloy Metals, Inc. Union Carbide Union Carbide Union Carbide Metco

\section{Powder}

Bond Coat \#1 ( $\mathrm{Ni}-22 \mathrm{Cr}-10 \mathrm{Al}-0.3 \mathrm{Y})$

Bond Coat \#2 (Special)

Bond Coat \#3 (Special)

Bond Coat \#4 (Special)

Top Coat $\left(\mathrm{ZrO}_{2}-8 \mathrm{Y}_{2} \mathrm{O}_{3}\right)$
Powder Size

(Mesh)

$-230+400$

- $230+400$

$-230+400$

$-230+400$

$-140+10 \mu \mathrm{m}$

TABLE XVII POWDER TRUE DENSITY*

Powders

Bond Coat \#1 ( $\mathrm{Ni}-22 \mathrm{Cr}-10 \mathrm{Al}-0.3 \mathrm{Y})$

7.31

Bond Coat \#2

8.35

Bond Coat \#3

7.88

Bond Coat \#4

7.36

Top Coat $\left(\mathrm{ZrO}_{2}-\mathrm{Y}_{2} \mathrm{O}_{3}\right)$
Density $(g / c c)$

* Density of as-received powder (Nu11-Pychometer) 


\section{TABLE XVIII POWDER SIEVE ANALYSIS (WEIGHT $\%$ )}

$\begin{gathered}\text { Sieve Size } \\ \text { (mesh) }\end{gathered}$
+170
$-170+200$
$-200+250$
$-250+270$
$-250+325$
$-270+400$
-400

\begin{tabular}{|c|c|c|c|c|}
\hline$\# 1$ & $\begin{array}{c}\text { Bond } \\
\text { \#2 }\end{array}$ & $\begin{array}{r}\text { pats } \\
\# 3 \\
\end{array}$ & $\# 4$ & $\begin{array}{r}\text { Top Coat } \\
\mathrm{ZrO}_{2}-8 \mathrm{YY}_{20}\end{array}$ \\
\hline 0.0 & 0.0 & 0.0 & 0.0 & 10.0 \\
\hline 0.4 & 0.8 & 0.0 & 0.0 & 13.7 \\
\hline 14.7 & 7.6 & 0.8 & 0.0 & 5.7 \\
\hline 34.5 & 27.7 & 23.5 & 14.8 & 9.5 \\
\hline 29.2 & 32.4 & 34.6 & 36.7 & 13.7 \\
\hline 12.2 & 25.1 & 28.0 & 32.6 & 9.4 \\
\hline 9.0 & 6.3 & 13.0 & 15.8 & 38.1 \\
\hline
\end{tabular}

TABLE XIX POWDER MICROTRAC ANALYSIS

Powders 10th Percentile 50th Percentile 90th Percentile Mean Diameter

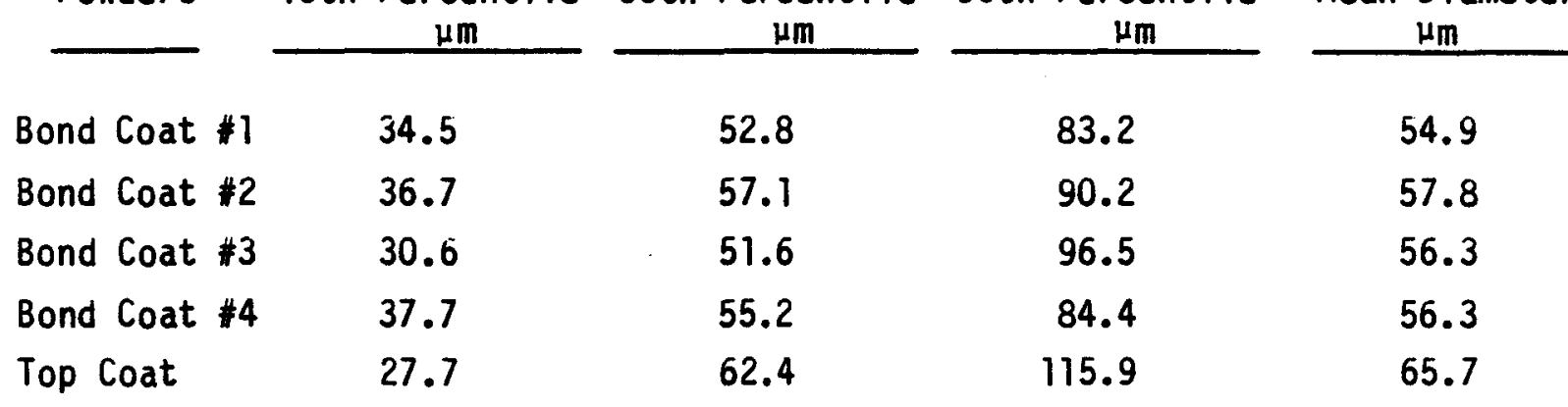


APPENDIX II, BOND COAT MICROSTRUCTURE

Phase identifications of bond coat microstructure after pre-exposure and thermal cycle testing are shown in this appendix. In all cases, the application of an aluminide overcoat has resulted in a microstructure containing a high $A 1 \quad B$ (NiAl Type) matrix. The phases labeled include $\gamma$ ( $N i$ solid solution), $\gamma^{\prime}\left(N_{3} A 1\right)$ type, $B$ (NiAl type), and $M_{23} C_{6}$. In some cases, certain phases which can only be identified by $x$-ray diffraction or election microprobe are labeled as "Other Phases". These "Other Phases" can include carbides, oxides, the Sigma phase, the Mu phase, and the $\alpha-\mathrm{Cr}$ phase. 

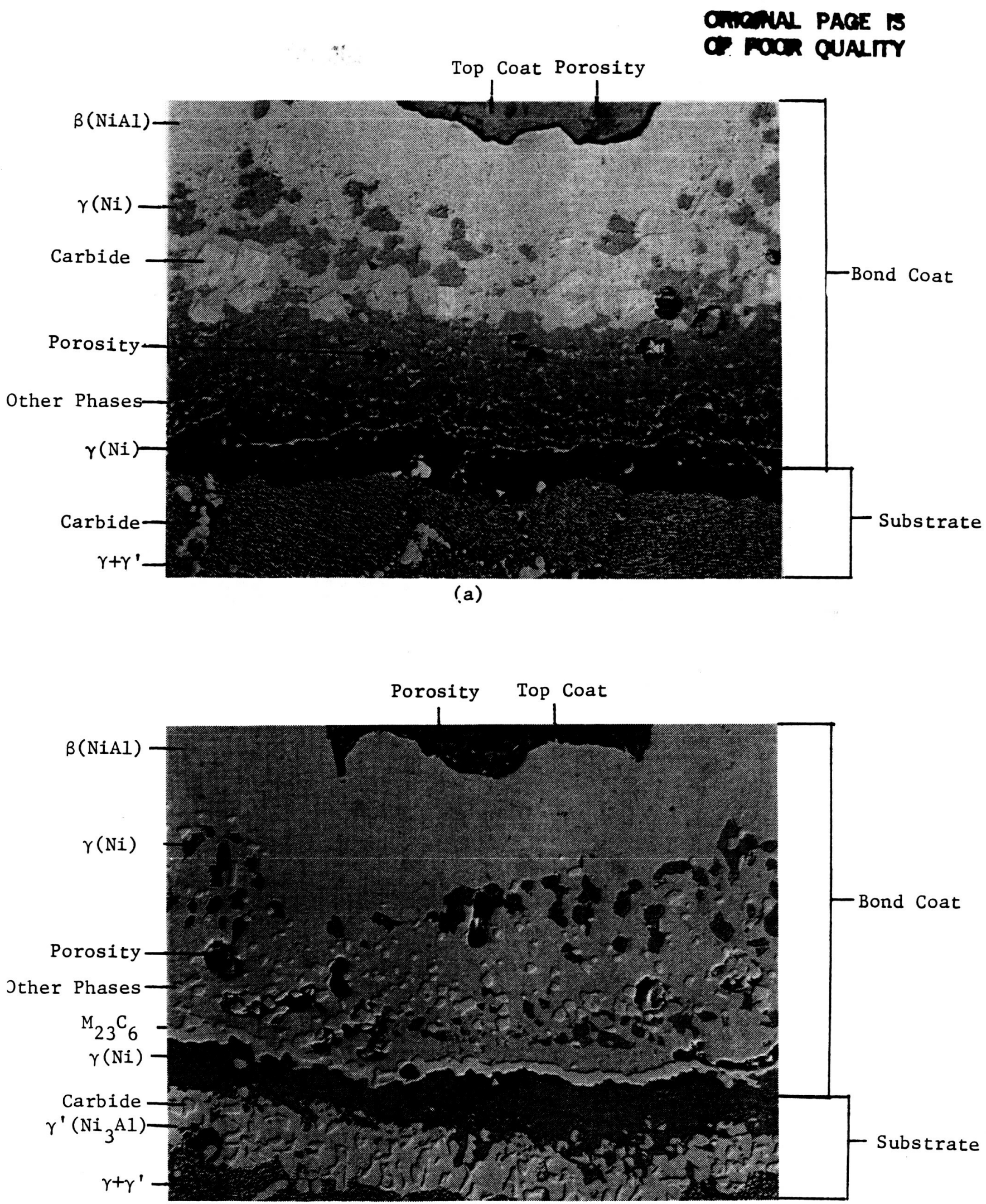

(b)

Figure 42 Phase identification of bond coat microstructure after pre-exposure and thermal cycle testing (cont'd)

a) Bond Coat 非 2 - 100 hour air pre-exposure (no thermal cycles)

b) Bond Coat 非 1 - 100 hour argon pre-exposure (no thermal cycles) 

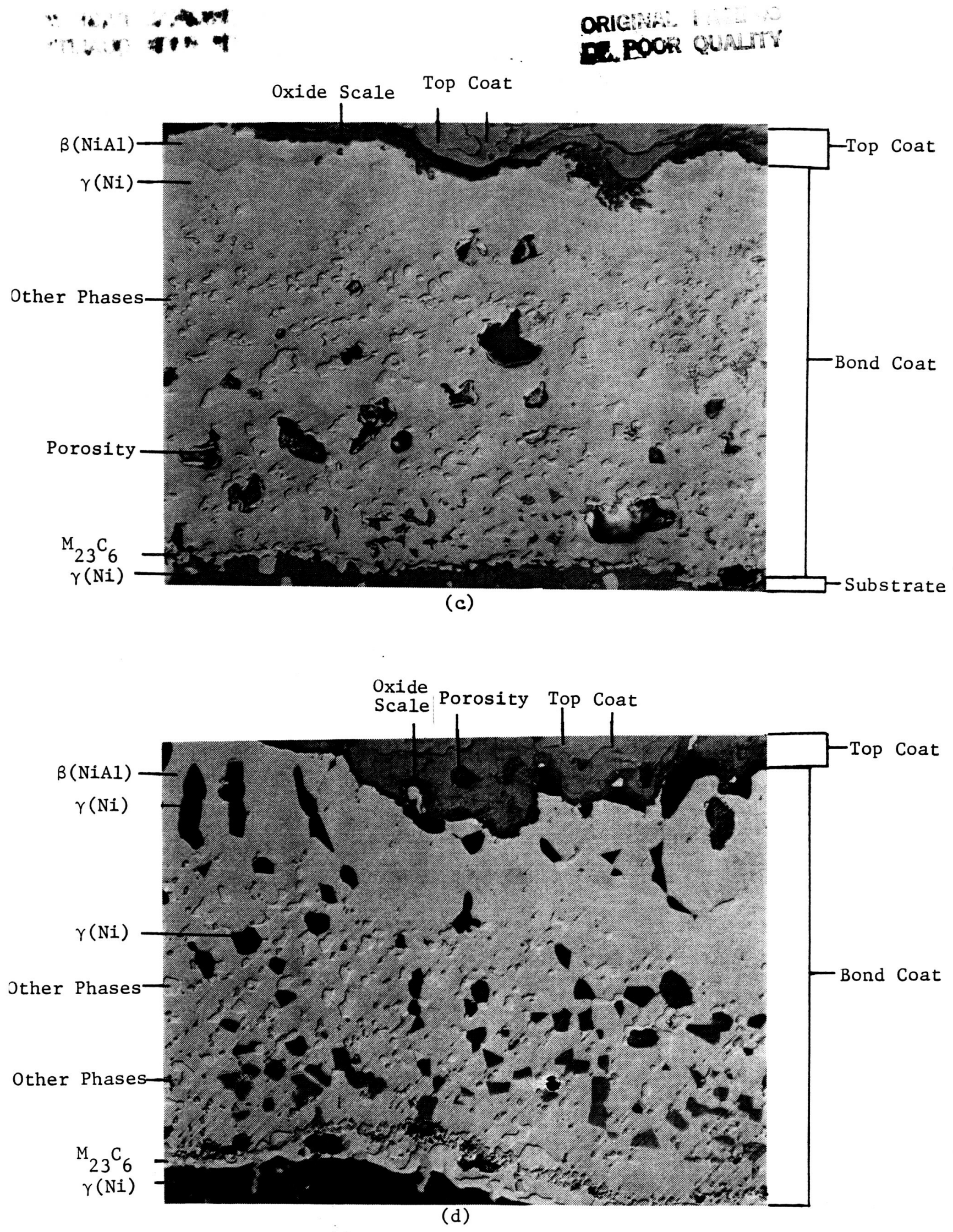

Figure 42 Phase identification of bond coat microstructure after pre-exposure and thermal cycle testing

c) Bond Coat $\|_{4}$ - 100 hour air pre-exposure(after 470 thermal cycles)

d) Bond Coat 非 3 - 100 hour argon pre-exposure(after 320 thermal cycles) 
TABLE XX ELASTIC MODULUS OF TBC COMPONENTS

\begin{tabular}{|c|c|c|c|}
\hline $\begin{array}{c}\text { Temperature } \\
{ }^{\circ} \mathrm{C}\left({ }^{\circ} \mathrm{F}\right) \\
\end{array}$ & $\begin{array}{l}\text { Rene' } 80 \\
\text { GPa (MSI) } \\
\end{array}$ & $\begin{array}{c}\mathrm{Ni}-22 \mathrm{Cr}-10 \mathrm{Al}-0.3 \mathrm{Y} \\
\mathrm{GPa} \text { (MSI) } \\
\end{array}$ & $\begin{array}{l}\mathrm{ZrO}_{2}-8 \mathrm{Y}_{2} \mathrm{O}_{3} \\
\mathrm{GPa}(\mathrm{MSI})\end{array}$ \\
\hline $21(70)$ & $208(30.1)$ & $198(28.7)$ & $48(7.0)$ \\
\hline $204(400)$ & $198(28.7)$ & $189(27.4)$ & $41(5.9)$ \\
\hline $427(800)$ & $186(27.0)$ & $162(23.5)$ & $33(4.8)$ \\
\hline $538(1000)$ & $180(26.1)$ & $151(22.0)$ & $31(4.5)$ \\
\hline $649(1200)$ & $175(25.3)$ & $143(20.7)$ & $28(4.0)$ \\
\hline $760(1400)$ & $166(24.0)$ & $134(19.4)$ & $26(3.8)$ \\
\hline $871(1600)$ & $157(22.8)$ & $129(18.7)$ & $23(3.4)$ \\
\hline $982(1800)$ & $145(21.0)$ & $124(18.0)$ & $21(3.0)$ \\
\hline $1093(2000)$ & $116(16.8)$ & $119(17.2)$ & $20(2.9)$ \\
\hline $1204(2200)$ & $86(12.5)$ & -- & $17(2.5)$ \\
\hline
\end{tabular}

TABLE XXI POISSON'S RATIO OF TBC COMPONENTS

\begin{tabular}{|c|c|c|c|}
\hline $\begin{array}{c}\text { Temperature } \\
{ }^{\circ} \mathrm{C}\left({ }^{\circ} \mathrm{F}\right) \\
\end{array}$ & Rene' 80 & $N i-2 Z C r-10 A 1-0.3 \gamma *$ & $\mathrm{ZrO}_{2}-8 \mathrm{Y}_{2} \mathrm{O}_{3}$ \\
\hline $21(70)$ & 0.31 & 0.31 & 0.076 \\
\hline $204(400)$ & 0.32 & 0.32 & 0.076 \\
\hline $427(800)$ & 0.32 & 0.32 & 0.076 \\
\hline $538(1000)$ & 0.33 & 0.33 & 0.076 \\
\hline $649(1200)$ & 0.33 & 0.33 & 0.076 \\
\hline $760(1400)$ & 0.34 & 0.34 & 0.076 \\
\hline $871(1600)$ & 0.34 & 0.34 & 0.076 \\
\hline $982(1800)$ & 0.35 & 0.35 & 0.076 \\
\hline $1093(2000)$ & 0.37 & 0.37 & 0.076 \\
\hline $1204(2200)$ & 0.39 & 0.39 & 0.076 \\
\hline
\end{tabular}

*Assumed identical to Rene' 80 for initial studies. 
TABLE XXII COEFFICIENT OF THERMAL EXPANSION

\begin{tabular}{|c|c|c|c|}
\hline $\begin{array}{c}\text { Temperature } \\
{ }^{\circ} \mathrm{C}\left({ }^{\circ} \mathrm{F}\right)\end{array}$ & $\begin{array}{l}\text { Rene' } 80 \\
\text { in/ in } /{ }^{\circ} \mathrm{C} \\
\end{array}$ & $\begin{array}{c}\mathrm{Ni}-22 \mathrm{Cr}-10 \mathrm{Al}-0.3 \mathrm{Y} \\
\mathrm{in} / \mathrm{in} /{ }^{\circ} \mathrm{C} \\
\end{array}$ & $\begin{array}{l}\mathrm{ZrO}{ }_{2}-8 \mathrm{P}_{2} \mathrm{O}_{3} \\
\mathrm{in} / \mathrm{in} /{ }^{\circ} \mathrm{C} \\
\end{array}$ \\
\hline $21(70)$ & 12.4 & 11.1 & 7.6 \\
\hline $204(400)$ & 12.7 & 11.7 & 8.5 \\
\hline $427(800)$ & 13.1 & 12.8 & 9.4 \\
\hline $538(1000)$ & 13.4 & 13.3 & 9.9 \\
\hline $649(1200)$ & 13.6 & 13.6 & 10.3 \\
\hline $760(1400)$ & 14.3 & 14.0 & 10.9 \\
\hline $871(1600)$ & 15.0 & 14.8 & 11.2 \\
\hline $982(1800)$ & 16.0 & 15.6 & 11.7 \\
\hline $1093(2000)$ & 17.2 & 16.7 & 12.2 \\
\hline $1204(2200)$ & 18.4 & -- & 12.6 \\
\hline
\end{tabular}




\section{REFERENCES}

1. Stecura, S. "Effects of Yttrium, Aluminum, and Chromium Concentrations in Bond Coatings on the Performance of Zirconia - Yttria Thermal Barriers," NASA TM-79206, 1979.

2. Gedwil1, M.A., "Improved Bond Coatings for Use with Thermal Barrier Coatings," NASA TM-81567, 1980.

3. Miller, R.A. and Lowe11, C.E., "Failure Mechanisms of Thermal Barrier Coatings Exposed to Elevated Temperatures", NASA TM-82905, 1982.

4. Miller, R.A. and Berndt, C.C., "Performance of Thermal Barrier Coatings in High Heat Flux Environments," NASA TM-83663, 1984.

5. Duderstadt, E.C., "Thermal Barrier Coating Technology," GE Internal Communication, 1984.

6. Hillery, R.V. and Pilsner, B.H., "Thermal Barrier Coating Life Prediction Model - First Annual Report," NASA CR-175010, 1985.

7. Miller, R.A., "High Temperature Protective Coatings," S.C. Singhal, Editor, AIME, page 293, 1982.

8. Saegusa, F., "Failure Mechanism Studies on Thermal Barrier Coatings," GE TM 86-AMD-004, February, 1986.

9. Pilsner, B.H., "Effects of Mar-M247 Substrate (Modified) Composition on Coating Oxidation and Coating Substrate Interdiffusion," NASA CR-174851, 1985.

10. Duderstadt, E.C., Pilsner, B.H., Torgesen, M., Groves, M.T., Nel son, W.A., and Butts, W.R., "Thermal Barrier Coating Technology," GE TM 86-348, 1986.

11. Spinner and W.E. Tefft, ASTM Proc. 61, page 1221 - 1238 (1961).

12. Marin, J., Pao, Y.H., and Cuff, G., "Creep Properties of Lucite and Plexiglass for Tension, Compression, Bending, and Torsion," Trans. ASME, 1975.

13. Pugh, C.E., "Constitutive Equations for Creep Analysis of Liquid Moderated Fast Breeder Reactor (LMFBR) Components," Advances in Design for Elevated Temperature Environment, S.Y. Zamrik and N.I. Jetter, Eds., ASME, 1975.

14. Mcknight, R.L., Laflen, J.H. and Spamer, G.T., "Turbine Blade Tip Durability Analysis" NASA CR-165268, 1982.

15. Siemers, P.A. and Hillig, W.B., "Thermal Barrier Coated Turbine Blades Study," NASA CR-165351, 1981.

16. Andress, D.E., "Analytical Study of Thermal Barrier Coated First Stage Blades in F100 Engines," NASA CR-135359, 1978. 


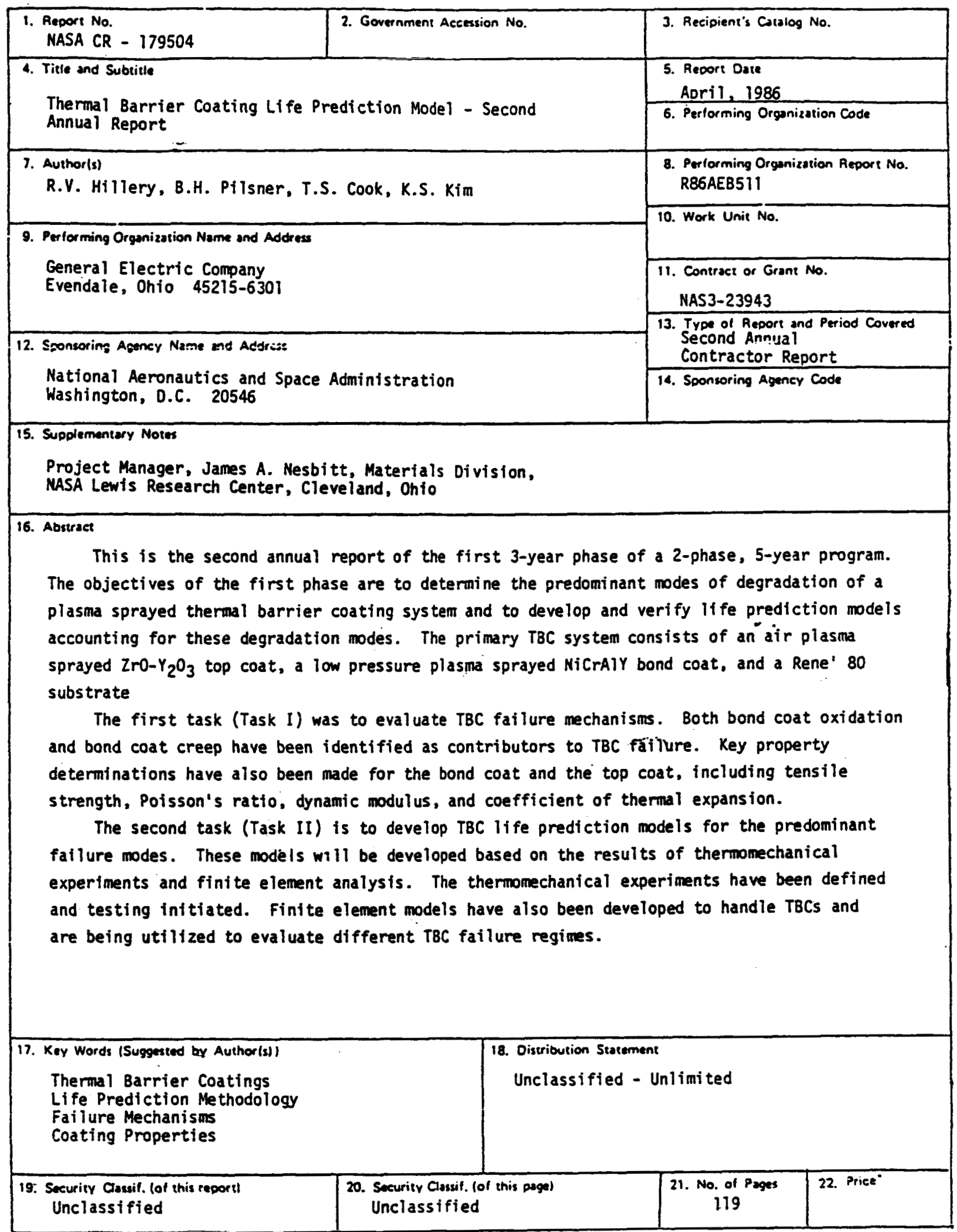

- For sale by the National Technical Information Service. Springfield. Virginia 22161 